
Sonja Georgi and Kathleen Loock (eds.)

Of Body Snatchers and Cyberpunks

This work is licensed under the

Creative Commons License 3.0 "by-nd", allowing you to download, distribute and print the document in a few copies for private or educational use, given that the document stays unchanged and the creator is mentioned. You are not allowed to sell copies of the free version.

SORE RIGHIS RESERVED 
erschienen in der Reihe der Universitätsdrucke im Universitätsverlag Göttingen 2011 
Sonja Georgi

and Kathleen Loock (eds.)

\section{Of Body Snatchers and Cyberpunks}

Student Essays on

American Science Fiction Film

Göttinger Schriften zur

Englischen Philologie, Band 5

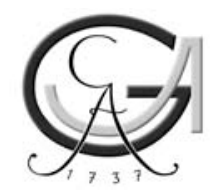

Universitätsverlag Göttingen 2011 


\section{Bibliographische Information der Deutschen Nationalbibliothek}

Die Deutsche Nationalbibliothek verzeichnet diese Publikation in der Deutschen Nationalbibliographie; detaillierte bibliographische Daten sind im Internet über $<$ http://dnb.ddb.de $>$ abrufbar.

Address of the Editors

Kathleen Loock

Georg-August-Universität Göttingen

Seminar für Englische Philologie

Käte-Hamburger-Weg 3

37073 Göttingen

E-Mail: Kathleen.Loock@phil.uni-goettingen.de

Dr. des. Sonja Georgi

Johannes Gutenberg-Universität Mainz

FB 05: Department of English and Linguistics/American Studies

Staudinger Weg 9

55128 Mainz

E-Mail: georgis@uni-mainz.de

This work is protected by German Intellectual Property Right Law.

It is also available as an Open Access version through the publisher's homepage and the Online Catalogue of the State and University Library of Goettingen

(http://www.sub.uni-goettingen.de). Users of the free online version are invited to read, download and distribute it. Users may also print a small number for educational or private use. However they may not sell print versions of the online book.

Satz und Layout: Frauke Reitemeier

Umschlaggestaltung: Franziska Lorenz

Titelabbildung: (C) iStockphoto.com/benignocom

(C) 2011 Universitätsverlag Göttingen

http:/ / univerlag.uni-goettingen.de

ISBN: 978-3-941875-91-3

ISSN: $1868-3878$ 


\section{Contents}

\section{Introduction}

Of Body Snatchers and Cyberpunks: Teaching American Science Fiction Film (SONJA GEORGI / KATHLEEN LOOCK)

\section{Part I: The Look and Sound of Science Fiction Film}

"There was a world once, you punk": Visual Subversion in Fleischer's Soylent Green (JÖRN PIONTEK)

"Like Alice in Wonderland": Special Effects in

The Matrix (DENNIS EDELMANN)

"What are you doing, Dave?": The Confrontation of Dave Bowman and HAL 9000 in Stanley Kubrick's 2001: A Space Odyssey (FABIAN GUMBRECHT).....

\section{Part II: Social and Political Commentaries}

"Jupiter and Beyond the Infinite" as Social Reflection? The Success of the

Sequence Among Young Adults of the Counterculture (NIKLAS FRANZEN) ... 75

It Used to Be a Man's World: Manhood and Masculinity in

Don Siegel's Invasion of the Body Snatchers (MANFRED ALEXANDER MÜLLER).... 87

"What keeps us safe also keeps us free": State Control vs. Personal

Liberty in Steven Spielberg's Minority Report and the Present-Day

United States (PHILIPP STÜCKRATH)

Religion in Soylent Green (MORITZ EMMELMANN)

\section{Part III: Themes and Motifs of Science Fiction Films}

The Doppelgänger Motif in Science Fiction Film (DENNIS KOGEL / IRIS

SCHÄFER)

"Can you see?": The Importance of Vision and the Eye Motif in Steven Spielberg's Minority Report (STEFANIE SCHWARZ)

Becky Driscoll as femme fatale? Elements of film noir in Don Siegel's Invasion of the Body Snatchers (SOLVEIG BURFEIND) 


\section{Part IV: (De)Constructing Bodies and Identities}

Human Monsters: The Function of the Horror Motif in Don Siegel's Invasion of the Body Snatchers and Its Remakes (BENJAMIN RYAN ULONSKA) ....161

Why Does the One Only Exist in Cyberspace? Obsolescence of the Body, Construction of a Virtual Subject and the Question of Control in The Matrix (GINA ZIEBELL)

\section{Epilogue}

The Creature from Brooklyn: My Life and Science Fiction Film (ERIC S. RABKIN)

List of Contributors 195

„Göttinger Schriften zur Englischen Philologie“: Zum Konzept der Reihe (FRAUKE REITEMEIER) 


\section{Acknowledgments}

The editors wish to acknowledge the financial support of the U.S. Consulate General Hamburg and the committee for the allocation of tuition fees (Studienkommission der Philosophischen Fakultät Göttingen), and the Department of Linguistics, Literature and Media Science of the University of Siegen toward the organization of the joint undergraduate conference "Of Body Snatchers and Cyberpunks: American Science Fiction Films from the 1950s to the Present" with students from both the University of Göttingen and the University of Siegen that took place in Göttingen from July 3 to July 5, 2009. Special thanks go to Daniel Stein and Rebecca Scorah for their help with the conference organization. For their valuable comments and suggestions regarding the introductory essay, we would also like to thank Carola Surkamp and Daniel Stein.

We are further indebted to Prof. Eric S. Rabkin. Not only did he come all the way from Ann Arbor, Michigan (USA) to join us in Göttingen as an expert in the field of science fiction studies. He enriched the conference with his wonderful keynote lecture and his great wealth of knowledge. We are delighted that he contributed an original essay to the present volume. Needless to say, we thank all the students from Siegen and Göttingen who participated in the conference and made it a successful event. All students who eventually contributed to this volume deserve our thanks for the enthusiasm and hard work they invested in this project. 

Introduction 

Sonja Georgi / Kathleen Loock

\section{Of Body Snatchers and Cyberpunks: Teaching American Science Fiction Film}

In 2006, the German Association for American Studies (DGfA) held its annual conference at the University of Göttingen. The conference topic, "American Studies as Media Studies," paid tribute to the different turns that have (re)shaped the field of literary and cultural studies after the linguistic, historical, and cultural turns of the 1970s and 1980s. ${ }^{1}$ Throughout the past two decades, new theoretical and methodological approaches have emerged that take into account different contemporary and historical mediations of (trans)national or cultural representations and have led to an expansion of American Studies as a discipline. In accordance with the overall topic, the conference program challenged the traditional hegemony of the printed word by including papers that focused on visual, audio-visual, and audio formats as well as on new electronic media. In other words, the conference "American Studies as Media Studies" came to terms with the fact that we live

1 For a discussion of recent theoretical turns in literary and cultural studies see BachmannMedick. 
in an increasingly audio/visual environment that is largely influenced by different kinds of new media. ${ }^{2}$

Our world is no longer governed by the logocentrism that has formed the basis of Western thinking: The written word has been losing its monopoly in our everyday lives because other semiotic channels - taking the forms of images, sounds, and spectacles - increasingly attract our attention (Seidl 2). Media and technology - the sight and sound of radio, television, film, music, photos, paintings, the Internet, computer games, but also print media such as magazines, newspapers, and comic books - have become an inescapable part of our existence (Kellner 1-2). Along these lines, Eckart Voigts-Virchow rightly states that "[w]e live in a thoroughly 'mediatized' world, a social and cultural environment which is permeated by the media, and more specifically electronic media" (5). In addition, Frank Kelleter and Daniel Stein have drawn attention to the major role the United States play in our media culture:

If we find it increasingly difficult to distinguish between what is universal and what is local - even between what is virtual and what is material - this has much to do with the presence of the media in our lives. And one cannot help but add: it has to do with the presence, both virtual and material, of the United States of America in our lives. (ix)

American Studies as a discipline provides tools to read not only contemporary but also historical non-verbal texts in order to (re)consider their cultural work both inside and outside the United States. The new focus on media other than the printed text is reflected in the American Studies programs at German universities. Apart from lectures and courses that deal with works from the traditional literary canon - which has already been expanded to include American literatures by women and minority writers - American Studies curricula now also offer courses on popular music, comic books and graphic novels, television series, and, of course, on film. ${ }^{3}$

American popular culture and mass media, it seems, fulfill at least one of the essential criteria Peter Freese lists for the selection of classroom texts or topics: "intrinsic motivational power" (193). Films in particular are an attractive and - to a certain degree - familiar medium for students, both at school and university (Surkamp, "Teaching Films" 3). But this is not the only reason for teaching films. What is more important - especially on the level of academic American Studies

2 The conference program is available online; see American Studies as Media Studies: 53. Jahrestagung der Deutschen Gesellschaft für Amerikastudien. See also the conference volume American Studies as Media Studies, edited by Frank Kelleter and Daniel Stein.

3 Voigts-Virchow somewhat critically assesses the number and contents of media-related courses in English and American Literary and Cultural Studies at German, Austrian, and Swiss universities from 1999 to 2004 (9-13). He laments "the sad fact that media studies have not been fully absorbed" into university curricula, even though, recent introductions to literary studies "have featured chapters on the media or at least on film" (11). 
directed at future teachers - is the necessity for critical media literacy. Douglas Kellner believes that "McLuhan to the contrary, today's media-saturated younger generations are not naturally media-critical or truly media-literate" (335). Indeed, many students of American Studies continue to understand and experience films along the lines of their everyday (and hence often unreflected) contact with Hollywood cinema or U.S. American television programs. American Studies curricula must therefore address precisely this unreflectedness and teach how "to read moving images as well as to deal competently and critically with them" (Surkamp, "Cultural Approach" 15-16).

In his book Media Culture: Cultural Studies, Identity and Politics between the Modern and the Postmodern, Kellner observes that rejecting or neglecting mass culture, as the Frankfurt School did, might be inappropriate today, because "media culture is here to stay and, if anything, its products are becoming increasingly popular and powerful" (335). He is further convinced that a "mindless celebration of media culture, without cultivating methods to promote critical media literacy, is equally pernicious" (335) and thus comes to the following conclusion:

$[1] \mathrm{t}$ is important to pursue a project of developing a critical media pedagogy and to teach ourselves and others how to critically decode media messages and to trace their complex range of effects. It is important to be able to perceive the various ideological voices and codes in the artefacts of our common culture and to distinguish between hegemonic ideologies and those images, discourses, and texts that subvert the dominant ideologies.

Similarly, Carola Surkamp's research on the teaching methodology of film stresses that the knowledge about film is essential for the orientation in a media society, "because filmic devices have a deep impact on our viewing habits, the formation of our opinions ... and the perception we have of other cultures" ("Cultural Approach" 28).

In this larger context, we conceived the idea of teaching parallel undergraduate courses on American science fiction film at the University of Göttingen and the University of Siegen that were to end with a joint conference. In the summer term of 2009, students from Göttingen and Siegen watched, analyzed, and discussed six science fiction films from the 1950s to the present; they gave papers in class and at the joint conference, wrote term papers, and continuously revised their work. One of the primary goals of this joint format was to provide students with an alternative learning experience that not only increases their motivation but also accentuates their academic research and performance skills. The final result of the undertaking is the present volume of student essays.

In the following, we will outline the theoretical, methodological, and didactic considerations that informed the planning and teaching processes of these two courses and the conference - considerations that should also give more general 
insights into new and/or different ways of teaching at university level. More precisely, in Part II, we will discuss the question of why American science fiction film provides an appropriate genre to teach critical media literacy and address a number of important issues both from filmic and cultural studies perspectives. We further elaborate on the choice of six specific films released in the decades from the 1950s to the 2000s. In Part III of this essay, we will then address the course format, organization, and content as well as the didactic approaches and methodology. We will deal with the question of how to teach film in general and science fiction film in particular in an American Studies context. Finally, Part IV briefly presents the structure and content of this volume.

\section{II}

Science fiction film as an essential element of American popular culture provides a valuable source for teaching media literacy in the American Studies classroom. The recent productions of Hollywood blockbusters and film remakes such as $W$ ar of the Worlds (Spielberg, 2005), I am Legend (Lawrence, 2007), and The Day the Earth Stood Still (Derrickson, 2008) attest to the continuing relevance of science fiction in contemporary mainstream culture. At the same time, science fiction allows students to investigate reigning attitudes toward social, political, cultural, and/or ecological developments in U.S. society by "embedding films in their historical and socio-cultural context as well as in the contemporary discourses in which they partake" (Surkamp, "Cultural Approach" 28). Since its beginnings, science fiction has served as an intellectual playground where pressing issues (such as scientific and technological progress, population growth, nuclear power, environmental protection, genetic engineering) have been projected onto different times and spaces in order to warn about inherent dangers, offer solutions, or simply speculate about and experiment with the future. In this function, they can provide insights into U.S. American cultural imaginaries. When analyzed as cultural products, science fiction films can also shed light on U.S. American cultural realities and enable a further understanding of particular historical and political contexts.

Most consumers of popular culture are to a certain degree familiar with science fiction and recognize specific generic elements and conventions. Or, as Jay P. Telotte writes, sporadic science fiction viewers and fans alike are able to formulate an amateur definition of science fiction: "Anyone who has watched even a few science fiction films, episodes of a Flash Gordon serial, or several episodes of the Star Trek or Babylon 5 television series, for example, would probably argue that he or she could, with little hesitation, decide if a certain work belongs within the science fiction category" (17). This assumption is based on the idea that science fiction films share what Telotte calls "particular hallmarks, visual icons, that, over the course of many years, have helped constitute a common signature that cultural consensus or historical use has by now assigned to the genre" (17). The "common 
signature," or "language," of science fiction film that Telotte describes in his book Science Fiction Film includes character types, situations, and settings as well as tools and weapons - to name but a few central filmic devices (17).

As a consequence, an undergraduate course on American science fiction film from the 1950s to the present (such as the one we taught at the University of Göttingen and the University of Siegen) can draw on the students' familiarity with U.S. American popular culture as well as on their familiarity with science fiction films and literature - albeit without taking their media or genre skills for granted. The students' prior knowledge of medium and content should only be the starting point for a more theoretical and historically guided approach to science fiction film. ${ }^{4}$

Eric S. Rabkin situates the beginnings of science fiction in the romantic period and defines it as an umbrella term for literature that "both warns against and applauds the advance of science and technology" ("Science Fiction" 19). As a genre, science fiction is both characterized by its "ambivalence toward the institutions of science and technology" and its interest in the encounter with the other, often in the form of new technologies, worlds, and beings (19). According to Rabkin, science fiction in general is concerned with the dangers of science and technology, yet at the same time it also celebrates the unlimited potentials of science and technology (19). Today, the beginning of the genre is often linked to the publication of Mary Shelley's Frankenstein in 1818 because the novel reflects many of the changes from an agricultural to an industrial society based on recent scientific findings. ${ }^{5}$ When discussing the further development of the genre, it is important to differentiate (1) between science fiction literature and film and (2) between European and American seminal science fiction works. With regard to the first point, one could state that thematically, science fiction film and literature share their concern with contemporary scientific and technological developments. Yet, Vivian Sobchack writes, "SF film is less contemplative and analytic and more spectacular and kinetic than its literary counterparts" (“American Science Fiction Film” 263). Concerning the second observation, Rabkin postulates a major difference between European and American science fiction with reference to their attitudes towards the exploration of space and the crossing of ever new frontiers. According to Rabkin, in European science fiction, the (usually male) hero takes the role of the adventurer who upon meeting the alien turns into himself and eventually, in the tradition of the Robinsonade, returns home. The American science fiction hero on

4 The question of what science fiction actually is and which works qualify as science fiction seems to be characteristic for the genre and acclaimed scholars of the field like Darko Suvin, Brian Aldiss, and Robert Scholes and Eric S. Rabkin advocate different approaches to, and definitions, of the genre. In the introductory sessions of the course, students could be shown a selection of definitions of the genre and asked to compare these approaches to science fiction (literature) with their own ideas of what constitutes science fiction.

5 However, Frankenstein is also, or foremost, regarded as a classic work of the romantic period in Britain and of the gothic genre (Maxwell 7). See also Rabkin, Brian Aldiss, and Edward James. 
the other hand, following the tradition of the Western, crosses the frontier with the aim to change and improve the new territory ("American Science Fiction Film: No Final Frontiers"). About the cultural significance of the science fiction genre for American society in the twentieth century Rabkin remarks:

Just as a mushroom cloud and a single footprint on the moon are this era's linked icons of despair and hope, so science fiction in both warning against arrogance and proselytizing for perpetual discovery embraces our deep ambivalence toward the institutions of science and technology, their products, and their effects on humanity. ("Science Fiction" 19)

Following this observation, we argue that American science fiction has specific themes that derive from, and only make sense within, specific American historical, cultural, and social contexts. The Industrial Revolution of the late eighteenth and nineteenth centuries, for example, resonates in American science fiction of the twentieth century in discourses on a growing U.S.-based global capitalist system, while the exploration of new territories takes the exploration of the New World as its model. In this context, Brian Aldiss notes that even though " $\mathrm{t}]$ he origins and inspirations for science fiction lie outside of the United States ... [s]cience fiction ... is now largely - in emphasis and in fact - an American art form, coinciding with a time of great technological evolution and with the rise of the USA to superpower status" (14). Science fiction, in other words, has become an American genre with a global audience.

Accordingly, the themes, settings, and motifs of science fiction films are defined by specific American cultural circumstances. Therefore, an undergraduate course in an American Studies context can provide a historical overview of American science fiction films on the one hand, and enable engaged readings of each individual film not only as a reflection of important political, cultural, and social issues of their times but also as "an active force in its own right which is involved in the actual generation of ways of thinking and of attitudes" (Nünning 360) on the other. This is important because, as Carola Surkamp writes, "the choice of topics and formal properties not only reflects, but also influences the cultural issues of a given period" ("A Cultural Approach" 18). As a consequence, she further explains, "the analysis of the means of representation employed in a film can give insight into the cultural knowledge, the conceptions of reality and the ways of thinking of the society in which it was produced" (18). Surkamp's assumptions are based on the complex relationship between fictional texts and their contexts which she describes as follows:

Within culture-oriented and context-sensitive literary studies, literary texts and films are not seen as closed systems and static products, but they are rather conceptualized as being closely related to reality. ... However, this does not mean that films simply reflect reality. It is rather the case that they stand in a close dynamic interrelation with the reality outside the film, 
which is critically questioned by their choice of topics as well as formal means. On the one hand, films select a few of the diverse events and experiences of a multi-layered reality and present them with the aesthetic means of the audiovisual medium. ... On the other hand, films also influence the discussion on specific cultural themes in various discourses outside the medium: they gain productive character through the fictional interpretation of culture-specific experiences. (17-18)

In accordance with Surkamp's claim that "films should also be analysed with regard to their function as a medium that creates cultural meaning" (18), an undergraduate course on science fiction film obviously allows to link film studies learning objectives and the cultural studies perspective prevalent in the academic field of American Studies in a fruitful way. ${ }^{6}$

With this idea in mind, it makes sense to follow a chronological order when choosing the films that are to be watched and/or discussed in class, e.g. one representative film for each decade starting from the 1950s and ending with the 2000s. If the overall course objective, then, is to map and analyze American culture from the 1950s to the present through science fiction films, the selection of one film for each decade must be influenced by two considerations: (1) The films must be key works of the science fiction genre. (2) At the same time, the films have to reflect specific American cultural discourses of their periods. In other words, the six films to be selected as representative of the six decades covered in the course should lend themselves to analyses from a science fiction genre perspective as well as from a cultural studies perspective. As such, they can offer further understanding of the particular historical and political contexts of their respective periods.

The twentieth century saw a variety of American science fiction film productions. Despite this diversity, one can find recurring topics and themes: the increasing development of new technologies, a shift from an industrial economy to a globalized mass consumer and information society, growing influences of computer technology on humans and their everyday lives, and the encounter with the "other," the new, or the "alien" potentially made possible by technological inventions and advances in the fields of biotechnology and genetic engineering. Although these topics have been of varying relevance in public debates throughout the last six decades, and their prevalence in science fiction films as well as the images and rhetoric used to portray them have changed, they can be regarded as the underlying themes in many science fiction films of that time period. For the course "Of Body Snatchers and Cyberpunks: American Science Fiction Film from the 1950s to the Present," the syllabus listed the following six films: Don Siegel's Invasion of the Body Snatchers (1956), Stanley Kubrick's 2001: A Space Odyssey (1968),

6 On cultural approaches in American Studies and the foreign language classroom see also Delanoy and Volkmann, as well as Bach and Donnerstag. On media use in this context see Donnerstag and Volkmann. 
Richard Fleischer's Soylent Green (1973), Ridley Scott's Blade Runner (1982), the Wachowski brothers' The Matrix (1999), and Steven Spielberg's Minority Report (2002). In the next part of this section, we give a brief overview of each decade from the 1950s to the present in terms of their cultural climate, we present the central science fiction films of each period, and explain why we chose the six films above for the course.

The 1950s marked the beginning of the Cold War. After the end of World War II, communism was the new enemy and developments in science and technology fueled fears of potential nuclear contamination. Within science fiction, the 1950s are also the starting point for American science fiction film as a genre, as Vivian Sobchack writes ("American Science Fiction Film" 263). Productions such as Irving Pichel's Destination Moon (1950), which was based on a novel by Robert A. Heinlein, Byron Haskin's The War of the Worlds (1953), and George Pal's The Time Macbine (1960), both of which were adapted from novels by H.G. Wells, established the genre (Booker 4-7). Don Siegel's Invasion of the Body Snatchers (1956) - a classic alien invasion film - seems most appropriate for a case study of this decade because it can be analyzed both as an allegory about the fear of communist infiltration in the wake of McCarthyism and as commentary on domestic issues such as changing gender roles in post-war American middle-class society.

The 1960s were influenced by two important events: the space program as a product of Cold War competition between the United States and the Soviet Union and the Civil Rights movement in the United States. Both Sobchack and Marvin Keith Booker observe a decline in science fiction film productions during this period. 'The decade's emphasis on 'relevance,' and the clear importance of such phenomena as the anti-war movement, the Civil Rights movement, and the women's movement, made SF film seem frivolous to many," Booker explains the recession of the American science fiction film in the 1960s (12). Yet the genre also began to "strive for artistic seriousness" (12). Franklin Schaffner's Planet of the Apes (1968) and Stanley Kubrick's Dr. Strangelove: or How I Learned to Stop Worrying and Love the Bomb (1964) are among the science fiction films that reflected the cultural discourses of the period (Roberts, The History of Science Fiction 267; Sobchack, “American Science Fiction Film" 266). We decided to screen Stanley Kubrick's 2001: A Space Odyssey (1968) because it engages in public discourses about the U.S. space program and the counterculture movement in an original way. Featuring an artificial intelligence and an advanced alien race, it contemplates human evolution and can be read as a film that both celebrates and questions the technological progress. In terms of film analysis, 2001 is also a hallmark of special effects.

A growing social and political skepticism in the aftermath of the Civil Rights and other liberation movements fostered by the Watergate scandal (1972-4) and the end of the Vietnam War (1975) characterized American social, political, and cultural debates of the 1970s. Booker writes that because of its escapist potential, science fiction films experienced hitherto unknown popularity during that decade (14). Films like Steven Spielberg's Close Encounters of the Third Kind and George 
Lucas' Star W ars (both released in 1977) refashioned the adventure story "in which good triumphed over evil," thereby meeting conservative viewer demands (13-4). In contrast to Booker, Sobchack sees the science fiction film of the 1970s not as escapist but as "[m]ore adult, socially relevant, and mainstream than it had been previously, ... dealing with overpopulation, food shortages, urban blight, and aging" ("American Science Fiction Film" 267). Richard Fleischer's maybe lesserknown Soylent Green from 1973 lends itself to analysis because it is one of the science fiction films of the decade that depicts a dystopian view of American urban future. At the same time, the film reflects on environmental concerns, discourses on globalization, and the class and gender struggles of the decade.

The 1980s were marked by economic deregulation and political conservatism combined in the term Reaganomics. Other current debates revolved around multiculturalism and advances in computer technology. Films like Spielberg's E.T. the Extra-Terrestrial (1982) still used the escapist component popular during the 1970s in order to address mainly young viewers (Booker 14). The 1980s were also the years of the first Star Trek feature film sequels, whose eleven films span the 1990s as well as the first decade of the new millennium. Like the Star Wars franchise, Star Trek became one of the largest science fiction commercial enterprises in the United States and abroad. Rejecting the boundaries of high and low culture as well as rigid genre distinctions, postmodernism emerged as the predominating critical theory of the time, and it exerted a substantial influence on the science fiction film as well. Films such as Ridley Scott's Alien (1979) and Blade Runner (1982) extensively employ postmodernist aesthetics and themes, and academic critics such as Fredric Jameson received them as the "paradigmatic cultural expression of postmodernism" (Booker 15), as films that "symbolically mark a transition" in the depiction of the other, the alien, in the science fiction genre (Jameson 140). Other examples of the postmodern influence on science fiction film are James Cameron's The Terminator (1984) and Paul Verhoeven's RoboCop (1987), which both feature cyborgs: beings that are partly human and partly machine. The noir-science fiction film Blade Runner, which is based on Philip K. Dick's novel Do Androids Dream of Electric Sheep? (1968), became part of the syllabus because it is generally regarded a key icon of the postmodern period in science fiction filmmaking and is - with its dark, rainy and overpopulated cityscape - one of the most visually influential science fiction films. Contemplating what Booker terms "the distinction between humans and the products of their technology" (15) in the form of cyborgs, the film addresses many aspects of the contemporary condition of Western societies, such as fragmentation and questions of identity, alienation of the middle and working classes in the process of globalization, and the fear that machines will eventually fully replace human workers. Moreover, Blade Runner takes a critical perspective on the system of global capitalism and postmodern culture.

The 1990s were characterized by the end of the Cold War and by the beginning of the so-called new world order of political unipolarity as well as by the 
increasing significance of computer technology and the Internet in all walks of life. Roland Emmerich's Independence Day (1996) promotes a political discourse of a new world order in which America saves the world from aliens, who in the film are the worlds' new enemies (Booker 17). Furthermore, virtual reality was no longer a space confined to science fiction in films such as Robert Longo's Jobnny Mnemonic (1995) and Alex Proyas' Dark City (1998), but had also found its way into the 1990s everyday culture. On the one hand, Andy and Larry Wachowski's The Matrix (1999) - which served as our case study for the 1990s - comments on virtual reality and the "reliability of perception" (Rabkin, "American Science Fiction Film: No Final Frontiers"). On the other hand, its entire production depended on recent advances in computer technology. By applying Jean Baudrillard's theory Simulacra and Simulation - which the French philosopher describes as "the generation by models of a real without origin or reality: a hyperreal" (1) - The Matrix and its sequels The Matrix Reloaded and The Matrix Revolutions (both 2003) partake in popular and critical discourses on the information technologies of the decade.

The first years of the new millennium were marked by the terrorist attacks on September 11, 2001, and George W. Bush's subsequent "war on terrorism.” Increasing calls for state action that relied on new surveillance methods are taken up in Steven Spielberg's Minority Report (2002). We selected this film, which is based on a short story of the same title by Philip K. Dick, for the 2000s because it portrays a future scenario where everyday technologies such as instant messaging, closed circuit television, and satellite communication are used and abused in the name of global commerce and crime prevention. On a philosophical level, the film asks questions about the "reliability of knowledge," as Rabkin has pointed out ("American Science Fiction Film: No Final Frontiers"). In terms of successful film productions, the first decade of the twenty-first century witnessed the triumph of fantasy films over science fiction remakes, of which Spielberg's War of the Worlds (2005) and Francis Lawrence's I am Legend (2007) - an adaptation of Richard Matheson's 1954 novel and a remake of Ubaldo Ragona's The Last Man on Earth (1964) and Boris Sagal's The Omega Man (1971) - are probably the most well known examples. This increasing turn to earlier films can be read as a sign of a recent nostalgia of the science fiction genre (Booker 23-5). In terms of box office success, the epic fantasy screen adaptations of J.R.R. Tolkien's The Lord of the Rings by Peter Jackson (2001-3) and of C.S. Lewis' The Chronicles of Narnia by Andrew Adamson (2005) as well as the Harry Potter film adaptations have met the demands of contemporary viewers who are turning away from depictions of technologysaturated societies to worlds far away and purely imaginary.

This brief overview of American science fiction films since the 1950s has sought to show that the six films selected for the course "Of Body Snatchers and Cyberpunks" are among the cornerstones of the genre. They can be watched and analyzed as exemplary cultural products of their respective decades because they engage in popular discourses through their depictions of current events and de- 
velopments. In other words, the specific topics these films discuss and their distinct cinematic realizations "give insight into the cultural knowledge, the conceptions of reality and the ways of thinking of the society in which [they were] produced" (Surkamp, "Cultural Approach" 18). However, they present only one way of studying science fiction film and approaching American culture since the 1950s. Other films could be selected for this purpose just as well, possibly providing similar or new insights. What all six films on the syllabus share is that the various issues discussed in the works as well as their roles within American science fiction film may become fully apparent to the young non-American viewers once they analyze the means of representation and research the historical backgrounds of the periods in relation to the development of the genre.

\section{III}

The American Studies division at the University of Göttingen has a strong record in offering joint courses with other German universities or departments that are usually conducted in parallel sessions with identical or similar syllabi. At the end of the term, the students meet for a common symposium where they have the opportunity to deliver the papers they have worked on during the term and to discuss their research with peers and international scholars invited for the occasion. ${ }^{7}$ These joint courses have been offered as Hauptseminare, i.e. they were geared toward advanced students of American Studies and English Philology. In most cases, the student papers delivered at the common symposia were astonishingly full-fledged academic contributions. The discussions revealed that the students had acquired an in-depth knowledge of the topic, which prompted them to formulate challenging questions and interesting comments. Apparently, the course format - and the symposium in particular - not only helped to create or increase

Over the last decade, Frank Kelleter - chair of American Studies at the University of Göttingen - has offered and organized the following joint courses and corresponding symposia: "Sexuality and Seduction in Early America" (summer term 2004) with Ruth Mayer from the University of Hanover; "Hybrid Literatures, Hybrid Cultures" (summer term 2005) with Manfred Engelbert, and Annette Paatz from the Department of Romance Languages and Literatures at the University of Göttingen; "Authors: Theories of Literary Authorship (and American Case Studies)" (winter term 2005/2006) with Ruth Mayer from the University of Hanover; "Slavery and the Southern Plantation Romance" (summer term 2006) with Ulrich Mücke from the Department of Romance Languages and Literatures at the University of Göttingen; “The McSweeney's School of Fiction" (summer term 2008) with Laura Bieger from the John F. Kennedy Institute for North American Studies in Berlin.

Furthermore, Barbara Buchenau from the American Studies Program and Carola Hecke from the Teaching Methodology Program at the University of Göttingen have organized the following joint student conference "¿Postethnicity? - Identity Politics Reconsidered: North American Theories and Literary Practices in and outside of German Multicultural Classrooms" (summer term 2007). They have published an article on their teaching concept in the German-language journal Literatur in Wissenschaft und Unterricht, see Buchenau and Hecke. 
the learners' motivation but also affected the quality of the students' academic performance. This was not only true for the more advanced students of the Hauptstudium but also for students in their first and second years. In the summer term of 2008, students of two Proseminare offered by the English Department of the University of Göttingen met for an undergraduate conference on the Gothic novel, ${ }^{8}$ and here, too, the students presented excellent papers, as the more advanced students had done before them. In sum, parallel courses in combination with joint conferences obviously inspire students to overachieve academically both at the beginner and advanced levels.

Plans to teach parallel undergraduate courses on American science fiction film at two different universities - the University of Siegen and the University of Göttingen - that were to culminate in a joint undergraduate conference at the end of the term needed to draw on the experience of colleagues who had organized earlier events when deciding on the format, organization, and content as well as on the didactic approaches and methodology of the entire undertaking. The advantages of this teaching format are manifold: First, the participation of students and teachers from two different university contexts creates multiperspectivity. Upon meeting and exchanging their ideas at a joint conference, students are required to transfer, negotiate, and possibly revise their preconceived notions and thus engage in an active learning process. Second, in the context of the parallel courses and the joint conference, responsibility, personal initiative, and self-organization on the part of the students lead to better learning results and a heightened awareness of and confidence in their own academic achievements. This is closely related to a third point: The high motivational potential of the format signals to the students that their work is meaningful outside the classroom. Not only are students from two different universities interested in each others' work. If international experts are invited to the joint conference, and if this conference is open to the public, the students' academic performance gains even more importance. Finally, the learning atmosphere in class improves with the prospect of a joint conference where results can be presented to fellow students and a critical audience. ${ }^{9}$

While at some German universities the format of joint courses in connection with symposia or undergraduate conferences might be established and therefore familiar to advanced students, it may yet be unknown to those who are in their first and second years. It is therefore necessary to introduce the format to the students and to emphasize the degree of commitment required by this timeconsuming endeavor. The appeal of the undergraduate conference can be enhanced by inviting an international expert who gives a keynote at the conference,

8 Stephanie Sommerfeld and Dorothea Schuller organized "Discourse, Dreams, Delusion: The Enlightenment and the Gothic in Transatlantic Perspective" (July 4-5, 2008) as a joint undergraduate conference for their individual courses.

9 For advantages of the teaching format that combines parallel courses and joint conferences, see Buchenau and Hecke. 
attends the entire event, and participates in the discussion of the student papers. ${ }^{10}$ The students' work and achievements during the term are thus appreciated by an audience consisting of an expert and fellow students who engage with a diversity of student papers. This is not only highly motivating for students but also helps to accomplish a number of important learning objectives both inherent in the format and specific for the topic of American science fiction film, namely:

- Critical media literacy/film literacy: As mentioned above, media awareness is essential in today's media-saturated society. Based on a historical survey of American science fiction films from the 1950s to the present, critical media literacy means knowledge about, and engagement with, different filmic devices and their effects and insights into the historical, political, and cultural contexts in which the individual films were produced and released.

- Intercultural competence: The insights students gain into the historical, political, and cultural contexts of the science fiction films surpass, in fact, the learning objective of critical media and film literacy. They also further the students' intercultural competences, or more precisely: their knowledge about a specific historical, political, and/or cultural context, about the beliefs, mindsets and world views of another culture. As students receive and process this knowledge against the background of their own experiences and preconceived notions, it is important to actively discuss and reflect on exactly this reception process. This can be achieved with student papers, in class discussions, and of course at the conference, where students not only negotiate their findings with their fellow students from another university but (if possible) also with an expert from the target culture (in our case with a professor from an American university).

- Revising strategies: A course format in which students present their findings in the context of an undergraduate conference at the end of the term requires very specific preparations. Ideally, students should get the chance to present a draft version of their papers or their work in progress in class and thus have the opportunity to revise and improve their work according to the students' and the teacher's feedback. However, this would only be the starting point of the revising process because the students should continue to improve their papers after the conference, i.e. before handing in the term

10 It is recommendable to include (at least) one text written by the external expert into the course readings. Furthermore, biographical information about the expert's research and/or teaching will raise the students' interest in the conference and in meeting the expert.

We had the extraordinary opportunity to invite Prof. Eric S. Rabkin from the University of Michigan in Ann Arbor (USA) for the undergraduate conference "Of Body Snatchers and Cyberpunks: American Science Fiction Films from the 1950s to the Present" (Göttingen, July 3-5, 2009). As an expert in the field of science fiction studies, he not only enriched the conference with his brilliant keynote lecture "American Science Fiction Film: No Final Frontiers," he also contributed to the success of the event by interacting with the students, commenting on their papers, and sharing his great wealth of knowledge. 
papers. The academic performance at the conference itself, the presence of fellow students from the partner university, and the participation of an external expert are important motivational factors: Students are encouraged to apply revising strategies and consciously improve their work.

- Presentation skills: Developing and practicing presentation skills by giving an academic talk before an audience is important for all students, whether they will be future teachers or pursue other professional careers. These presentation skills include the command of the English language, i.e. the mastery of an adequate register and vocabulary for an academic presentation, confidence in public speaking, and the appropriate use of handouts and/or (audio)visual support (e.g. PowerPoint).

- Media competence: In contrast to the teaching goal of critical media literacy, media competence refers to the students' know-how concerning the use of PowerPoint or other presentation programs, clips and/or screenshots in their talks (and written papers). Film analysis depends on the serious engagement with the audiovisual material. Clips and/or screenshots serve as (audio)visual support for the students' arguments. Hence, students must not only learn how to recognize, analyze and interpret filmic devices in specific scenes or sequences, but also how to capture them as clips or screen shots and how to integrate them into a presentation.

- Organizational skills: Students should be involved in the preparation of the joint conference. They can be asked, for example, to put together their individual panels; students who act as panel chairs can prepare short presentations of the speakers and decide on how to proceed (if each presentation is followed by a discussion or if all presentations will be discussed at the end of the panel). Students can further be in charge of providing a place to stay for their fellow students from the partner university. This responsibility and personal initiative does not only practice organizational skills but also demands interinstitutional communication.

These teaching goals should further be reflected in the organization of the parallel courses. Joint conferences have proven to be most successful if both courses follow the same syllabus and students work with the same primary material and secondary literature. Especially discussions may turn out to be more difficult if the students follow different syllabi in their individual courses. While a common frame of reference might enable most advanced students to critically engage with other student papers and the talks delivered by experts, younger students probably still lack the skill to reflect on new insights within the short time of the discussion sections or to apply the knowledge they have gained throughout the term to new texts and contexts.

When teaching film and preparing the students for an undergraduate conference at the end of the term, two major questions will arise with regard to the practical organization of the course: (1) should the films be viewed in class or at 
home? (2) Should the students present their papers in a simulated conference situation or give a report on their work in progress? The answers to both questions depend on the number of students and sessions or on the available time slots and the possibility to schedule additional (screening) sessions. All solutions have their advantages and disadvantages. On the one hand, viewing the films on the syllabus in class is very time-consuming and might even require scheduling extra screening sessions. Moreover, some students will prefer to watch the films at home, with friends etc. A collective viewing experience, on the other hand, ensures active (as opposed to passive) watching and contributes to a productive atmosphere in class. Additional screening sessions may test but also strengthen the students' commitment and foster a common bond among the participants. Inclass viewings also avoid the practical and legal problem of providing each student with the DVDs and take into account that not all students may be able to watch the films at home.

Presenting papers in a mock conference situation as opposed to a report on the work in progress is likewise debatable. While the first option enables students to practice both the academic talk and the subsequent discussion in the (relatively) safe environment of the classroom, it can also be highly repetitive - as revised versions of the same talks will be given at the conference - and exhausting if too many students attend the class. Even if the presentations are no longer than ten minutes, the students will leave less time for practicing film analysis and for discussing more general aspects of the films in class. The second option, on the other hand, leaves more room for discussion and more time for the students' individual work on their presentations. However, revising strategies can only partly be applied if work in progress is presented.

Once the organization of the courses is decided upon, the content, didactic approaches and methodology gain center stage. The following questions are crucial: How can American science fiction film be taught? And more generally: How can film be taught in an American Studies context? Background readings on science fiction and science fiction film are, of course, indispensable, and teachers should provide excerpts from classic and more recent publications on the genre in literature and film. ${ }^{11}$ Yet, above all, a course on science fiction film - as any other course on film - must start with an introduction to film analysis. Students must be able to register cinematic means of expression and to make use of the exact terminology for different filmic devices if they are to analyze film scenes and sequences. For a historical, political, and cultural contextualization, they must further know how to semanticize these cinematic means of representation, and how to analyze their functions and effects on contemporary audiences as well as on viewers today.

11 On science fiction, see Gunn, Rabkin and Scholes, Suvin, Parrinder, Seed, James and Mendlesohn as well as Roberts. On science fiction film, see the recent studies by Sobchack, Hendershot, Telotte, Booker, and Cornea, or the essay collection edited by Sanders. 
Bernard F. Dick's Anatomy of Film and Timothy J. Corrigan's very accessible $A$ Short Guide to Writing about Film can be helpful tools for developing a vocabulary of technical terms as well as for learning how to take notes and write about film.12 It is useful to provide the students with a worksheet that lists selected terms and - if possible - illustrative figures for the main categories in film analysis: narrative, composition, camera/image, montage/editing, and sound. Having prepared their readings on film analysis taken from Dick and Corrigan or other introductions, students can fill in the worksheet with the respective definitions (e.g. for different field sizes, camera angles, cuts, and transitions) and add their own annotations. It is highly recommended to compare the students' notes in class - in preliminary pair work followed by class discussion - and to provide audio-visual examples for a selected number of terms such as the shot-reverse-shot pattern, different camera movements, match cut, jump cut, and varying forms of transitions, to name just a few. Rüdiger Steinmetz explains and illustrates these basic terms in volumes one and two of his Filme sehen lernen series that is equipped with additional, easy-tohandle DVDs. The newly acquired technical vocabulary - to which the students can and should refer throughout the term - will enable them to make specific statements about the cinematic aspects of the films discussed in class. Furthermore, it makes interpretative statements transparent to other students and intersubjectively comprehensible.

Apart from learning the terminology for filmic devices mentioned above, students will need to familiarize themselves with methods of sequence analysis and ways to take notes when watching and analyzing a film. As Corrigan writes, "despite the difficulty in taking your eyes off the screen momentarily, it is important to take notes of some sort during a first and only viewing" (26). For a start, he suggests, "to limit yourself to noting, with as much detail as possible, what you consider the three or four most important scenes, shots, or sequences in a film" (26). In her article "Teaching Films," Carola Surkamp offers another approach to taking viewing notes by providing a table that follows the distinction between literary (setting, characters, events, themes, point of view), dramatic (location/props, actors, costumes, make-up), and cinematic (camera, color/lighting, montage/editing, sound/music) aspects (9). ${ }^{13}$ This method is very practical for group work in class: As individual groups focus on one of the aspects during the film viewing and then exchange their observations, both the processing of audiovisual information and note taking can be considerably relieved. Most complex are the examples of sequence analyses from Helmut Korte's Einfïbrung in die systema-

12 Other excellent introductions include Monaco, Hickethier, Korte, and Jahn.

13 See also Nünning and Surkamp (245-75). 
tische Filmanalyse in which he uses elaborate graphs to analyze sound, camera movements, cuts, and transitions. ${ }^{14}$

Students should be introduced to these different approaches, yet, for the purpose of teaching a class on American science fiction film in an American Studies context, a middle ground that combines these (and other) ideas might be most appropriate. More precisely, we suggest the following set of guiding questions that the students should keep in mind when watching the films on the syllabus and preparing the analysis of specific sequences:

- Narrative: What happens in the sequence on the level of plot? What is the function of the sequence within the larger plot? How is the story being told (e.g. linear, flashbacks, flash-forwards)? How do the various channels of information used in film (visual image, print, speech, sound) interact to produce meaning? Can you recognize a source of narration (e.g. voice-over, on or off-screen commentary)? What is the narrator's perspective? Is he reliable?

- Composition: How would you describe the setting (on location or in the studio, historical/contemporary/futuristic)? Do certain props take a symbolic function? How do sets and props comment on the narrative? Is the space cluttered or empty? Is it a landscape or an interior? Does the space express a certain atmosphere or comment on a character's state of mind? Which colors are used (black and white/color/sepia, warm/cold/strong/washedout colors)? Can you discern any symbolic or subjective uses of colors? How would you describe the lighting (high-key or low-key)? What is illuminated and what is in the shadow? Are there any special lighting effects (e.g. shadows, spotlights)? How does the lighting enhance the expressive potential of the film? How do the actors interact verbally and/or non-verbally? Are there special groupings of characters? What do appearance, gestures, facial expressions signify? Are costume and make-up realistic/contemporary/futuristic? What do costumes signify with regard to social and cultural coding (class, gender, status, age)?

- Camera/Image: What are the field sizes used in the sequence (extreme long shot/long shot/medium shot/close-up/extreme close-up etc.)? Is it a deep/soft/sharp focus? Who or what is in and out of focus? How would you describe the camera angle (high/low/straight-on/eye-level)? Does the camera pan/tilt/zoom? Is it a tracking shot/crane shot/hand-held shot? Does the camera always follow the action? What are the types of shots used in the sequence (establishing shot/point-of-view shot/shot-reverse shot)?

- Montage/Editing: What comes before and what comes after the sequence? Are there any transitions (fade/dissolve/wipe/iris)? Are there any match

14 See Chapter 3 "Systematische Filmanalyse" (24-55), in which Korte provides a detailed introduction to film analysis. Sub-chapter 3.3 (39-53) is particularly helpful because it presents different ways and tools to visualize cinematic structures. 
cuts or jump cuts? Are the transitions gradual or abrupt? How do the transitions enhance the expressive potential of the film? Can you determine the purpose of editing (cutting for continuity, i.e. invisible cutting/thematic or dialectical montage/cross-cutting)? How long are the individual shots? Is the sequence fast-paced/slow-paced? Are there major changes in rhythm due to the narrative?

- Sound: What kind of music can you hear? Does it come from an on- or offscreen source (intra-diegetic/extra-diegetic)? Is it part of the story? Does it comment on the action? Is it linked to a character? With what purpose is music employed in the film? How does it direct our attention within the image? How does it shape our interpretations of the image? How would you describe the dialog (artificial/futuristic/foreign language, slang/dialect)? Do different characters use different kinds of language? Are there silences? Are the sound effects used in the sequence artificial or natural? Do they have an on- or off-screen source? Does the sound belong to the action? Is there subjective sound? If there is a voice-over: Who is speaking? Is the voice-over narrator part of the action or outside of it? ${ }^{15}$

The set of guiding questions could be provided as a worksheet, and the students could form five expert groups, each group dealing with one cluster of guiding questions. While the expert groups remain the same throughout the course - again to enhance the bond among the participants and to create a productive work atmosphere - the respective guiding questions might rotate with each film. The focus on one specific filmic category (narrative, composition, camera/image, montage/editing, or sound) would not only ensure active viewing on the part of the students but would also constitute an important practice of film analysis in the while-viewing phase. This approach to science fiction films could be first put to use in an exemplary analysis of the opening sequence of Don Siegel's Invasion of the Body Snatchers (1956). Ideally, the students' observations should be discussed and commented on in class. However, if there is not enough time, it is also possible to do so on an Internet platform or blog, where students can post their notes and interact with each other. ${ }^{16}$

A forum for discussion on an Internet platform/blog and/or a designated time slot in class should also be reserved for pre- and post-viewing activities. Having read a designated selection of secondary literature on the historical background of the time in which the film was produced or on the film itself, students could for-

15 The set of guiding questions is based on Timothy J. Corrigan, Helmut Korte, and Carola Surkamp ("Teaching Films"). It is also indebted to Eric Rentschler and Anton Kaes and takes up ideas from Dick and Monaco.

16 In the two courses "Of Body Snatchers and Cyberpunks: American Science Fiction Films from the 1950s to the Present" taught at the University of Göttingen and the University of Siegen, the Internet-based learning sites Stud.IP (Göttingen) and Moodle (Siegen) were used as platforms for discussion throughout the term. 
mulate notes about their expectations before watching the film. It should be stressed that the students attempt to make statements from film analytical and cultural studies perspectives. This pre-viewing activity is important and usually very productive because, as Corrigan states, preliminary notes help students to make economical use of their time and to recognize key sequences, shots, or narrative facts, which subsequently enables them to come up with a thesis (29-30). Secondary literature on the cultural, historical, and political background helps students to situate the films in a larger U.S. American context. Formulating a thesis and presenting a paper in class and/or at an undergraduate conference will constitute the most challenging post-viewing activity for students in their first and second years. Teachers should therefore provide assistance and feedback during the process of finding an adequate topic and developing a tentative thesis.

In order to ensure active course participation during the presentations, students could focus on the following questions: What do you think about the presentation? Are there points with which you agree or disagree? Could you find additional pieces of evidence to support the thesis or would you rather take a different approach to the aspects pointed out? Answering these questions not only fosters critical engagement with the topics and theses presented in class. It also serves as a preparation for the discussion sections at the conference. Formulating critical comments and questions constitutes an important aspect of academic performance and has to be practiced accordingly. The safe environment of the classroom is an ideal place for "trial and error" experimentations before the undergraduate conference.

For all those students who feel that there is never enough time for discussion in class or that important issues have not been raised, the teacher can provide a space to post their ideas and final thoughts on the Internet platform or blog. Students should also be encouraged to formulate concluding remarks as a post-viewing activity and to reconsider the preliminary notes they have formulated before watching the film and if those issues were addressed in class.

Considering the parallel undergraduate courses on American science fiction in Göttingen and Siegen as a case study for the teaching approach presented here, it might be interesting to add that the format, organization, and content as well as the didactic approaches and methodology have received mostly positive feedback from the students both in final class discussions and on anonymous evaluation forms. The main points of critique were that the course was extremely timeconsuming - with (extra) screening sessions and a three-day conference - and that scheduling the undergraduate conference at the end of the term interfered with exam preparations. Yet, positive opinions prevailed: Most students enjoyed the productive atmosphere in class, liked the discussions, and thought that the conference with our external expert Prof. Eric S. Rabkin and the fellow students from Göttingen and Siegen were special and enriching experiences they would not want to miss. What is more important from the teachers' perspective is the students' 
efforts and achievements, or, in other words, the fact that all students excelled in their academic performance in class, at the conference and in their term papers.

\section{IV}

The present volume documents the hard work, dedication, and commitment of thirteen students from Göttingen and Siegen who have participated in the course "Of Body Snatchers and Cyberpunks: American Science Fiction Film from the 1950s to the Present" and the concluding undergraduate conference in the summer term of 2009. They have repeatedly revised and improved their contributions: first, after presenting their initial ideas in class; then, after the undergraduate conference; and, finally, after handing in their term papers. The results of this continuous revision are collected in this volume. The progress of the students during the entire process - from conceiving their ideas for the paper to the final publication - has been really astounding. This is also true for those students whose papers could not be included in this book. Unfortunately, the editors had to select the best among many excellent papers. The final result are twelve student essays one is co-authored by two students from Siegen - divided into four sections that group the essays according to shared research interest and do not reflect the chronological approach taken in the course. This arrangement brings to the fore lasting, changing, and recurring themes as well as stylistic and filmic devices that are part of both American culture and the science fiction genre.

Part I is entitled "The Look and Sound of Science Fiction Film." All three contributions in this section focus on the filmic use of visual effects, special effects, and sound that evokes what could be called a particular science fiction atmosphere. First, Jörn Piontek's essay analyzes different examples of visual subversion in Richard Fleischer's Soylent Green (1973). In Vivian Sobchack's words - on whose definition Piontek's analysis is based - visual subversion is a cinematic technique that is often used in science fiction films and that can be understood as "the alienation of the familiar" (Screening Space 107). Piontek shows how disturbingly familiar images are used to create the effect of a threateningly possible dystopian future. Dennis Edelmann then explores the special effects in the Wachowski Brothers' The Matrix (1999). He argues that critics have mostly focused on the revolutionary content and unique visuals of the film but have neglected the groundbreaking special effects and their impact on the film industry. Edelmann's discussion of the special effects in The Matrix pays particular attention to how reality is deconstructed and how bullet time is employed in the film. In the next essay, Fabian Grumbrecht turns to Stanley Kubrick's 2001: A Space Odyssey (1968). He provides a close reading of the sequence in which astronaut Dave Bowman turns off the board computer HAL 9000. According to Grumbrecht, this specific sequence stands in stark contrast to other cinematic showdowns in which the 
antagonist is destroyed - not only on the level of plot but also on the visual and aural levels.

Part II, entitled "Social and Political Commentaries," contains four essays that deal with the critical potential of science fiction films. They investigate to what extent science fiction films can participate in the cultural, political, and religious discourses of their respective decades. First, Niklas Franzen takes a close look at "Jupiter and Beyond the Infinite" - the Stargate sequence in 2001 - and examines its popularity with young adults of the 1960s U.S. counterculture. While contemporary critics were convinced that young viewers enjoyed the innovative, highly psychedelic sequence in 2001 because of its hallucinogenic effects (commonly enhanced by the use of drugs), Franzen reads the success of the sequence also as an expression of opposition by relating the film's release to the Vietnam War, the Civil Rights Movement, and student protests in the 1960s. In the following essay, Manfred Alexander Müller analyzes manhood and masculinity in Don Siegel's Invasion of the Body Snatchers (1956). He interprets key scenes of the movie as highly charged reflections on the post-war decline of small-town patriarchy and the related threat to male social and political dominance in the United States. Philipp Stückrath's reading of Steven Spielberg's Minority Report (2002) then links the theme of personal liberty vs. state control prevalent in the post-9/11 film to the current political situation in the United States. Even though the film is based on a science fiction short story by Philip K. Dick that was first published in 1956, Stückrath reveals many similarities between the celebrated yet dysfunctional PreCrime system in the film and the institutions and laws of state control in the present-day United States that were established after the terrorist attacks in 2001 (such as the Department of Homeland Security and the USA PATRIOT Act). Part II closes with Moritz Emmelmann's analysis of religion in Soylent Green. Emmelmann argues that in the context of the extreme social, economic, and moral crisis depicted in Soylent Green the Christian Church is presented as a charitable institution and stronghold of spiritual leadership and moral integrity.

Part III of this collection is entitled "Themes and Motifs of Science Fiction Films." The section starts with an essay by Dennis Kogel and Iris Schäfer. They look at a key motif of science fiction film and literature: the doppelgänger. Kogel and Schäfer provide a survey of five distinct motifs used in science fiction film and TV series (clones, artificial intelligence, time travel, parallel universes, virtual identities) in order to demonstrate how the idea of the self is challenged in contemporary science fiction productions, and how it relates to modern capitalism in an information society. In the second essay of this section, Stefanie Schwarz analyzes the importance of vision and the eye motif - another recurring motif in science fiction films - in Minority Report. Schwarz reads images of eyes that serve to identify citizens in the dystopian Pre-Crime society of the film as well as visions of future crimes arranged and interpreted by the Pre-Cops in the context of power relations, determination, and reliability. Solveig Burfeind's reading of Invasion of the Body Snatchers finally focuses on elements of film noir in the 1950s film and exam- 
ines whether Becky Driscoll can be classified as a femme fatale. Burfeind shows that Becky shares many characteristics with a femme fatale: Not only does Becky look like a femme fatale (especially when compared to other female characters in Invasion), as a divorced woman she is also sexually experienced and effectively seduces Miles Bennell, whom she later tries to turn over to the alien pod people.

The final section of this volume, Part IV, is entitled "(De)Constructing Bodies and Identities" and consists of two essays that deal with the body and its various functions and realizations in science fiction film. First, Benjamin Ryan Ulonska reads Invasion of the Body Snatchers and its remakes as a narrative that combines elements of science fiction and horror in order to comment on changing perceptions of the body in the respective decades of the film's remakes. Ulonska argues that the specific horror elements and outer appearance of the aliens - their bodies - in these invasion films reflect the dominant political, cultural, and social anxieties of the decades in which the individual versions were produced. In the last student essay, Gina Ziebell analyzes the realization of the cinematic body in times of information technology in The Matrix. Ziebell examines the human body and identity in terms of the obsolescence of the body and the construction of the virtual subject by relating it to the question of agency based on space, mobility, and bodily control inside and outside the Matrix.

The volume closes with an essay by Eric S. Rabkin in which he describes his personal experiences and lifelong fascination with science fiction films. Rabkin's autobiographical essay is entitled "The Creature from Brooklyn: My Life and Science Fiction Film" and tells the story of a young boy from Brooklyn who discovers and falls in love with science fiction and eventually becomes an acclaimed teacher and internationally recognized critic of the field. It is his courtesy of contributing this original essay to the present volume as well as his invaluable presence at the conference, his instructional comments during the publication process, and his enthusiastic dedication to the entire project for which the editors are most grateful. 


\section{Works Cited}

Aldiss, Brian. Trillion Year Spree: The History of Science Fiction. 1973. London: Gollancz, 1986. Print.

American Studies as Media Studies: 53. Jahrestagung der Deutschen Gesellschaft für Amerikastudien. English Department / American Studies, U of Göttingen, n.d. Web. 16 Dec. 2010. <http://www.amstud.uni-goettingen.de/files/Progheft_AmStud_end.pdf>.

Bach, Gerhard, and Jürgen Donnerstag, eds. Teaching American Studies in the Twenty-First Century. Spec. issue of Amerikastudien/American Studies 52.3 (2007). 315-60. Print.

Bachmann-Medick, Doris. Cultural Turns: Neuorientierungen in den Kulturwissenschaften. Reinbek bei Hamburg: Rowohlt, 2006. Print.

Baudrillard, Jean. Simulacra and Simulation. Trans. Sheila Faria Glaser. 1994. Ann Arbor: U of Michigan P, 2007. Print.

Booker, Marvin Keith. Alternate Americas: Science Fiction Film and American Culture. Westport, CO: Praeger, 2006. Print.

Buchenau, Barbara, and Carola Hecke. "Die Literatur zur eigenen Sache machen: Offener, fächerverbindender Unterricht in der universitären Fremdsprachenlehrerausbildung." Literatur in Wissenschaft und Unterricht 41.2 (2008): 179-97. Print.

Cornea, Christine. Science Fiction Cinema: Between Fantasy and Reality. Edinburgh: Edinburgh UP, 2007. Print.

Corrigan, Timothy J. A Short Guide to Writing about Film. 6 ${ }^{\text {th }}$ ed. New York: PearsonLongman, 2007. Print.

Dick, Bernard F. Anatomy of Film. New York: St. Martin's P, 1978. Print.

Delanoy, Werner, and Laurenz Volkmann, eds. Cultural Studies in the EFL Classroom. Heidelberg: Winter, 2006. Print.

Donnerstag, Jürgen and Laurenz Volkmann. "Introduction: Media and American Studies in the EFL-Classroom." Media and American Studies in the EFL-Classroom. Ed. Jürgen Donnerstag and Laurenz Volkmann. Heidelberg: Winter, 2008. 5-14. Print.

---, eds. Media and American Studies in the EFL-Classroom. Heidelberg: Winter, 2008. Print.

Freese, Peter. "American Studies and EFL-Teaching in Germany: A Troubled Relationship." Amerikastudien/American Studies 50.1/2 (2005): 183-229. Print.

Gunn, James. Alternate Worlds: The Illustrates History of Science Fiction. Englewood Cliffs, NJ: Prentice-Hall, 1975. Print.

Hendershot, Cyndy. Paranoia, the Bomb, and 1950s Science Fiction Films. Bowling Green, OH: Bowling Green State U Popular P, 1999. Print.

Hickethier, Knut. Film- und Fernsehanalyse. $2^{\text {nd }}$ ed. Stuttgart: Metzler, 1996. Print. 
Jahn, Manfred. "A Guide to Narratological Film Analysis." Poems, Plays, and Prose: A Guide to the Theory of Literay Genres. English Department, U of Cologne, 2003. Web. 10 Mar. 2009. <http://www.uni-koeln.de/ ame02/pppf.htm\#F5>.

James, Edward. Science Fiction in the $20^{\text {th }}$ Century. Oxford: Oxford UP, 1994. Print.

Jameson, Fredric. Archaeologies of the Future: The Desire Called Utopia and Other Science Fictions. New York: Verso, 2005.

--- and Farah Mendlesohn. The Cambridge Companion to Science Fiction. Cambridge: Cambridge UP, 2003. Print.

Kelleter, Frank and Daniel Stein, eds. American Studies as Media Studies. Heidelberg: Winter, 2008. Print.

---. "American Studies as Media Studies." American Studies as Media Studies. Ed. Frank Kelleter and Daniel Stein. Heidelberg: Winter, 2008. ix-xvi. Print.

Kellner, Douglas. Media Culture: Cultural Studies, Identity and Politics between the Modern and the Postmodern. New York: Routledge, 1995. Print.

Korte, Helmut. Einführung in die Systematische Filmanalyse. 2nd. ed. Berlin: Erich Schmitt Verl., 2001. Print.

Monaco, James. How to Read a Film. New York: Oxford UP, 1977. Print.

Maxwell, Richard. "The Historiography of Fiction in the Romantic Period." The Cambridge Companion to Fiction in the Romantic Period. Eds. Richard Maxwell and Katie Trumpener. Cambridge, Cambridge UP, 2008. 7-21. Print.

Nünning, Ansgar. "Towards a Cultural and Historical Narratology: A Survey of Diachronic Approaches, Concepts, and Research Projects." Anglistentag 1999 Main Proceedings. Ed. Berhard Reitz and Sigrid Rieuwerts. Trier: WVT, 2000. 345-73. Print.

---, and Carola Surkamp. Englische Literatur unterrictten: Grundlagen und Methoden. SeelzeVelber: Klett/Kallmeyer, 2006. Print.

Parrinder, Patrick, ed. Learning from Other Worlds: Estrangement, Cognition and the Politics of Science Fiction and Utopia. Liverpool: Liverpool UP, 2000. Print.

---. Science Fiction: A Critical Guide. London/New York: Longman, 1979. Print.

Rabkin, Eric S. "American Science Fiction Film: No Final Frontiers." Of Body Snatchers and Cyberpunks: American Science Fiction Films from the 1950s to the Present. Undergraduate Student Conference. Georg-August-Universität Göttingen. 3 July 2009. Keynote speech.

---. "Science Fiction." International Encyclopedia of Communications." Eds. Eric Barnouw et al. New York: Oxford UP, 1989. 19-23. Print.

--- and Robert Scholes. Science Fiction: History, Science, Vision. New York: Oxford UP, 1977. Print.

Rentschler, Eric and Anton Kaes. Reading a Film Sequence. U of Victoria, n.d. Web. 19 Apr. 2009. <http://web.uvic.ca/geru/439/seq.html>. 
Roberts, Adam. Science Fiction. London: Routledge, 2000. Print.

---. The History of Science Fiction. Houndmills: Palgrave, 2006. Print.

Sanders, Steven M., ed. The Philosophy of Science Fiction Film. Lexington, KY: U of Kentucky P, 2008. Print.

Seed, David, ed. A Companion to Science Fiction. Malden, MA: Blackwell, 2005. Print.

---. American Science Fiction and the Cold War: Literature and Film. Edinburgh: Edinburgh UP, 1999. Print.

Seidl, Monika. "Visual Culture: Bilder lesen lernen, Medienkompetenz erwerben." Der fremdsprachliche Unterricht Englisch 87 (2007): 2-7. Print.

Sobchack, Vivian. "American Science Fiction Film: An Overview." A Companion to Science Fiction. Ed. David Seed. Malden, MA: Blackwell, 2005. 261-74. Print.

---. Screening Space: The American Science Fiction Film. New Brunswick, NJ/London: Rutgers UP, 1999. Print.

Surkamp, Carola. "A Cultural Approach to Films in the Foreign Language Classroom: Gender Roles and Questions of Identity in The Hours." Media and American Studies in the EFL-Classroom. Ed. Jürgen Donnerstag and Laurenz Volkmann. Heidelberg: Winter, 2008. 15-30. Print.

---. "Teaching Films: Von der Filmanalyse zu handlungs- und prozessorientierten Formen der filmischen Arbeit." Der fremdsprachliche Unterricht Englisch 68 (2004): 2-12. Print.

Suvin, Darko. The Metamorphosis of Science Fiction: On the Poetics and History of a Literary Genre. New Haven / London: Yale UP, 1979. Print.

---. Positions and Prepositions in Science Fiction. Basingstoke: Macmillan P, 1988. Print.

Steinmetz, Rüdiger. Grundlagen der Filmästhetik: Filme sehen lernen 1. 8th ed. Frankfurt/M.: Zweitausendeins, 2007. Print.

---. Licht, Farbe, Sound: Filme sehen lernen 2. Frankfurt/M.: Zweitausendeins: 2008. Print.

Telotte, Jay P. Science Fiction Film. New York: Cambridge UP, 2001. Print.

Voigts-Virchow, Eckart. Introduction to Media Studies. Stuttgart: Klett, 2005. Print. 



\section{Part I}

The Look and Sound of Science Fiction Film 

Jörn Piontek

\section{"There was a world once, you punk": Visual Subversion in Fleischer's Soylent Green}

\section{Introduction}

[Thorn:] There was a world once. You punk.

[Sol:] Yes. So you keep telling me.

- Soylent Green (Fleischer, 1973)

In many ways, Soylent Green is a film about humanity in the future looking back at, and longing for, a world that is long gone - the world of the film's audience in 1973. For the majority of people living in the dystopia of Soylent Green, life has been reduced to a struggle for survival due to overpopulation, pollution and diminishing resources. Over 40 million people live in New York City and barely survive on the scarce food and water rations provided by the Soylent Corporation. After one of New York's few wealthy men is murdered in his apartment, police detective Robert Thorn is assigned to the case and slowly but steadily uncovers the truth behind the Soylent Corporation: the new miracle food called Soylent Green is made from the bodies of people who died in voluntary euthanasia clinics. 
Before further discussing this film, I would like to explain why I chose Soylent Green as the topic of this article and not one of the other films (Invasion of the Body Snatchers, 2001: A Space Odyssey, Blade Runner, The Matrix, and Minority Report) discussed in the course.

Initially, the most important factor was the fact that I had not seen Soylent Green before and therefore had no preconceived notions about the film which might have distracted me while trying to analyze it from a scholarly perspective. Although this was also the case with Invasion of the Body Snatchers, I had always been interested in watching Soylent Green, mostly because of various references to it in TV shows, most of which parody the film's final revelation that "Soylent Green is people!" (Soylent Green), such as this example from Futurama:

Fry: My God. What if the secret ingredient ... is people?

Leela: No. There's already a soda like that: Soylent Cola.

Fry: Oh, how is it?

Leela: It varies from person to person.

(Morton)

Given the status of Soylent Green as a cult classic that was and is spoofed and parodied in popular culture, I was very much interested in seeing and analyzing it.

In contrast to other films in the syllabus of the course, hardly any research has been conducted on Soylent Green. Whereas a search for articles on Blade Runner in the MLA International Bibliography returns over 100 results written in English, a search for Soylent Green returns only one, an article that is "concerned with the scientific and technological regimes of efficiency within [the] broader discourse of a limited earth" (Höhler). A different article by Ronnie Lipschutz focuses on the insight that Soylent Green offers "into twenty-first-century capitalism based as it is on the same principles, to wit, commodification of the body" (Lipschutz 573).

Of the little academic writing on Soylent Green, the majority of publications deals with the film's political, ecological or social implications rather than its visuals. One notable exception is Vivian Sobchack. In her book Screening Space: The American Science Fiction Film, however, Soylent Green is only one of many films analyzed in a broader context. I can only speculate why there is so little research on Soylent Green and especially its visuals, but I think there are multiple reasons for this neglect in the past.

First of all, Soylent Green is not a particularly critically acclaimed film. Even though it has the status of a cult classic, this is mostly due to the film's 1970s production values that seem unintentionally funny to many modern viewers as well as Charlton Heston's iconic performance, especially in the film's ending scene. ${ }^{1}$ Much of the story's premise is lost due to the focus that lies on the classic detective plot. Instead of directly dealing with the problems that arise in Soylent Green,

1 See, for example, the parody of the ending sequence in an episode of Saturday Night Live on March 13, 1993 (Season 18, Episode 15). 
the plot revolves mostly around Thorn slowly discovering the secret of Soylent Green and his relationship with Shirl.

Furthermore, Soylent Green lacks the spectacular special effects of films like 2001: A Space Odyssey or the somber, intense atmosphere of Blade Runner. Instead, it meanders between luxurious apartments in the world of the rich, chases through deserted streets and some scenes that actually depict the consequences of overpopulation that were much more present in Harry Harrison's Make Room! Make Room!, the novel the film is based on. When special effects are used, they have not aged well. The scoops in the riot scenes might have looked impressive in 1973 but they do not work in the twenty-first century. In contrast to the strange visuals and distorted images of 2001: A Space Odyssey, Soylent Green literally relies on brute force. Modern viewers who have seen the spectacular visuals of films such as The Matrix or Minority Report will not be awestruck by what the special effects in Soylent Green have to offer.

Additionally, the alarmist predictions by Paul Ehrlich that were the trigger for the fear of overpopulation that spawned Make Room! Make Room! and Soylent Green never became true, at least not in the Western world. ${ }^{2}$ It is therefore easy to dismiss many of the implications present in the film. In other words, I would argue that Soylent Green seems to be neglected by academics mostly because it does little to elaborate on the interesting background of its story but rather treats it as merely the setting of an ultimately very conventional and bland detective plot. Moreover, it suffers because special effects failed to recreate the terror of riots in a vastly overpopulated city that is so compelling in the novel and even on the film poster. Together, the film's shortcomings result in a lack of timelessness compared to films that enjoy a higher degree of interest in scholarly writing, such as Star Wars.

Although the film does not have a high standing among critics, in my opinion, Soylent Green is - despite its flaws - still a film worth seeing today. One of the reasons for that is its sometimes subtle use of visual subversion, which is the topic I will analyze in the following. Instead of dehumanizing people directly, Soylent Green visually subverts the staples of life in order to make the viewers aware of how the things they take for granted may easily be lost in the future.

\section{Visual Subversion}

Before talking about Soylent Green, I will explain visual subversion as used by Vivian Sobchack and give a few examples of how this technique is used in other films. In short, visual subversion is "the alienation of the familiar" (Sobchack

2 Having published several articles and books on the subject of overpopulation and its effects, Paul Ehrlich was a central figure in the discourse that led to the publication of Make Room! Make Room! and the making of Soylent Green. His most famous work is The Population Bomb and Ehrlich, professor of Population Studies at Stanford University, also wrote the introduction to the paperback edition of Make Room! Make Room!. 
107). More precisely, an entity or abstract concept that is familiar to the viewer is visually related to something alien and strange. Consequently, the viewer is caught somewhere between familiar territory and the disconcerting unknown. In contrast to the solely new and alien, the "opposing impulses" (108) created by the connection of familiarity and strangeness create a disturbing and uncomfortable atmosphere rather than a simply frightening one.

One example of the effects of visual subversion can actually be found in Invasion of the Body Snatchers (1956), a film that was also part of the syllabus. In Body Snatchers, people created by seed pods take over a small town. The pod people look exactly like the humans they replace and in fact only their close relatives are able to notice that there is something wrong with them. Although they are sure that something is wrong, they cannot comprehend it and question their own judgment. This can be seen in a scene where a woman doubts her impression that her Uncle is not who he used to be. To quote her friend, the film's protagonist: "No one could possibly impersonate your Uncle Ira ... the trouble is inside you" (Body Snatchers). Similarly, the viewer can often only guess who has already been taken over and thus watches the character's every gesture, creating an uncanny aura of paranoia.

The pod people in Body Snatchers are not run-of-the-mill aliens but visual equivalents of humans that lack one defining feature of their counterparts: emotion. Thus, they are debumanized. The effect created is not so much the fear of the unknown but rather the fear of the familiar turning into the unknown, causing the need to question everything that is familiar.

Visual subversion is a common technique in Science Fiction film and not limited to the dehumanization found in Body Snatchers. In the opening sequence of Danny Boyle's 28 Days Later ..., the familiar concept of the contemporary city is visually subverted. In this sequence, the protagonist awakens in a hospital and soon finds out that no one else is in the building. He then stumbles to the outside and wanders through the city of London without seeing another human being. The city is completely devoid of any human life except for himself. This stands in stark contrast to what a viewer would expect of a densely populated urban area like London. Through the use of extreme long shots and a very slow pace as well as an eerie silence instead of the noise of modern cities, this sequence makes for a very uncomfortable beginning of the film. With regard to the two film examples, then, visual subversion is best described as "[ $\mathrm{t}]$ he way in which the secure and familiar are twisted into something subtly dangerous and slyly perverted" (Sobchack 124).

In the remainder of this article I will analyze how Soylent Green visually subverts the familiar and point out what it does differently in contrast to the previously mentioned examples. 


\section{Visual Subversion in Soylent Green}

In my thesis I claim that Soylent Green does not feature the same kind of visual subversion that is found in Invasion of the Body Snatchers because it does not dehumanize people but rather their living conditions. While the latter is rather obvious, it is also directly stated in the film that it is not the people that have changed:

[Thorn:] When you were young. People were better. (sic)

[Sol:] Oh. Nuts. People were always rotten. But the world was beautiful.

(Soylent Green)

As Sol states, the world used to be different, but people have not really changed as they have always had the same flaws. The same idea is also stressed on the film poster which reads, "It's the year 2022 ... People are still the same."

According to my thesis, Soylent Green instead visually subverts the staples of life, the things most critical for human survival. Among them are access to personal space, privacy, water and food. For "[a] starving person cares very little about writing majestic poetry, buying an impressive-looking car, finding a sweetheart, or avoiding injury - or anything other than the overriding goal of obtaining food" (Ewen). Whilst in the film other needs such as the need for a family are subverted, I will focus on the aforementioned ones as they are either visually more striking or more central to the film. Moreover, the notion of family, for example, is subverted in the film as it is not depicted at all, except for a short scene in which Thorn finds a baby next to the corpse of its mother.

Subversion of Space and Privacy

Even though the lack of space and consequently the lack of privacy are not depicted as strongly as they are in Make Room! Make Room! by Harry Harrison, there still is a large number of scenes that try to illustrate the effect of extreme overpopulation in an urban area. Both small cramped spaces such as hallways and open spaces such as the streets filled with people (during the riot scene, for example) are supposed to convey the idea of a completely overpopulated New York City.

Although no numbers are given in the film, it is safe to assume that an overwhelming percentage of the population is homeless. These people spend the day outside in the heat and dirt, and during the night they have to find temporary homes and cram themselves into hallways or onto stairs because the curfew forbids them to stay outside. Without a home and spending their nights together with dozens of strangers cramped into the tiniest spaces, they have no refuge to withdraw to, no place to store their belongings and no walls or doors to secure their physical well-being while they sleep.

These living conditions for the majority of the population are contrasted by the images shown to Sol when he decides to visit one of the euthanasia-facilities. 
The previously ever-present grainy brownish filter used during the outside scenes gives way to the vivid and natural colors that appear in the vast landscapes shown on the huge screen during Sol's death. This effect is enhanced by the joyous music as well as the zoom of the camera in one particular moment where the camera starts out with a long shot of a herd of sheep and then zooms out until the sheep can hardly be seen.

In the cramped and overpopulated world of Soylent Green, reminders of the past with its vast landscapes and beautiful scenery are used to entice the elderly to die. The waiting lines in the euthanasia-facility show that they are willing to do so as the real world hardly offers the bare minimum needed for survival.

\section{Subversion of Water}

Both the original audience and the contemporary viewer take easy access to clean water for granted. Every home has running tap water that you can use to wash yourself or to drink. To us, these are ordinary things. In Soylent Green, they are only available to the wealthy people and the ordinary citizens have to make do with rationed water handed out in plastic containers. Even for a policeman like Thorn, water is too rare to use for shaving or even taking a shower. Consequently, the running tap water in Mr. Simonson's apartment amazes him.

Usually, in a film a shot of a character washing his hands would be an afterthought, last a few seconds at best, and would actually not be about the character washing his hands but something else that is going on. In Soylent Green, a single shot of running tap water lasts for about 40 seconds, showing how extraordinary such a simple thing is to Thorn. It is not about Thorn thinking about the murder case or even thinking of anything, it is about his pure enjoyment of the water. By putting such emphasis on banalities, it is - in Sobchack's words - "impossible for us to look at the bathroom in the film as a familiar place" (132).

At a later point in the film, it is not the promise of intimacy with Shirl that convinces Thorn to stay in her apartment. It is only when she mentions that they can take a hot shower that he agrees to stay and this is further strengthened by the focus of the camera: Initially, the shot only shows the shower head and the water pouring down and then it tilts down very slowly to show the characters in the shower. Once more water is not just an afterthought but essential to the characters' state of mind.

\section{Subversion of Food}

The same can be said about the treatment of the concept of food in Soylent Green. As the eponymous miracle food Soylent Green suggests, food is of paramount importance to the story. In the world of Soylent Green, there are two kinds of food. There are Soylent products, described as "[t] asteless, odorless crud" (Soylent Green) by Thorn and then there is the kind of food that the viewer is familiar with: vege- 
tables, fruit, meat, bread. In Soylent Green, the latter kind of food is - just like space, privacy and water - available only to the rich people. Even Thorn's superior at the police office is only seen eating Soylent products. These products are the only food available to the common people and at best manage to keep them alive. Visually, the "miracle food" (Soylent Green) Soylent Green resembles wafers of metal or plastic and seems to be rather brown than green. Its appearance is wholly inorganic. Hardly anyone would be able to identify it as food without the context of the film and yet a riot starts when the stores run out of it on Soylent Green Tuesday, the only day of the week on which it is actually sold.

The proper food, on the other hand, is sold at black market grocery stores protected by armed men. For a small amount of groceries Shirl has to pay $\$ 279$, a price that - startling as it is to a contemporary viewer - becomes even more estranging when it is adjusted for inflation: \$279 in 1973 equal about \$1,353 in 2008 . In a city where hardly anyone has a job, a single proper meal costs more than $\$ 1,000$, assuming that the value of the dollar in the film was supposed to equal the actual value in 1973 ("Consumer Price Index"). The emotional reaction such a meal causes is thus not surprising in this context but astounding nonetheless. In one shot, Sol is at first awestruck by the sight of a piece of beef and only moments later he realizes what the world around him has become and how it has changed during his lifetime. The sight of such a common thing to the viewer as a piece of beef causes him to cry and leaves him devastated, forcing the viewer to reflect on his own reaction to such banalities and compare them to the effect they have on the characters.

In what is probably the most extreme case of visual subversion in the film, Sol and Thorn celebrate their dinner, which also marks the first time that Sol eats anything other than Soylent products. In this sequence of about two minutes, the characters do not talk at all except for the Yiddish toast L'Chayim, meaning literally to life. Combined with the celebratory music it seems like they try not to talk because it would ruin the moment. Although they do not talk, their reactions to the food and the whole ritual of cooking and eating together become obvious in their gestures and facial expressions. And to someone like Sol, who grew up religious and remembers the old world, eating such a meal becomes a spiritual experience.

Before, eating food was merely something that was necessary to survive, a means to an end, but the completely different experience of actually cooking food, putting it on a plate and paying attention to all the other little details of eating a dinner that are so much taken for granted by the viewers, are extremely special to the characters. Consequently, the camera focuses on all these small details such as using a spoon to put the meat on the plate or the stalk that is left over after Thorn eats the apple. The fact that Thorn waits for Sol to eat the apple and imitates the way Sol rubs it on his shirt also shows that Thorn does not know how to eat an apple, which both amuses and irritates the viewer. Another small detail of which there are many in this sequence is the fact that Sol has to use a plastic fork, pre- 
sumably because they possess only one proper silverware fork as they are completely useless when all you have to eat are Soylent crackers or wafers.

Just like the bathroom in the shot mentioned before, this dinner may at a first glance be similar to what a viewer would expect a regular dinner to be like in a film, but there are so many things that defamiliarize the whole event, only some of which have been mentioned here. This is not only a dinner, it is much rather a celebration of things trite to the viewer and also serves as escapism from the bleak reality of Soylent Green. Not coincidentally does the sequence end with a fade to the next shot, a transition that is unique in the film that otherwise only has clear cuts thus giving the sequence an almost dreamlike quality.

\section{Conclusion}

Despite its numerous flaws, Soylent Green also has some strong points, some of which I have discussed in this chapter. While there may be more impressive, intelligent or engaging science fiction films, Soylent Green's attention to small details in many scenes is worthy of praise, and it is a testament to good film making when such subtle things as a plastic fork or the stalk of an apple contribute more to the defamiliarization of the viewer than big, expensive special effects.

Soylent Green differs from many science fiction films in that it does not feature any alien species invading the world or huge technological breakthroughs. On the contrary, there seems to be no scientific progress at all. The very few rich people do live in quite luxurious and extravagant apartments, but they look like apartments from the 1970s and not from the year 2022. Soylent Green is science fiction in which science has not found the answer to the world's problem. By putting emphasis on the notion that people have not changed, it urges viewers to reflect on their own attitude and actions and this is successful to a large extend because of the subversion I have analyzed in this article. For these are the things that establish the connection between the familiar actual world the viewer lives in and the dystopian future of Soylent Green.

Calling it "an interesting bad film" (Johnson 62), William Johnson wrote in his review: "[t] he best scenes in Soylent Green are effective because simple: Thorn reveling in water from a faucet or in a dinner of genuine meat and vegetables - luxuries almost beyond imagining in his world" (62). Through the creation of such a similar yet alien world by means of visual subversion, Soylent Green manages to make us aware of just how much we take for granted and it makes us realize that resources which seem abundant nowadays may very well be depleted in the notso-distant future.

In the end, it is not only the film's take on a society that is pushed towards and ultimately beyond - its limits, but also the techniques of visual subversion employed that makes it a film worth seeing, even 36 years after its release. 


\section{Films Cited}

28 Days Later ... Dir. Danny Boyle. Perf. Cilian Murphy. 2002. DNA Films, 2003. DVD.

Invasion of the Body Snatchers. Dir. Don Siegel. Perf. Kevin McCarthy and Dana Wynter. 1956. Walter Wanger Productions, 1998. DVD.

Soylent Green. Dir. Richard Fleischer. Perf. Charlton Heston, Leigh Taylor-Young, and Edward G. Robinson. 1973. MGM, 2003. DVD.

\section{Works Cited}

“Consumer Price Index 1913-2009.” U.S. Department of Labor, n.d. Web. 10 Sep. 2009. <ftp:/ ftp.bls.gov/pub/special.requests/cpi/cpiai.txt>.

Ehrlich, Paul R. The Population Bomb. New York: Ballantine Books, 1968. Print.

Ewen, Robert B. An Introduction to Theories of Personality. 6th ed. Mahwah, NJ: Lawrence Erlbaum Associates, 2003. Print.

Harrison, Harry. Make Room! Make Room!. 1966. New York: Tom Doherty Associates, 2008. Print.

Höhler, Sabine. "“Carrying Capacity': The Moral Economy of the 'Coming Spaceship Earth."” Atenea 26.1 (June 2006): 59-74. Print.

Johnson, William. Rev. of Soylent Green, by Richard Fleischer. Film Quarterly 26.4 (Summer 1973): 62-63. Print.

Lipschutz, Ronnie D. "'Soylent Green ... is ... PEOPLE!': Labour, Bodies and Capital in the Global Political Economy." Milennium 34 (2005): 573-7. Print.

Morton, Lewis. "Futurama 2x04: Fry \& The Slurm Factory." tvtdb.com. The Television Transcript Database, n.d. Web. 15 Aug. 2009. <http://www.tvtdb.com/ futurama/transcripts/2x04.php>.

Sobchack, Vivian. Screening Space: The American Science Fiction Film. 2nd ed. New Brunswick, NJ: Rutgers UP, 1997. 107-36. Print. 

Dennis Edelmann

\section{"Like Alice in Wonderland": Special Effects in The Matrix}

A great deal has been written on The Matrix (and its sequels), both in popular literature, as well as in academic research, ranging from complete book volumes of several hundred pages to essays of just a few pages. The majority of texts on The Matrix lay their focus on the numerous allusions to (popular) culture like, for example, Alice in Wonderland, religion, and, above all, philosophical works like Jean Baudrillard's Simulacra and Simulation. In this context, scholars often anatomize the movie, and interpret every character's name, their utterances and even the slightest details in props in order to make them into symbols for their particular thesis. By doing so, they often neglect the film's very unique look and visual content, and no credit is given to the groundbreaking special effects that were used and their impact on the movie industry.

Since the beginning of science fiction film, special effects have played an important role because special effects are a visual technique of showing the audience something they have never seen before, or by making ordinary things appear in a strange and unfamiliar way. As special effects rely heavily on technology and technological progress, the extent to which special effects have been used in science fiction films has increased significantly over the past decades. Naturally, the quality of these special effects has constantly increased over the course of the history 
of science fiction film, just as (especially computer) technology is advancing on an almost daily basis.

The undergraduate course "Of Body Snatchers and Cyberpunks: American Science Fiction Films from the 1950s to the Present" focused on different science fiction movies from various decades. Each single film has been of significant influence on the science fiction genre, both concerning their plots and ideas, as well as the usage of special effects. In Stanley Kubrick's 2001: A Space Odyssey and Ridley Scott's Blade Runner the use of special effects was particularly revolutionary for the (science fiction) film genre. But in none of the movies which the course made a subject of discussion special effects and their twisting of reality played an equally important role as in the Wachowski brother's The Matrix.

This chapter thus focuses on exactly this aspect because the special effects in The Matrix deconstruct reality on the visual level and have significantly influenced the display of action in (science fiction) movies. "Reality" in this context is "the state of things as they actually exist" outside the movie theater ("Reality"). In support of this thesis, I will first cover the deconstruction of reality by special effects within the movie. Secondly, I will take a closer look at the so called bullet time effect and its relation to pace. The third part of this article will then focus on the influences of The Matrix on the science fiction film and the movie industry in general.

\section{The Deconstruction of Reality by Special Effects}

It can be said that as early as in the first scene of The Matrix, the viewer experiences a reality which is very much different from an everyday perception of reality. Police cars with flashing sirens arrive in front of a hotel for a raid, which in itself is not yet something special or unfamiliar. But right from the start, the atmosphere of the film is very dark, with little to no lighting, and everything is kept in a strange grayish-green tone. This sense of unfamiliarity peaks when the female protagonist Trinity has her first appearance on screen. When approached by the police officers, she jumps up and seems to freeze in her movement. Meanwhile, the camera rotates around her horizontally. After the camera has completed a 180 degree spin, Trinity's movements continue: she kicks one of the police officers and sends him flying through the room against a wall. She effortlessly battles off the rest of them and then miraculously flees over the rooftops, exercising sheer impossible jumps, to finally disappear into a telephone. Clearly, the audience is immediately thrown into the alternative world of the matrix, in which certain physical rules do not seem to apply.

But in the following sequences, in which the movie's male protagonist $\mathrm{Neo}$ is introduced, the reality we are shown seems very much familiar to our own contemporary reality outside of the movie theater, except for an unfamiliar green filter that has been laid over the camera. Also, little by little we again begin to doubt 
what we see to be real, because scenes like the interrogation of Neo by Agent Smith imply that reality here is different. As Neo, whom we have only known as Thomas Anderson so far, is being questioned by Smith and two other agents, he refuses to cooperate, resulting in his mouth nightmarishly growing shut, leaving him unable to speak (or scream). In addition, Neo is literary being "bugged" as Smith inserts an electronic device into his navel which then turns into a giant bug.

It is to a certain relief that what follows is a drastic and sudden cut to Neo waking up. Has all we have seen so far then merely been a dream? The answer seems to be yes, although the atmosphere created by little lighting, menacing sound and the confusing plot continues to uphold a certain mysteriousness. However, when Neo rides in the car with Trinity and the others, the excerption of the bug makes us realize that what has happened so far was in fact real. But how can this be real? The world portrayed looks very much like reality, yet the gradually dispersed special effects indicate that this place is of another origin. Just like Neo, the audience hopes to find an answer in Morpheus. He seems to know the answer as to what the matrix is, so maybe he can finally clarify what is happening here. Unfortunately, the sequence in which Morpheus gives Neo the choice as to either learning the truth about the matrix or waking up in his bed from a strange dream offers quite the opposite. The strange green tone remains and the menacing lighting does not change either. In addition, a mirror Neo touches simply liquefies.

What is even more confusing for the audience, however, is the following scene in which $\mathrm{Neo}$ is freed from the matrix, which turns out to be a computer animated illusion created by machines in order to control humans while exploiting them. Again, he wakes up, this time inside a tank filled with an unspecified pink liquid. As we have learned by now, he finds himself in what is supposed to be the "real world" of the movie. For no apparent reason though, his surrounding does not look at all like reality as we would expect it. The camera shows us huge towers with countless tanks just like the one Neo has just awoken in, and suddenly an insect-like robot grabs him and unplugs various cables that are attached to his body. Even for a science fiction movie, this scene is special, as this first scene of the movie set in the supposedly "real" world is a scene in which the protagonist is the only thing that is not a computer animation.

As we notice in the following scenes, also the strange green filter is gone, only to have been replaced by a strange blue touch. Morpheus and his crew fly around in an (obviously computer animated) hovercraft and the idea of the matrix as it is described by Morpheus over the following sequences does not only evoke Neo to vomit, but also shocks the audience. After all, they cannot be absolutely sure about the fact that their reality is nothing but a "computer animated dream world" just like the matrix.

That the matrix is not real could be accepted more or less, considering Morpheus' repeated demonstrations of the fact that certain aspects such as strength, speed and physical rules can easily be bent inside the matrix. But why is it, then, 
that the matrix seems a lot more familiar to our understanding of reality than the world portrayed as the "real" world? In the "real" world of the movie, there are also numerous aspects which make it very unappealing as an actual concept of reality. The atmosphere stays frightfully dark, and just as inside the matrix there is little to no lighting, a blue filter is used and most of the surroundings have obviously been created digitally. Of course, most of all the idea of human beings being no longer born, but "grown" as batteries for the machines (which is repeatedly shown in an utterly realistic array of special effects), is what renders this "real" world so unappealing.

How come, then, that all the technical instruments, weapons, the ship, clothing and other ordinary items still look somehow familiar, just the way you would find them in the real world outside the movie theater? Is this reality after all? What is reality, and what is just a dream?

Up to this point in the movie, the viewer cannot find a clear answer to these questions. Both in the matrix and in the "real" world there are things that make them seem unreal, be it people jumping from one skyscraper to another, or flying hovercrafts. Yet the matrix features everything we know from our own society and civilization. While the "real" world is portrayed as an utterly sad and dark place, it still features all the things that we would expect to find when believing what Morpheus told us about the war between men and the machines as a consequence of which the few remaining free humans have to live in the sewers of the machine world. The question therefore is whether there are facts/incidents that indicate that one of the two worlds is "more real" than the other?

The lobby scene provides us with a first answer. Here it becomes quite clear that the reality of the matrix is definitely not real. In this scene, the idea that speed and rules of gravity do not apply inside the matrix (as was suggested by Morpheus when explaining the matrix to Neo) is very obvious. Neo and Trinity effortlessly battle numerous police officers by shooting hundreds of bullets from every position one could (or could not) imagine. The whole scene is shown in slow motion and some of the camera angles that are used resemble any given ego-shooter perspective of popular computer games, resulting in what John Stratton calls "a pornography of stylish and stylized violence" (38). The scene ends with Neo and Trinity escaping via the escalator blowing up the lobby in a highly digitally animated explosion. Reality here has become more like a video game in which everything is designed to look spectacular and aesthetic.

This concept is further developed in the following scenes in which Neo frees Morpheus. The fights look and sound sensational and the excessive use of special effects goes to show that the reality of the matrix cannot be taken for granted. As Andrew Shail writes, "the matrix is the place where a body can move with total freedom in three dimensions, dress cool, possess all the equipment it needs, fight bloodlessly, communicate without limitations, and be both omnipotent and extremely graceful" (23). 
This questioning of reality in the matrix reaches its peak in the scene in which Neo stops the bullets because here it is finally clear that the portrayed reality is no longer bound to any rules whatsoever. It can easily be altered by Neo in any desirable way, while we as the audience "see the world through his eyes, eyes that create a freeze-frame effect out of 'bullet-time' speed" (Ndalianis 5).

But what about the "real world" as opposed to the matrix? It is full of special effects, but in contrast to the matrix, in which the effects de-familiarize the familiar, they serve to give all things an ordinary look. Cinematographer Bill Pope admits that "the future world is cold, dark, and riddled with lighting" and that "lighting [was left] a bit bluer and [was] made ... dark as hell," resulting in "the future reality [to look] very grimy" (qtd. in Lutzka 122). Nevertheless, (computer animated) special effects still make everything look ordinary, as the ship and clothing, for example, have a strikingly used look, making even the most science fictional apparatuses like hovercrafts floating on electromagnetic fields seem part of everyday life in this (future) world. The otherwise perfectly real-looking world of the matrix is only made unappealing to the audience by the (grayish-)green filter and by the excessive use of computer animated special effects in amazingly spectacular-looking fight scenes.

Yet the one question that remains is whether the "real world" of the movie is just another computer animated reality like the matrix and as such merely another form of control by the machines. Especially the two sequels offer a lot of support for such a thesis since Neo, for example, is eventually not only able to exercise his "superpowers" inside the matrix but also outside of it, in the supposedly "real" world. Furthermore, already The Matrix, the first movie of the trilogy "frequently undermines the idea that the Real World is anything other than an illusion as potent as the Matrix" (Wood 121) by an excessive use of special effects, special colors and lighting as I have described above. Unfortunately, neither the first Matrix movie nor the two sequels provide a clear answer to this highly interesting question. Despite the fact that special effects play a much more obvious role inside the matrix, the "real" world is also full of them. As Avlish Wood has pointed out, until the very end of the whole trilogy, "the Real World and the Matrix are no more or less real than each other" (125).

\section{Bullet Time and Its Relation to Pace}

While The Matrix in general features an excessive use of special effects, there is one single effect that stands out due to its revolutionary character. This effect is called bullet time. I do not want to elaborate on the history of this special effect but would like to point out that it originated in Japanese manga comics. This fact is important because it accounts for the basic idea behind bullet time, which is its central technique to capture movement not with one movie camera, but with many by putting together still images made by picture cameras. In doing so, this 
effect very much resembles the creation of any given cartoon as "it takes the attributes of full-cell animation, only with people, not characters" (Gaeta, "What is Bullet Time?”).

The creation of a scene in bullet time is a complex procedure. The first step is to make a fully digital computer animation of the whole scene that is to be shown. Just like a regular storyboard, this animation helps to visualize the character's actions and the movement of the camera and camera angles. In a second step, 120 picture cameras and two motion picture cameras are set up in a circle (or any other desired form) with a green-screen surrounding them. The two motion picture cameras, placed on opposing sides, mark the start and the end of the movement. Each picture camera captures a single frame, which is mixed with supporting digital frames in the next step. Together, all the single frames form the whole movement, and make it look as if there was just one single motion picture camera circling around the action. ${ }^{1}$

The actors who perform their movements within the green-screen surrounding held by wires are thus captured frame by frame, and everything is then put together on the computer. As every frame exists separately, there is significant freedom as to how the particular scene or movement is presented virtually. Just as in cartoons, you can freeze the action by simply staying on one frame, go back and forth in time between frames, and of course slow down time. The latter is the technique mostly used in The Matrix, since, as special effects supervisor John Gaeta has stated "the aim of bullet time was slowing down time to such an extent that you really see everything around you as clearly as you possibly could" ("What is Bullet Time?"). The result of this effect, then, is a never-before-seen focus on the aesthetics of movements and fight scenes. Usually, the bullet times in The Matrix appear within otherwise fast-cut, fast-(camera) moving scenes or sequences and disrupt the narrative flow quite openly. By using this effect, the directors lay the focus not on the narrative aspect of the particular scene but on the aesthetics of the movements themselves. The results are spectacular looking fight scenes in which every bullet fired or punch dealt seems to be part of a well-planned choreography, which at times very much resembles classical ballet. Just as in ballet, the characters in The Matrix are able to move in ways beyond the regular moviegoer's physical abilities. Taking place in near silence because the pounding music present in most of the fight scenes is interrupted in the bullet time sequences, this audiovisual spectacular of bullet time leaves the audience marveling at the sheer beauty of otherwise dull and brutal action scenes.

There is an ongoing discussion about the question whether or not the makers of The Matrix simply copied already existing ideas and techniques for creating their bullet time effect. Some critics (who unfortunately pose their criticism anony-

1 Apparently, the original plan was to strap a rocket onto a motion picture camera and so be able to capture the whole movement as well, but for obvious reasons this approach has been neglected (Gaeta, "VFX Supervisor"). 
mously in online chat rooms) say that the effect existed long before The Matrix and that the Wachowski brothers merely named it differently (although again a similar effect had already been used in the computer game Max Payne, in which it had already been called bullet time). Whichever way one puts it, though, the bullet time effect in The Matrix was revolutionary to cinematography since it offered a variety of new possibilities to display certain scenes. And actually even Gaeta himself does not claim that it was an invention. Rather, he insists on the fact that for The Matrix already existing ideas and techniques were optimized in order to create a "method for capturing ultra slow motion" ("VFX Supervisor"). In this context, he further explains that "bullet time is a concept created by Larry and Andy W. which basically means 'Mind Over Matrix' and is not the name of a technique which uses still cameras to make virtual camera paths" ("VFX Supervisor"). Regardless of its name, even Gaeta himself claimed that as a filmic technique the effect would "be as revolutionary as cameras coming from cranes to steady cams ...," because "cameras are [now] broken from the subject matter, virtual" ("What is Bullet Time?"). Most significantly, Gaeta adds that "computers brought the next step to cinematography" ("What is Bullet Time?"). This is a fact that is definitely verifiable and thus will be the focus of the next part of my paper.

\section{Influences of The Matrix on Science Fiction Films and the Movie Industry}

As I have initially stated, science fiction films often rely on special effects. Technological advancements hence allow for a constant evolving of the quality and complexity of these special effects. It is always people like John Gaeta and his associates who push the limits of movies' visuals and cinematography.

Of course, any new technology or filmic technique relies heavily on preceding movies, since it is always the case that certain procedures are adapted or optimized. Thus, one could argue that if The Matrix had not been made, there would have been some other movie pushing digital effects and film-making to the next level. But the fact that The Matrix beat Star Wars Episode 1: The Phantom Menace, which was released in the same year, in the race for the Oscar for best visual effects, strongly suggests that the effects used in The Matrix were indeed special and groundbreaking.

The Matrix is situated within a long tradition and constant evolution of digitally animated surroundings, characters and movements. However, it was the first movie to work with camera angles that are not dependent on a fixed point but allow for an independent, digitally constructed movement of the camera giving the audience a much more intense experience of being inside the action as well as making supposedly unrealistic movements look authentic. In doing so, The Matrix gave way to a flood of film adaptations of superhero comics such as Spider Man 
(2002/2004/2007), Hellboy (2004) or Van Helsing (2004). As an example, think of the way Spider-Man is flying through the skyscraper canyons of New York City and how realistic his movements and the camera angle following him look. Upon watching the scene, one could be inclined to believe that a "Spider-Man" could actually exist and exercise such movements.

In addition, The Matrix has pushed the science fiction film into a whole new direction with - as Marvin Keith Booker describes it - "its combination of a thoughtful science fiction premise with high action sequences" (252). Since action is not a requirement for a science fiction film, it becomes quite clear that such an excessive use of brutal and yet aesthetic-looking action scenes as is the case in The Matrix is special and that it takes the subgenre of "action science fiction" to a new level. An example for this is the movie The Island (2005), in which there is a freeway-action scene that resembles The Matrix's action scenes to almost a hundred percent.

But this significantly aesthetic portrayal of action also affected other (action) movies. The single special effect which has been used and parodied the most is of course bullet time. Movies such as Scary Movie (2000) and Shrek (2001), as well as cartoon series like The Simpsons or Family Guy have made fun of bullet time. Also, the idea of bullet time showing high action in an exceedingly aesthetic manner has become quite ordinary in action movies today. Some of the movies which actually use a classic bullet time sequence include Blade 1+2 (1998/2002), Charlie's Angels (2000/2003), Password Swordfish (2001) and Bad Boys 2 (2003).

In addition, the bullet time effect "crossed formal boundaries into TV ads, music videos and computer games" (Rehak 28). Examples include BMW commercials, and the Resident Evil computer game series. In this context again, however, Bob Rehak claims that "once detached from the narrative, characters, and mise en scene of the original Matrix, bullet time no longer seemed astonishing but hackneyed" (46). This adaptation of the bullet time effect by science fiction and action films presented the makers of he Matrix Trilogy with difficulties, because bullet time now had to become even more spectacular in order to achieve the same kind of reaction in the moviegoers.

The Matrix Reloaded and The Matrix Revolutions both were released in 2003 and again took the idea of an aesthetic display of action to a new dimension. The bullet time effect had been optimized by making it even more digital, allowing for the realization of even more unfamiliar camera movements as well as character's actions, peaking in a full-out digital "super battle" between Neo and Smith at the end of the trilogy. Naturally, this evolution of special effects again marked the next step in cinematography, with fight scenes now becoming more and more fully digitally animated. But the two sequels nevertheless failed to provoke the same kind of cultural impact. Both fans and scholars saw the increased digitalization of the bullet time effect and other action scenes as rather negative, since "the sequels' visual effects, whose abstraction, excess, and artificial cleanliness left au- 
diences confused and unsatisfied" (Rehak 46). What had worked so brilliantly with bullet time in the first Matrix movie now just seemed to be too much, because "by taking effects to the next level, The Matrix makers were outdone by their own success" (Rehak 46).

\section{Conclusion}

The Matrix makes use of special effects in a way that no (science fiction) movie had done before. On the visual (and narrative) level, the gradually dispersed computer-generated effects together with certain film techniques (color filter, cutting and lighting) lead the viewer to doubt the reality presented in the movie. Once the idea of the matrix is established, reality in it becomes surreal, with effects like bullet time constantly disrupting the natural relation of time and action, while at the same time special effects serve to familiarize the unfamiliar in the "real world" of the movie. According to Dan North, the result is that "spectators are not asked to marvel at an independent simulacrum, but at the discrepancy between the real and its mimic" (49). Inside the matrix, however, it is mostly the bullet time effect that is responsible for a revolutionary glorification of action scenes. For the first time in a (science fiction) movie, action is portrayed as highly aesthetic and almost ballet-like in nature. This concept has been parodied increasingly and ultimately could not even be topped appropriately by the makers in the two Matrix sequels. Nevertheless, what remained is the idea of portraying even the most brutal action scenes as aesthetic as possible, an approach which not only tipped the science fiction film into a whole new direction, but as of today has become a standard in (action) films in general.

\section{Films Cited}

Bad Boys 2. Dir. Michael Bay. Perf. Martin Lawrence, Will Smith and Jordi Mollà. Sony Pictures Home Entertainment, 2004. DVD.

Blade 1. Dir. Stephen Norrington. Perf. Wesley Snipes, Stephen Dorff and Kris Kristofferson. Universum Film GmbH, 1999. DVD.

Blade 2. Dir. Guillermo Del Toro. Perf. Wesley Snipes, Kris Kristofferson and Ron Perlman. Warner Home Video, 2002. DVD.

Charlie's Angels. Dir. Joseph McGinty Nichol. Perf. Cameron Diaz, Drew Barrymore and Lucy Liu. Sony Pictures Home Entertainment, 2002. DVD.

Charlie's Angels: Full Throttle. Dir. Edward Shearmur. Perf. Cameron Diaz, Drew Barrymore and Lucy Liu. Sony Pictures Home Entertainment, 2003. DVD.

Password: Swordfish. Dir. Christopher Young and Paul Oakenfold. Perf. John Travolta, Hugh Jackman, Halle Berry. Warner Home Video, 2003. DVD. 
Scary Movie. Dir. Keenen Ivory Wayans. Perf. Jon Abrahams, Shannon Elizabeth and Cheri Oteri. Highlight, 2002. DVD.

Shrek. Dir. Andrew Adamson and Vicky Jenson. Paramount Home Entertainment, 2006. DVD.

Spider-Man. Dir. Sam Raimi. Perf. Tobey Maguire, Kirsten Dunst and Willem Dafoe. Sony Pictures Home Enterteainment, 2004. DVD.

The Island. Dir. Michael Bay. Perf. Ewan McGregor, Scarlett Johansson and Djimon Hounsou. Warner Home Video, 2006. DVD.

The Matrix. Dir. Andy Wachowski and Larry Wachowski. Perf. Keanu Reeves, Laurence Fishburne, and Carrie-Anne Moss. Warner Home Video, 1999. DVD.

The Matrix Reloaded. Dir. Andy Wachowski and Larry Wachowski. Perf. Keanu Reeves, Laurence Fishburne and Carrie-Anne Moss. Warner Home Video, 2006. DVD.

The Matrix Revolutions. Dir. Andy Wachowski and Larry Wachowski. Perf. Keanu Reeves, Laurence Fishburne and Carrie-Anne Moss. Warner Home Video, 2006. DVD.

\section{Works Cited}

Booker, Marvin Keith. "The Matrix." Alternate Americas: Science Fiction Film and American Culture. Westport, CO: Praeger, 2006. 247-63. Print.

Gaeta, John. "The Matrix VFX Supervisor speaks about the impact of Bullet Time."” MovieWeb.com. 12 Nov. 2002. Web. 01 Aug. 2009. <http://www.movieweb.com/ news/NE76md8eb0jw99>. Web.

---. "What is bullet time?" The Matrix. Dir. Andy Wachowski and Larry Wachowski. Perf. Keanu Reeves, Laurence Fishburne, and Carrie-Anne Moss. DVD. Warner Home Video, 1999. Print.

Lutzka, Sven. "Simulacra, Simulation and The Matrix." The Matrix in Theory. Eds. Myriam Diocratetz and Stefan Herbrechter. Amsterdam/New York: Rodopi, 2006. 113-29. Print.

Ndalianis, Angela. "The Frenzy of the Visible: Spectacle and Motion in the Era of the Digital." Senses of Cinema 3 (Feb. 2000): n. pag. Web. 25 Jan. 2010. <http://arch ive.sensesofcinema.com contents/00/3/matrix.html>.

North, Dan. "Virtual Actors, Spectacle and Special Effects: Kung Fu Meets 'All That CGI Bullshit." The Matrix Trilogy: Cyberpunk Reloaded. Ed. Stacy Gillis. London: Wallflower, 2005. 48-61. Print.

"Reality." Compact Oxford English Dictionary of Current English. Oxford: Oxford UP, 2005. Print.

Rehak, Bob. "The Migration of Forms: Bullet Time as Microgenre". Film Criticism 32.1 (Fall 2007): 26-48. Print. 
Shail, Andrew. "'You hear about them all the time': A Genealogy of the Sentient Program." The Matrix Trilogy: Cyberpunk Reloaded. Ed. Stacy Gillis. London: Wallflower, 2005. 23-35. Print.

Stratton, John. "So Tonight I'm Gonna Party Like It's 1999: Looking Forward to The Matrix." The Matrix in Theory. Eds. Myriam Diocratetz and Stefan Herbrechter. Amsterdam/New York: Rodopi, 2006. 27-51. Print.

Wood, Aylish. "The Collapse of Reality and Illusion in The Matrix." Action and Adventure Cinema. Ed. Yvonne Tasker. London: Routledge, 2004. 119-29. Print. 

Fabian Grumbrecht

\section{"What are you doing, Dave?": The Confrontation of Dave Bowman and HAL 9000 in Stanley Kubrick's 2001: A Space Odyssey}

\section{Introduction}

The genre of Science Fiction film has been frequently marked by heated battles between human beings and various menacing forces. These forces are mainly embodied by alien races (Invasion of the Body Snatchers [1956], Alien [1979]), mutated life forms (Tarantula [1955]), dystopian regimes (Brazil [1985], Nineteen Eighty-Four [1984]), or rebellious artificial intelligences. Within the last-mentioned category, one example of a computer turning against human beings can be found in Stanley Kubrick's 2001: A Space Odyssey (1968), namely: HAL 9000. In addition to the computer's menacing act of murdering four astronauts, scholars and critics like Michael Mateas have focused on HAL's apparent "emotional and psychological depth" (106). The computer appears in the film's second part "JUPITER MISSION, 18 MONTHS LATER." Barton Palmer has pointed out that this part "is handled in more or less traditional Hollywood fashion" (19). Moreover, Mateas adds that HAL primarily serves "a function within the plot" (123) until he is deactivated by the astronaut Dave Bowman. HAL's unexpected and enigmatic malfunction turns the computer into the antagonist of the film when it attempts to 
kill the crew of the spaceship Discovery. Consequently, Dave Bowman, as the only surviving crewmember, is generally identified as HAL's counterpart. This constellation culminates in a confrontation, in which the astronaut wants to turn the computer off.

In this chapter I would like to analyze the confrontation of Dave Bowman and HAL, because it may not necessarily be classified as a "big battle" (Mamber 64). Instead, the showdown between HAL and the astronaut is not marked by physical violence. It is rather portrayed in a unique way as an almost trivial act of shutting down a technical apparatus, an act that is completely devoid of violent struggles. Nevertheless, the confrontation is subtly enhanced on the visual and aural levels. Consequently, this article will focus on HAL's status as an antagonist to Dave Bowman, followed by the analysis of the visual and aural presentation of the confrontation and interaction of the two characters on the level of plot.

\section{HAL's Status as an Antagonist}

HAL's antagonistic status can be inferred from Dave Bowman's position as a protagonist, which is established in the course of the plot and emphasized during the confrontation. At first, Dave Bowman is introduced as the equal of his fellow astronaut Frank Poole (Booker 86), but when Dave becomes the only surviving member of the crew on board of the Discovery, the focus on him as the protagonist increases in a significant way. Furthermore, Dave is the only character who arrives at Jupiter - the place the human characters want to reach -, and in the end becomes the Star Child. These aspects do not only single him out from his fellow astronauts but also from the scientist squad of Dr. Heywood Floyd, because their progress is either thwarted (in the case of the other astronauts) or presented en passant (in the case of Dr. Floyd, who discovers the monolith located on the moon but is not part of the monumental expedition to Jupiter).

While the plot of the whole film seems to underline Dave Bowman's position as a protagonist, the "revolt" (Booker 87) of HAL resembles an obstacle to the astronaut's progress: According to Philip Kuberski, the effect of "HAL's cold violence" (69) on Dave "prepares him for the psychic journey" (69) after the computer's demise. Therefore, HAL is indirectly marked as an antagonist and, according to Mateas, "functions as a character within the narrative machinery" (116) by counteracting Dave.

\section{The Visual Level}

The actual showdown between the astronaut and the computer sets in after Dave has managed to leave his space pod and returns to the Discovery. Meanwhile HAL has succeeded in killing the other astronauts, but its strategy of murdering Dave 
has failed. While the computer has ambushed and directly attacked the rest of the crew (the scientists in their sleep and Poole by a separation of his air hose in outer space), Dave has enough time to intrude into the spaceship after HAL has denied him access. The fact that Dave survives underlines his pivotal status in the plot and leads to the actual confrontation between him and the antagonistic computer.

While the astronaut is on his way to HAL's core the low angle of the camera dominates the scene. Mostly over-the-shoulder shots and medium shots are given by what Kevin L. Stoehr describes as "a subjective use of handheld camera ... that reveals Bowman's unique personal perspective and emotional context" (124). Then Dave climbs up the ladder, and when he walks through the crammed spaces, he seems to tower over the audience. Hence, the camera does not only mediate Dave's point of view but also assumes an external perspective. This perspective is influenced by the narrow architecture of the Discovery and makes the protagonist appear in an almost imposing way until he arrives at the small door which leads to the computer's brain room.

The first shot inside of the computer's core is taken from the actual point of view of the virtually omnipresent and "bodiless HAL" (Mateas 111). Situated in what Stephen Mamber describes as the "geometrical space ... of the memory core" (64), the technical devices and modules reveal the computer's 'physical' location. By entering this room, the protagonist is able to participate in a genuine 'confrontation' with an artificial intelligence that seems to be impalpable.

In contrast to the previous sequences of this section, the iconic shot of "HAL's red-lit eyeball" (Stoehr 127) is not depicted as extensively as before. Earlier in the film, HAL's red eye functioned as the main visualization of the artificial intelligence as a character. It was furthermore accompanied by the use of a fisheye lens that emphasized the look through HAL's eye. The computer's "subjective view" (Mateas 108) is completely abandoned during the showdown. By neglecting the tendency to "use his vision in pursuit of goals" (Mateas 108), HAL seems to focus on the use of its voice instead. ${ }^{1}$ Full shots of Dave's body in the core alternate with shots of his body reflection in the artificial eye and serve thus to portray the two as opponents.

According to J. P. Telotte, the protagonist "moves at odd angles and even floats ... as he deactivates HAL" (49). This is especially evident when Dave Bowman approaches the computer's modules: Suddenly, the camera's position changes twice, thus evoking the illusion that Dave does no longer float in a horizontal position while facing the room's ceiling. After a sudden cut, the camera's position has turned upside down and after a second cut, a medium shot portrays Dave sideways. He seems to stand vertically in front of the modules now. This change in position seems to establish a more matter-of-fact portrayal of the astronaut's following actions, which rather resemble a customary behavior instead of a

HAL's voice is analyzed in section four of this article. 
confrontation with an antagonist in a state of weightlessness. An over-theshoulder shot reveals the various modules Dave works on in order to shut HAL down. During this process, a close-up of Dave's head gives way to his neutral facial expressions while the technical devices are mirrored in the visor of his helmet, resembling the apex of the way the two characters "are superimposed several times" (Mamber 64).

On the whole, the depictions of Dave seem to prevail on the visual level. But how could the widespread interpretation of HAL's "establishing empathy with the audience" (Mateas 116) have been accepted and emphasized, when the computer's visual point of view (as an obvious device for creating identification with a character in a film) is neglected in this sequence? The reasons for this interpretation may be found on the aural level.

\section{The Level of Sound}

There is no underlying soundtrack; instead the constant noise of the air supply and breathing (introduced during Poole's examination of "the ship's AE-35 unit" [Booker 78]) dominate this section of the film. These sounds replace dramatizing music which is mostly used in films of various genres in order to underline the final confrontation of protagonist and antagonist. The "vivid contrast between sound and silence" (Landy 96) used during the death of Poole and the other astronauts is no longer employed. In addition to his own breathing, Dave and the audience also perceive HAL's "range of natural language competencies" (Mateas 107), performed by Douglas Rain.

Once the computer's iconic visual representation (i.e. the red eye) is no longer predominating, HAL is mainly embodied by its voice. HAL tries to apologize for its actions and to reason with Dave, for example by saying, "I know I've made some very poor decisions recently." Two interpretations regarding the effect of the computer's utterances may be contrasted: The idea that the computer's demise evokes "sadness and pity" (Mateas 116) in the audience as part of an "ambiguous double reading" (Mateas 110), and the view that "HAL's actions mime human limitations in thinking and decision making" (Landy 96). It can be argued that the aural level contradicts the visual level when Dave enters the brain room. HAL's voice and remarks are used to conceal what the sight of the modules and technical devices in its core affirms. HAL may be able to use "general language and reasoning capabilities" (Mateas 107) and he seems to voice "inner conflicts" (107), yet the pleading, "disembodied voice" (Landy 96) contrasts with the artificial structure of the computer's electronic nerve centre. As a result, it becomes obvious that HAL is a highly developed computer instead of a living creature. In his role as antagonist, HAL uses its voice as a tool of deception and manipulation, but this strategy is exposed when Dave confronts the actual origin of the voice (i.e. the artificial structure of the modules). 
Because of the combination of sounds (especially the stream of oxygen, the breathing, and HAL's voice), Dave's point of view dominates on the aural level. All the sounds he perceives in his suit are transmitted and the absence of a soundtrack or sound effects contributes to a sober and plain presentation, which is devoid of commentative sounds that are usually employed in films in order to increase tension. Dramatizing aural effects are not used in an excessive manner; even Dave's way of breathing seems to be controlled: He does not hyperventilate; instead his breathing is determined by his physical actions (e.g. climbing up the ladder, walking through the corridors, floating through the brain room).

\section{The Interaction of HAL and Dave}

The final and confrontational encounter of protagonist and antagonist is marked by a number of peculiarities. HAL tries to counteract and stop Dave Bowman by corresponding to his emotions instead of using brute violence, although the computer killed Frank Poole and the three sleeping crewmen. According to Telotte, it seems as if HAL virtually "controls all functions, including life support on board Discovery" (48). Yet after Dave has managed to enter the ship again, the computer resumes a non-violent strategy.

Therefore, HAL's control over the ship does not turn into a life-threatening danger for Dave. Although the human characters are "dependent for their life functions on" (Landy 97) the computer, they have to assume a special state before they fall victim to his "goal-driven behavior" (Mateas 108): The three hibernating scientists are killed while they are defenceless and Poole has to exit the Discovery in his space suit before HAL attacks him by seizing control over his space pod. Moreover, the computer's attempt at eliminating Dave also involves excluding him from the spaceship once HAL sees that Bowman has forgotten his helmet. Yet the protagonist's return to the spaceship does not trigger a similar attempt targeted at HAL. Although HAL's "function is to manage the ship" as Mateas puts it (107), he either has to make use of his victims' defenceless and inactive state (in the case of the sleeping astronauts), or he has to lure them into space (in the case of Frank Poole and Dave Bowman) instead of violently confronting them on board of the Discovery. Having overcome the computer's insidiousness, Dave's special status as the protagonist of the film is implicitly underlined while HAL changes its strategy.

Dave does not react to HAL's voice (until he answers the antagonist's offer to sing a song). Instead, the protagonist proceeds to shut down the computer in a matter-of-fact way, acting extremely unfazed and seemingly without showing any emotions. While this behavior of Dave Bowman (and also Frank Poole) let HAL appear "more human and empathetic" (Stoehr 125) in the previous sequences, now it makes the portrayal of the confrontation appear almost trivial. It may be doubted that Palmer's definition of the confrontation as a "struggle, which is 
more physical than psychological and climaxes in ... violence" (19) is appropriate. Landy points out that no "vivid and excessive images of mutilation" (97) are employed: HAL is not destroyed in the course of a heated battle, but turned off very soberly. Likewise, the astronaut has to protect himself mentally from succumbing to HAL's simulated reasoning and emotions (e.g. "I'm afraid, Dave") and is not confronted with some kind of a violent assault unleashed by the computer. What some critics and scholars who tend to humanize the antagonist describe as an act of "lobotomizing HAL's computer brain" (Landy 96) is actually the deactivation of "HAL's higher mental functions" (Mateas 116), while HAL's lack of another opportunity to kill Bowman makes him use his voice as a device of selfprotection.

Although Landy argues that "Dave's action suggests that his motives are tinged with vengefulness" (97), he neither smashes the artificial eye or modules, nor does he tear them out in a fit of rage. Some pragmatic reasons may be given for this behaviour. Managing to ignore the computer's voice, the protagonist is not able to deactivate HAL in frenzy or to completely destroy the computer without risking his own life (or the success of the mission). In this respect, "the film's tampering with conventional cinematic language" (97) as pointed out by Landy is determined by the circumstances given in the fictional world, because the computer's "primary function is to manage the ship and participate in the mission" (Mateas 107). Consequently, Dave's very calm reaction to HAL's live-threatening behavior does not only remain peculiar on the visual and aural level, but is also motivated on the level of plot. Although all physical actions in the final confrontation are enacted by the protagonist, HAL is actually not "heroically confronted and destroyed" (Kuberski 70) in a battle but simply shut down. What Landy describes as Dave's apparent "precipitousness" (97) only seems to make the interaction of the two characters appear one-sided because of the computer's apologetic and reasoning verbal strategy, which, however, only enhances the peculiarity on the level of sound.

Only when Dave Bowman begins to shut down HAL's memory circuit, one can assume that the protagonist has won the battle against the computer. Booker interprets the way HAL's voice slows down while singing "Daisy" as "a reversion to "childhood" (86). What Booker calls an "almost trance-like" (86) behavior as a human character on board of the Discovery has allowed Dave to overcome his opponent. Finally, the astronaut answers HAL when the computer's demise is inevitable and his utterances may not be targeted at deceiving Dave anymore. It is striking that HAL's use of its voice in order to prevent the "dismantling" (Palmer 22) does not succeed on the level of plot but influences the audience's empathy. Strictly speaking, the spectators are likely to be deluded by HAL, while Bowman manages to remain unaffected. This is achieved by contrived aspects such as the computer's age (Booker 86-87), or the way HAL sings "Daisy" while slowing down, but without making use of melodramatic elements. Only at this point 
(when the antagonist's decline has already set in), the spectators' possible "sadness and pity" (Mateas 116) may be partly justifiable. Yet, Hal's status as the film's antagonist, as well as what Landy calls "malevolent instigator of violence" (96), should not be completely overshadowed by this fairly one-sided and emotional reading.

\section{Conclusion}

In the course of 2001: A Space Odyssey, there is no heated battle between the protagonist and the villain. HAL is not destroyed, but turned off in a rather sober and trivial way. The unemotional portrayal of the showdown is achieved by the interaction of the visual and aural levels which both correspond and contrast. The visualization of the sequence is dominated by the camera focus on Dave Bowman's actions (e.g. by the use of over-the-shoulder shots and changing camera positions in between the shots) instead of assuming the computer's point of view. On the level of sound, the astronaut's perspective is underlined by the transmission of all aspects influencing his aural perception in the space suit. Furthermore, HAL attempts to exert psychological influence on the protagonist. The computer is unable to murder the astronaut because Dave is not in a state of hibernation and because he has re-entered the spaceship Discovery. Faced with the fact that Dave is on his way to HAL's core, the computer tries to prevent its disconnection by uttering apologies and remorse. Likewise, the conditions on board of the spaceship require that Dave faces the antagonist in a non-violent and calm way.

On the surface, a simple and obvious contrast between the almost "robotic" (Booker 86) actions of the astronaut and a computer who "seems more human and empathetic" (Stoehr 125) is established. However, the portrayal of HAL's core reveals that the computer' emotions, which fail to deceive Dave Bowman, are actually simulated. As a result, a certain ambiguity and a hint at banality are established by the cinematography of the showdown: The fact that the computer is turned off in a calm and matter-of-fact manner evokes trivial overtones. Dave's portrayal within the core thus makes him resemble a computer operator rather than an astronaut fighting for his life against a murderous artificial intelligence.

The two characters are confronted in the only section of the film that makes use of a conventional Hollywood-type plot (Palmer 19). However, the realization of the actual showdown does not come across as bombastic or dramatic. Consequently, the contrast between the plot and the way the showdown is displayed is highlighted even more, because the trivial and non-violent approach is usually not part of traditional Hollywood movies which mainly rely on physical clashes and vivid destruction.

The non-violent confrontation can be seen as an innovation and it has remained exceptional in the genre of Science Fiction film to this date. Hence, the tactics and demises of other vile artificial intelligences in motion pictures of the 
Fabian Grumbrecht

following decades: Proteus IV in Demon Seed (1977) turns a house into a dangerous environment in order to trap and impregnate his inventor's wife. Similar to HAL, this villainous computer is also embodied by a strikingly memorable voice (provided by Robert Vaughn). At the same time, though, it contrasts with the antagonist of 2001: A Space Odyssey by making brutal use of lasers and arm-like devices. Moreover, the Ultimate Computer in Superman III (1983) does not voice its concerns, but turns a human being into an android and emits rays in order to prevent the other characters from turning it off. As another very famous example of an antagonistic computer system, Skynet in The Terminator (1984) makes use of androids and robots in order to attack mankind and, as the main kernel of the film's plot, sends them back in time in order to indemnify its own existence and to endanger the human characters. All of those antagonistic computers make use of violence and also the protagonists in the respective films tend to defend themselves by sheer force. While HAL's defeat has sometimes been parodied and mocked in episodes of American TV-series like Parker Lewis Can't Lose (1991) or The Simpsons (2001), the final interaction between HAL and Dave has not become a paragon for showdowns between humans and computers moving beyond conventional (and primarily physical) clashes. As a result, the filmic realization of the showdown is exemplary for the whole film in having "no peers or direct successors" (Booker 88).

\section{Films Cited}

2001: A Space Odyssey. Dir. Stanley Kubrick. Perf. Keir Dullea, Gary Lockwood, William Sylvester. MGM, 1968. DVD.

Demon Seed. Dir. Donald Cammell. Perf. Julie Christie, Fritz Weaver, Gerrit Graham. MGM, 1977. DVD.

Superman III. Dir. Richard Lester. Perf. Christopher Reeve, Richard Pryor, Jackie Cooper. Warner Bros. Pictures, 1983. DVD.

The Terminator. Dir. James Cameron. Perf. Arnold Schwarzenegger, Michael Biehn, Linda Hamilton. Orion Pictures, 1984. DVD.

\section{Works Cited}

Booker, Marvin Keith. "2001: A Space Odyssey." Alternate Americas: Science Fiction Film and American Culture. Westport, CO: Praeger, 2006. 75-89. Print.

Kuberski, Philip. “Kubrick's Odyssey: Myth, Technology, Gnosis.” Arizona Quarterly: A Journal of American Literature, Culture, and Theory 64.3 (2008 Autumn): 51-73. Print. 
Landy, Marcia. "The Cinematographic Brain in 2001: A Space Odyssey.” Stanley Kubrick's 2001: A Space Odyssey: New Essays. Ed. Robert Kolker. New York: Oxford UP, 2006. 87-104. Print.

Mamber, Stephen. “Kubrick in Space.” Stanley Kubrick's 2001: A Space Odyssey: New Essays. Ed. Robert Kolker. New York: Oxford UP, 2006. 55-68. Print.

Mateas, Michael. "Reading HAL." Stanley Kubrick's 2001: A Space Odyssey: New Essays. Ed. Robert Kolker. New York: Oxford UP, 2006. 105-25. Print.

Palmer, Barton. “2001: The Critical Reception and the Generation Gap.” Stanley Kubrick's 2001: A Space Odyssey: New Essays. Ed. Robert Kolker. New York: Oxford UP, 2006. 13-27. Print.

Stoehr, Kevin L. "2001: A Philosophical Odyssey." The Philosophy of Science Fiction Film. Ed. Stephen M. Sanders. Lexington, KY: U of Kentucky P, 2008. 119-33. Print.

Telotte, J. P. “The Gravity of 2001: A Space Odyssey." Stanley Kubrick's 2001: A Space Odyssey: New Essays. Ed. Robert Kolker. New York: Oxford UP, 2006. 43-53. Print. 



\section{Part II}

Social and Political Commentaries 

Niklas Franzen

\section{"Jupiter and Beyond the Infinite" as Social Reflection? The Success of the Sequence Among Young Adults of the Counterculture}

\section{Introduction}

Stanley Kubrick's motion picture 2001: A Space Odyssey is one of the most successful and legendary films in cinematic history. Its release in 1968 earned the thirdbest box office gross and a total of $\$ 138$ with its initial and subsequent releases. It has been acknowledged as one of the greatest movies ever made, and in 2002 the British film magazine Sight \& Sound ranked it among the top ten films of all times.

2001 has marked "a turning point in the science fiction film genre" (Cornea 87) and by Hollywood standards it certainly was a radical innovation. The film attracted a remarkable amount of critical attention, "but critical opinion was markedly divided when it was first shown in America" (83). The controversy about the film becomes especially apparent in the final sequence, "Jupiter and Beyond the Infinite." Therefore I will narrow down my analysis to this particular sequence.

"Jupiter and Beyond the Infinite," also known as the Stargate sequence, begins with impressive shots of a black monolith in orbit around Jupiter. When astronaut Dave Bowman leaves the spacecraft in a pod to approach the monolith, he finds 
himself suddenly racing through a tunnel of colorful light sequences. During the journey, strange astronomical entities are shown and the voyage concludes with views on the surface of an oddly colored planet. Eventually Bowman is shown in a room decorated in old Renaissance style, where he discovers older versions of himself, with the visual angle each time switching to the older Bowman. Ultimately an ancient and deceasing Bowman is shown lying in a canopy bed, with a black monolith on its foot, and the old Bowman is transformed into a fetus-like creature, the Star Child. The last scene shows the Star Child floating in space, looking down on earth.

According to Christine Cornea, the release of 2001 in 1968 "responded to the zeitgeist of the era and assured its eventual success at the box office" (83). Barton R. Palmer has pointed out that especially young people flocked the country's theaters, "turning the film's exhibition into one of the signal cultural events of the decade" (13).

In this paper, I will pursue the questions of why "Jupiter and Beyond the Infinite" in particular has been so popular among young viewers and of how the sequence became a means of opposition and subversion of the 1960s counterculture. I will therefore begin my analysis with an account of the historical background of the 1960s. After that, I will closely examine the sequence, considering psychedelic, drug-related interpretations and the use of subversive cinematic devices. By discussing the social perception of the film, I will then seek to answer my initial question and conclude my paper with a summary of my findings.

\section{From Frustration to Counterculture: The USA in the 1960s}

The decade began with optimism carried over from the economic boom of the 1950s, and was enhanced by newly elected President John F. Kennedy. Events like the Cuban missile crisis, which brought the world to the edge of nuclear annihilation, the assassinations of major figureheads (John F. Kennedy, 1963; Malcolm X, 1965) and America's entering the Vietnam War however shattered much of this optimism in the mid 1960s.

The attempt to demonstrate unity in the space race against the Soviet Union and in the intensifying Cold War failed, and a variety of protest movements swept American society, challenging government policies and middle-class values and lifestyles. Bruce J. Schulman claims that " $[\mathrm{f}]$ rustration and alienation pushed Americans toward the counter-culture, but also exerted a strong pull of its own: the conviction that it was possible to drop out of the polluted, corrupt mainstream and live according to one's values" (qtd. in Cornea 89-90).

The year 1968 is often considered as the peak of social and political unrest and to this day serves as symbol for revolt and for the conflict between what was regarded as counterculture and establishment. Stanley Kubrick's controversial film 2001: A Space Odyssey was also released in this tumultuous year. I will therefore 
focus my examination of the historical background particularly on the year 1968 . My argumentation will be based on the analysis of three major events that heavily affected the American social development and turned 1968 to the year that changed history.

\section{Vietnam: Between Trauma and Protest}

On the 30th of January 1968 the North Vietnamese troops launched a major military offensive against South Vietnam and their American allies, what later came to be known as the 'Tet Offensive.' The offensive ended with nearly 4000 U.S. troops dead and with the irrevocable conviction that this war was not going to be won. The military intervention of the USA in Vietnam began in 1965 following a war fought between South Vietnam and communist North Vietnam (the Democratic Republic of Vietnam) that sought to overthrow the Southern Vietnamese government and unify the country under rule of Ho Chi Mihn. The United States supported Southern Vietnamese premier Ngo Dihn Diem because of their Cold War policy of containment of the spread of communism. The belief of a great number of Americans was that "if South Vietnam fell to communism, it would then spread to neighbouring countries, which would fall like a row of dominoes" (Trevino 122). By the end of 1968 more than half a million American soldiers were in action.

The public opposition to the war in Vietnam began in 1964 on college campuses across the country and increased in size and intensity as the Vietnam conflict continued and American soldiers were shipped out and died. The most visible representatives of the antiwar movement were the hippies. With their recognizable appearance and rejection of mainstream behavior and culture, the so-called flower people rebelled peacefully against the conservative foundations of U.S. society with a mix of rock music, drug use and frequent sexual activities.

But not only had the hippies taken to the streets at that time to protest U.S. involvement in the conflict and the war-mongering political culture. Members of the New Left, black civil rights activist and even soldiers and veterans also expressed their fierce opposition to the U.S. American military policy. When in March 1968 an American Army Division massacred hundreds of civilians in the village of My Lai, the American public was outraged and the peace movement reached its peak of strength. As Chino Fernandez puts it: "At the same time the Vietnam War was raging, the seeds of change were being sown in homeland United States" (112). 


\section{Civil Rights Movement: Hope and Setback}

On the evening of April 4th 1968 Dr. Martin Luther King was murdered by James Earl Ray on the balcony of Lorraine Hotel in Memphis. In response, violence broke out in many American cities and over forty people were killed. A nation was stunned and the Civil Rights Movement had to mourn the loss of one of its symbolic figures.

The Civil Rights Movement grew out of the struggle of black Americans to obtain long denied constitutional rights and to end racial segregation in American society. In the early 1960s, the movement could produce considerable successes like the March on Washington, where Baptist priest and civil rights leader Martin Luther King gave his famous speech "I have a dream", which was followed by the signing of the Civil Rights Act in 1964 that prohibited a greater part of discrimination based on race, color and religion. Yet, endeavors to end discrimination in the United States were continuously overshadowed by terror and persecution against African Americans and civil rights activists, and by the still visceral racism in the USA, especially in the South. Organisations like the National Association for the Advancement of Colored People (NAACP) and King's Southern Christian Leadership Conference (SCLC) tried to overcome racism and discrimination in a nonviolent way and propagated civil disobedience as a remedy against the political practice of racial segregation.

Many young blacks, however, held the view that peaceful protests in consideration of the sweeping injustice and daily police brutality would lead to nowhere. For that reason, many of them were attracted by the militant struggle against discrimination that was led by figures such as Malcolm X, who was a proponent of separation and self-sufficiency from white America, as opposed to the full integration that people like Martin Luther King advocated. All in all, the protests radicalized in the late 1960s, also due to the advancing activism for civil rights of white students, leftists and young insurgents, who felt associated with the arising counterculture. Or, as Luca Prono states: "The campaign for civil rights was a dynamic force that shook American society during the whole decade" (189).

\section{Student Protests: From the Campuses to the Streets}

In the springtime of the year 1968 protests erupted at Columbia University in New York when student Bob Feldman discovered Columbia's affiliation with an institute closely related to the U.S. Department of Defence, thereby supporting America's war in Vietnam. The uprisings, which lasted several weeks, were a part of student protests all across America and Europe.

The American student activism was born at the University of California in Berkeley and gave rise to the counterculture of the 1960s, which called into question the basic foundations of American society. The so-called Free Speech Move- 
ment spread to hundreds of campuses and "was a source of inspiration to activists in the diverse coalition of the New Left, which gathered civil rights, anti-war, women's and gay liberation movements" (Prono 198).

The escalation of violence in Vietnam became a specific target of criticism and university campuses were the site of anti-war marches, demonstrations and committees. Students demanded the dissociation from institutions which were built on racism and discrimination and "stressed the importance of genuine human relations as an alternative to the alienation of modern society" (Prono 198). Moreover, the Free Speech Movement was closely linked to the Civil Rights Movement and called for racial cooperation and integration. Luca Prono concludes that "the Free Speech Movement had a key role in the development of the 1960s counterculture and the struggle for civil rights" (189). The 1960s, then, can be described as a time of political and social upheaval and the date of foundation of a counterculture which was about to leave an enormous imprint on the following decades.

Braunstein and Doyle argued that "[t]he Sixties counterculture in the United States didn't come out of nowhere" (8). Focusing first on discrimination against African Americans, the movement soon spread to address issues confronting other ethnic groups, women, homosexuals and the disabled. Through criticism about America's involvement in the Vietnam War and a general suspicion of the U.S. military policy, the newly formed anti-war movement unsettled the American establishment. "A general sense of frustration among the young radicals" (Cornea 89 ), which led to an ultimate breach with the institutional authorities, was cemented after the disappointments over the Democrats support of the war, the assassinations of key leaders such as Kennedy, King and Malcolm X and a political swing to the right after Richard Nixon's election in 1968. The contrasts between the rebellious youth and the old-established, conservative faction increasingly intensified and a generation gap developed that was fundamental for the explanation of Stanley Kubrick's success and the contrary receptions of the final sequence of 2001: A Space Odyssey.

\section{"Jupiter and Beyond the Infinite": Between Drugs and Cinematic Subversion}

One of the most commented, disputed and legendary sequences in film history is "Jupiter and Beyond the Infinite" in Stanley Kubrick's motion picture 2001: A Space Odyssey. But why has especially this sequence been so popular among young Americans and why did it become an expression of opposition for the $1960 \mathrm{~s}$ counterculture?

Many establishment critics such as fantasy writer John Brosnan tried to trace the sequence's success merely back to the psychedelic experiences that many intoxicated, young moviegoers had in particular during the final Stargate sequence 
(Cornea 83). Other film critics like Stanley Kauffmann, however, argued that the success of the sequence cannot simply be explained with hallucinogenic effects and attributed the adoption of the film by counter-cultural youth movements to Stanley Kubrick's unconventionality and his subversive use of cinematic devices (Palmer 16-17). In the following analysis, I will try to pursue the question to what extent the sequence's success among the youthful generation is a product of its psychedelic and mind-extending effects and to what extent "Jupiter and Beyond the Infinite" can be considered as a reflection on the social circumstances of the 1960s.

\section{A Literal Trip}

The press labelled Stanley Kubrick's oeuvre as a film "for grooving, not understanding," a "psychedelic experience" and the "ultimate trip" (Chion 43). "Trip" certainly is a keyword of the 1960s culture as well as of the final sequence in 2001, which also became known as cosmic trip. And indeed, the film, especially the Stargate sequence, became a cult attraction among a young generation seeking for consciousness-raising experiences. Psychedelic drugs, in particular LSD, were extremely fashionable for the youthful generation and "recreational drug use in the auditorium was commonly reported" (Palmer 14).

Especially during astronaut Bowman's rapid journey, reports of altered states of consciousness and colorful visions seem plausible. The interaction between multicolored light effects, the conveyance of speed and the depiction of abstract imagery, accompanied by creepy and frightful sounds of György Ligeti's "Atmospheres," made this particular scene so appealing for young viewers seeking for maximum trip. Referring to the Stargate sequence, film critic Stephen Mamber states that "[n]o more hallucinatory and dreamlike a segment has ever appeared in a mainstream film," and that "2001's early reputation as a 'trip' movie was not entirely undeserved" (61).

Additionally, director Stanley Kubrick succeeded in enhancing the impression of a trip with the application of specific cinematic methods. Kubrick deliberately used the point-of-view shot during the voyage as visual angle to let the spectator take astronaut Bowman's position. As a result the literal trip appears more realistic and personal, and the viewer is directly integrated in the happenings. The application of several jump cuts leads over to close-ups of Dave Bowman's face. His facial expression changes intensively in the course of the journey, and his seemingly serene and calm countenance turns into a panic-stricken, fearful face with widely opened eyes and mouth. Once the journey ends, Bowman seems to be in a dream-like state close to unconsciousness. Due to the character's modification of mental and physical being, parallels with young viewers that had the experience of a similar but drug-related trip, seems reasonable and logic. 
A term that is frequently used when talking about "Jupiter and Beyond the Infinite" and altered states of mind is escapism. According to Christine Cornea, the final sequence, accompanied by chemical intoxication was central to a movement's "serious attempts at imagining/creating a different or alternative world" (83-84). The gentle floating of the black monolith in the universe, in the very first scene of the sequence, conveyed a feeling of weightlessness on the one hand and invited young viewers on the other hand to immerse in a world beyond rationality and the imaginable. During the 20-minute voyage many young viewers abandoned their touch with reality and certainly also used the sequence to escape from the misery of the actual world. In the next sections of this chapter, I will elaborate on the question of what they actually tried to flee from and how their criticism of the modern world was constituted.

Quite a few young people used the film, particularly the "Jupiter and Beyond the Infinite" sequence, to turn themselves on under the influence of mindchanging drugs (Cornea 83-83; Palmer 14). For that reason the sequence can be understood as a social phenomenon of the 1960s youth culture, which lined up in related forms of cultural entertainment such as rock concerts that functioned with similar audiovisual tools. In contrast to this mere hedonistic use of the sequence, the rebellious nature was already at this place indicated by the attempt of a quite noticeable number of young viewers to apply "Jupiter and Beyond the Infinite" as an escapist retreat from the misery of the actual world. Nevertheless, I would call this sort of subversion rather unintentional. In the next chapter, I will show that there was indeed direct and conscious use of subversive elements.

\section{Kubrick vs. Hollywood}

The recognition of the film as "an attempt at metaphysical philosophy" (Hunter qtd. in Agel 215) by counter-cultural critics already suggests that the popularity of "Jupiter and Beyond the Infinite" could hardly entirely be explained with its supposedly hallucinogenic effects. However, I will return to critics and perceptions of the sequence and a more elaborate analysis of the social context later and start my analysis with Kubrick's unusual usage of cinematic and stylistic devices.

The most visible subversive element in the depiction of the Stargate sequence is director Stanley Kubrick's omission and violation of established industry standards. Film critic and author R. Barton Palmer states that it is hard to imagine "how Kubrick could have further undermined the ideological presuppositions of Hollywood storytelling" (16). One of the most obvious breaks with mainstream conventions in the 25-minutes long sequence is the absence of any kind of dialogue and speaking. Thereby, the traditional narration, with its "narrative driven by and centred on character" (Palmer 16), and the emphasis on human relations retreats to the background. As a result, the focus of the sequence shifts to audiovisual impressions. 
A close examination of the character Dave Bowman seems useful here in order to show the distinction between how characters were presented in conventional Hollywood productions and how Kubrick portrayed the character in the final sequence of 2001. In "Jupiter and Beyond the Infinite," Bowman appears heteronomous and as subordinate to human evolution. Contrary to characters in established Hollywood films, Bowman is not depicted as the master of his own fate but takes up a passive role, whereby he has no active power of intervention. The effect of this portrayal is that the focus shifts and that the subordination of humans comes into view once again.

An additional cinematic method is Stanley Kubrick's use of contrasts and visual extremes. This device becomes particularly apparent in the director's contrast between the scenes of the floating monolith and Bowman's rapid journey. In the first scene, the shots of the levitating monolith and of Jupiter and its moons, conveys an impression of slowness and gentleness. In contrast to that, in the literal sense of the word, astronaut Bowman's colorful voyage implies an opposing feeling of speed, fear and uncertainty.

Another visible contrast is the opposition between the futuristic, abstract and alien imagery during the journey and the old-fashioned room at the end of the sequence that seems rather familiar. This fairly unconventional use of contrasts serves various purposes. Stanley Kubrick provokes, shocks and even tries to ridicule the audience with contrariety, delusion and the depiction of the unexpected. Furthermore, he defies the Hollywood convention of predictability by showing the unforeseen. A further implication of this contrastive technique is the absence of coherence of the story and the causally link of the plot. Thus, this form of depiction serves as another deliberate trespass against Hollywood standards.

Another stylistic device that immediately leaps to the eye and has also been interpreted as breaking with industry conventions is Kubrick's extraordinary choice of colors. During Bowman's voyage, shortly before his landing, various colorful pictures of a planet are shown and with every cut a new combination of exclusively contrasting, neon colors, is presented. The planet seems alienated by these artificial and unnatural colors and these images provoke the viewers with their almost aching intensity and glariness.

Moreover, Stanley Kubrick sends viewers on a journey into the unknown and irritates them purposely. Kubrick presents pictures that raise essential questions about life only to leave them ultimately unanswered. Whereas in Hollywood films the pictures mostly speak for themselves and the viewer's interpretation is often determined by a clear message and logical images, the Stargate sequence works in an entirely different way. There are no clear answers but irritation about the displayed pictures. For instance, why do seven flashing diamonds appear in the sky above the alien planet or what does the appearance of the Star Child mean? With the deliberate omission of answers, Kubrick leaves the audience with an ample scope for personal interpretation, a topic to which I will return. 
The end of the sequence, which is also the end of the movie, distinguishes it fundamentally from traditional Hollywood film endings: While Hollywood movies generally end with a narrative closure - be it a happy or tragic ending - "Jupiter and Beyond the Infinite" works differently. It does not become explicit if the ending is meant to be happy, neutral or even sad, and also at this point it comes down to personal interpretation. Bowman's death does not, as one could have expected, constitute the ending but the birth of the Star Child, or Bowman's reincarnation respectively, and Kubrick succeeds once again in provoking irritation with an unexpected cinematic device. Hence, it can be stated that the Stargate sequence features a variety of unorthodox cinematic devices that explicitly isolate the film from established mainstream conventions and also foster the controversial discussion about the sequence.

\section{Perception of the Sequence}

The generation gap during the 1960s might not only help to explain the success of the sequence, "but to an important degree its critical reception as well" (Palmer 17). The discussion about "Jupiter and Beyond the Infinite" initiated a debate between a traditional mainstream faction on the one side and the counterculture on the other. I would argue that this debate about the final sequence of 2001: $A$ Space Odyssey symbolizes the generation gap and the division of the American society in the 1960s. I will begin my analysis of the perception of the sequence with a brief examination of the establishment critics. After that, I will present the young 1960s generation's perception of the sequence and explain why it has been so popular, particularly among the youth.

\section{Establishment}

The majority of conservative film critics of the 1960s could not identify with the sequence because conventional standards did not apply and they criticized director Stanley Kubrick blisteringly for his violation of mainstream industry conventions. Stanley Kaufmann argued that "unlike the usual Hollywood product, it did not provide enough in the way of customary structural elements (particularly a main character to focus the story)" (qtd. in Palmer 18). The mainstream reviewers were convinced that Kubrick ignored his talent because he did not, as afore-mentioned, adjust to certain standards and "had proven either unable or unwilling to provide the film with a causally linked plot leading to an exciting, last-minute conclusion" (Palmer 19). Especially the "Jupiter and Beyond the Infinite" sequence, which also constitutes the end of the film, was met with disapproval and misinterpretation. In this context, journalist Jeremy Bernstein wrote: "after reading the book, I realized 
that I really hadn't 'understood' the film, and I had especially not understood the ending" (qtd. in Nelson 106). Referring to the fierce criticism of establishment critics, Joseph Gelmis was convinced that Kubrick's movie was a film of "such extraordinary originality that it upset the members of the critical establishment because it exists outside their framework of apprehending and describing movies" (qtd. in Agel 264).

\section{Counterculture}

The success of "Jupiter and Beyond the Infinite" with the young audience in general and the counterculture in particular "went far beyond the purview of what might be properly called the aesthetic" (Palmer 14). While the "sweeping rejection of those structures and themes so customary in the American commercial cinema certainly challenged the analytical and critical acumen of journalists and reviewers at the time" (Palmer 16), young film critics and moviegoers of an alternative culture praised exactly this rejection and the sequence soon became one of the key manifestations of cultural opposition.

In other words, Stanley Kubrick's dissociation of traditional Hollywood conventions and his unorthodox use of cinematic devices reflect the counterculture's ideas of rebellion against rationality. As mentioned above, the 1960 s were a time of political, social and cultural upheaval and youth revolt. The sequence quickly caught on with the counterculture youth audience open to a contemplative viewing experience of a film, suggesting that the way to personal enlightenment was to free one's mind of the militaristic, reactionary and conservative status quo. In this context, "it is easy to see how the non-rational and creative force in the final sequence of 2001 spoke to a younger generation fighting for change and attempting to break away from institutional authorities that had brought them the futile war in Vietnam" (Cornea 89). Stanley Kubrick "had something different to say, in the largest sense of that term, and had found a different way to say it" (Palmer 16) and therewith captured the right tone of the countercultural movement. Similar to Kubrick and his unusual piece of art, young people across the country felt the necessity to reject middle-class values and institutions. Thus the film and particularly "Jupiter and Beyond the Infinite" became "the source of a special knowledge that distinguished them [young viewers] from their parents and 'square' adults in general" (Palmer 14).

A further socio-political aspect that illustrates the counterculture's positive reception of the final sequence of 2001: A Space Odyssey is Kubrick's deliberate dodging of dichotomies. The traditional classification into good and bad was avoided and it was left to the viewers to decide whether Bowman and his mission were well intentioned or not. While in established Hollywood productions public enemies, communists and oppositionists usually embodied the evil, Kubrick's 
dissolution of dichotomies was received favourably by young Americans who were tired of stylized enemy stereotypes.

Another aspect that explains the sequence's popularity among young Americans feeling associated with the counterculture is the aforementioned possibility of subjective interpretation. In an interview with Playboy, Kubrick states that: "I intended the film to be an intensely subjective experience. ... You're free to speculate as you wish about the philosophical and allegorical meaning of the film" (Nordern 47-48). Christine Cornea also recognizes this subjective potential of interpretation, in particular in the Stargate sequence: "However, my own view is that 2001 encouraged an active engagement on the part of the spectator, which is perhaps most clearly evidenced in the confoundingly abstract imagery in the long final sequence" (87).

Many young viewers derived from their personal interpretation of the happenings in "Jupiter and Beyond the Infinite" subjective messages. Yet, many of these viewers interpreted Bowman's speedy journey and his transformation into the Star Child as a symbol for renewal and change. This common interpretation found an echo in the counterculture's attempts of reformation and transformation of the American political, social and cultural life. Other young spectators transferred their desire for freedom to the sequence and recognized in the rebirth the liberation from exterior influences and the possibility of broadening one's mind. According to Barton R. Palmer, "[m] any reported undergoing religious conversions, rather than experiencing altered states, during the film's famous twenty-fourminute, dialogue-free final sequence" (14).

Yet not every interpretation of the sequence was optimistic. A common, more critical interpretation was that the interaction between death and birth in the final scene could "also be read as a symbol of recurrence" (Cornea 89) and quite a number of young viewers deduced that this was a symbol of human conformism. However, I would not attribute the appreciation of Kubrick's technique to a single message but rather generally to his rejection of dichotomies and the overall possibility for viewers to abstract an individual and subjective message from the film.

\section{Conclusion}

The popularity of the sequence "Jupiter and Beyond the Infinite" in Stanley Kubrick's 2001: A Space Odyssey among young viewers can be traced back to different reasons. Many young spectators certainly used the sequence and especially the hallucinogenic light effects during Bowman's rapid journey as a psychedelic experience and as an escape from reality. These experiences were often reinforced by excessive drug-taking. However, it would be naive to attribute the Stargate sequence's success among young moviegoers to its use of mind-expanding effects only. It is indeed much more. Stanley Kubrick produced an exceptional piece of art that captured the tone of the U.S. counterculture and young viewers in general, 
who recognized themselves in the critical, subversive and provoking tone of the movie. The counterculture that developed out of anger and frustration felt for the conservative, racist and militaristic climate in the USA was addressed by Kubrick's non-conformist avoidance of established standards and conventions. Moreover, the controversy about the final sequence of 2001 certainly can be seen as a reflection of the social circumstances of America in the 1960s. The success of Stanley Kubrick's legendary sequence can be explained with its double aspiration of entertainment and contemporary, intellectual statement. The sequence was like the decade: provocative, colorful and rebellious.

\section{Works Cited}

Agel, Jerome, ed. The Making of Kubrick's 2001. New York: Signet, 1974. Print.

Braunstein, Peter and Michael William Doyle. Image Nation: The American Counterculture of the 1960s and '70s. New York: Routledge, 2002. Print.

Cornea, Christine. "Spaced Out: Between the 'Golden Years." Science Fiction Cinema: Between Fantasy and Reality. Edinburgh: UP, 2007. 75-110. Print.

Chion, Michael. Kubrick's Cinema Odyssey. London: BFI Publishing, 2001. Print.

Fernandez, Chino. "The Tet Offensive." America in Revolt during the 1960s and 1970s. Ed. Rodney P. Carlisle, and J. Geoffrey Golson. Santa Barbara: ABC-CLIO, 2007. 101-19. Print.

Mamber, Stephen. “Kubrick in Space.” Stanley Kubrick's 2001: A Space Odyssey: New Essays. Ed. Robert Kolker. New York: Oxford UP, 2006. 55-68. Print.

Nelson, Thomas Allen. Kubrick: Inside a Film Artist's Maze. Bloomington: Indiana UP, 2000. Print.

Nordern, Eric. "Playboy Interview: Stanley Kubrick." Stanley Kubrick Interviews. Ed. Gene D. Phillips. Jackson: U of Mississippi P, 2001. 47-74. Print.

Palmer, Barton R. "2001: The Critical Reception and the Generation Gap." Stanley Kubrick's 2001: A Space Odyssey: New Essays. Ed. Robert Kolker. New York: Oxford UP, 2006. 13-27. Print.

Prono, Luca. "Free Speech Movement." America in Revolt during the 1960s and 1970s. Ed. Rodney P. Carlisle, and J. Geoffrey Golson. Santa Barbara: ABC-CLIO, 2007. 189-206. Print.

Trevino, Marcella Bush. "Kent State." America in Revolt during the 1960s and 1970s. Ed. Rodney P. Carlisle., and J. Geoffrey Golson. Santa Barbara: ABC-CLIO, 2007. 121-34. Print. 
Manfred Alexander Müller

\section{It Used to Be a Man's World: Manhood and Masculinity in Don Siegel's Invasion of the Body Snatchers}

And so I ran. I ran, I ran, I ran! I ran as little Jimmy Grimaldi ran the other day.

- Dr. Miles J. Bennell, Invasion of the Body Snatchers (1956)

Don Siegel's Invasion of the Body Snatchers features a rather peculiar ending. We witness a grown man running away in panic from an unseen young woman, eerily mirroring a young boy running away from his mother in an earlier scene. The movie offers a multitude of possible interpretations and several have been put forward by different scholars over time. The predominant one, of course, has always been to see the movie as an allegory for the communist threat prevalent in the United States at the time the movie was released (Sanders 59). Fredric Jameson even sees all Science Fiction films produced in the 1950s as influenced by the Cold War: 
Arguably, the golden age of the fifties Science Fiction film, with its pod people and brain-eating monsters, testified to a genuine collective paranoia, that of the fantasies of the Cold War period. ... The enemy within is then paradoxically marked by non-difference: "communists" are people just like us save for the emptiness of the eyes and a certain automatism which betrays the appropriation of their bodies by alien forces. (96)

But since the release of the movie more than 50 years have passed and since then the focus of research has shifted dramatically and with it the possible interpretations of Invasion of the Body Snatchers. Cut off from outside help, a young doctor and his childhood sweetheart try to save their home town Santa Mira on their own. The absence of external influence - with the focus of the plot on only one small town - enables the viewer to learn about Santa Mira, its social structures and the self-concept of its inhabitants. This paper will deal with the depiction of gender within the movie, focusing especially on Dr. Miles Bennell's rank in the social hierarchy. It will either underline or deconstruct common stereotypes concerning "typical" male behavior, but also take into consideration the depiction of Becky Driscoll as the lead female character. In my analysis, I will focus on how the relationship between Miles Bennell and Becky Discroll develops in the course of the movie, and on how the interaction between the two characters influences Bennell. More generally, I want to suggest that the alien invasion depicted in Invasion of the Body Snatchers can be seen as an allegory of the post-war decline of small-town patriarchy and male social and political dominance in the United States. The movie is critical of this development and warns of a possibly terrible outcome. The analysis will take into consideration the historical background in which the movie was produced and how changes in society have also brought about changes in perception: the reaction of a contemporary audience to certain aspects of the movie will most probably be quite different from that of a 1950s audience. Since the movie was created in a society that was heavily influenced by the Cold War and other aspects unique to the 1950s United States, it is likely that the aspects of plot and production a contemporary observer regards as the most important ones differ from the ones an observer from another time would choose and the ones that the creators originally intended.

\section{Santa Mira: An All-American Town?}

In order to fully grasp the context in which the story takes place, one has to take into consideration where it is set. Invasion of the Body Snatchers takes place almost completely within the fictional town of Santa Mira, California. From what we can see on screen, it does not seem to be a suburb, but rather an independent small town, with a town center, stores and its own train station. It seems to be surrounded by hills and thus appears geographically isolated, which adds to the idea 
of autonomy. In his article "Picturing Paranoia: Interpreting Invasion of the Body Snatchers," Steven M. Sanders refers to this as "small-town insularity" (55). And Santa Mira seems like an island, indeed, with almost the entire plot taking place there. Additionally, Bennell's attempts to call for outside help fail, adding to the feeling of insularity.

The audience does not see what Santa Mira is like before the invasion starts because at the time Bennell arrives, an unknown number of people have already been replaced by the alien life forms. As the aliens are mimicking normal human behavior, however, the viewer might still get a good impression of what the town used to be like. According to Katrina Mann, the town's population is characterized by "stable patriarchal management, a Protestant work ethic, and courtly love" (50).

The way that both Dr. Bennell and Dr. Kauffman act, implies that this town is firmly in the hand of men. There is a clear social hierarchy, which subordinates women like Wilma and privileges men like Bennell and Kauffman. All the main characters and most of the other people seen on screen are white. The streets are clean, most people are friendly and seem content with their lives - or, this is at least the impression the audience gets. Santa Mira appears to be almost too good to be true - reminiscent of the fictional town of Seahaven in Peter Weir's The Truman Show. While Seahaven turns out to be a film set in a gigantic television studio, Santa Mira is supposed to be real, although it is almost exactly as unrealistic. Invasion of the Body Snatchers glorifies the all-American small town, prosperous, clean, and evoking a feeling of general happiness. The absence of poverty and racial tensions as well as the traditional gender relations between the characters paint the picture of a perfect community, not burdened by the real life problems the United States faced in the 1950s.

This of course changes during the alien invasion: The town is still clean and the population is still white; yet the people are unable to feel any emotions. Now the general cleanliness appears to be as sterile as the alien life forms who do not reproduce physically. The way Santa Mira is portrayed before the alien invasion can be seen as an idealized small version of the United States itself. Thus, I would argue that what happens in Santa Mira can and should be read as a comment on issues which were contemporary at the time the movie was released.

\section{The Gender Issue}

In Invasion of the Body Snatchers we witness an alien invasion - not a military one, but one relying on deception. The enemy has infiltrated the town of Santa Mira and now lives among the town's population, slowly taking power from within. The prevalent interpretations have been linking the movie to either the Communist threat or McCarthyism. What is more interesting, I would suggest, is how the reaction to this threat is reflected in the depiction of gender. 
Although the movie ends in a slightly more optimistic way than it was originally intended, it is not a typical happy ending, more of an ambiguous one, in fact, - and in any case the population of Santa Mira is lost for good. This is partly caused by Bennell's inability to cope with the situation in Santa Mira. In fact, the situation gets out of control because Bennell lacks character traits that are generally considered as masculine, namely anger, determination, and aggression. Instead he is hesitant, fearful and full of self-doubt. If we go back now to the historical context in which the movie was made we can clearly see what message is conveyed here: The real United States, just like the fictional town of Santa Mira, is threatened by an invasion from within. The formerly independent and strongwilled Becky - representing the new type of emancipated woman - is unable to do anything against it and falters easily under the pressure of this threat. This is only one aspect of the generally rather negative portrayal of women in Invasion of the Body Snatchers. There are only very few instances in this movie in which women are portrayed positively. Becky Driscoll, as the main female character, relies heavily on Dr. Bennell to save her - and in the end is too weak to stay awake, enabling the Pod People to replace her. Becky Driscoll, who at the beginning of the movie is portrayed as confident and self-reliant, first becomes the damsel in distress and then betrays the protagonist, Miles Bennell. As a result, in case of the Red Scare, women can not be trusted to help in the defense against a communist Fifth Column. And even men may not be helpful, if they do not show stereotypically masculine behavior. The answer to this and indeed any threat to the United States must thus be a masculine one. In order to defeat the enemy, one must be determined, unyielding, strong and calm. The audience might remember from the last scene that the doctors and police officers who find out about the invasion first from Bennell himself and then via the truck accident are all men; men who then try to rally men from the army and the FBI in order to fight the enemy. Thus, the slightly more optimistic ending is a more optimistic one just because now the defense lies in the hands of able men.

\section{Miles Bennell: A Strong and Able Man?}

In order to analyze how Miles Bennell is portrayed in the movie, one has to take a closer look at his relationship with other people and their reactions to him. There are several characters in Invasion of the Body Snatchers that show us quite clearly what Bennell's rank in the social hierarchy of Santa Mira is. In one of the very first scenes of the film, Sally Withers, Bennell's nurse, drives a car to the train station to pick up the doctor. But as soon as they meet - and without even saying a word about it - Bennell takes the driver's seat. It may strike the contemporary viewer as odd that a person who is picked up somewhere almost naturally takes the driver's seat from the person who has driven the car to the pick-up point. Driving here appears to be some kind of a male prerogative. Another interesting factor in this 
scene is that the camera is placed on Bennell's side of the car, which puts him in the foreground of the shot. Sally is turned towards him and looks at him almost adoringly while he jokingly talks about being able to break up her marriage if he wanted to. His right to drive the car and thereby his control of the situation is underlined, when in the next scene he jumps out of the car to run after a boy who has run into the street in obvious distress. Sally slides over onto the driver's seat, moves the car a few feet forwards and then Bennell gets back in and drives on. Thus, every time Sally is alone in the car she drives, but as soon as Bennell gets in, he takes the wheel. This repeated procedure of exchanging control of the car quite clearly shows what relationship the two have. Although Sally Withers and Bennell have an employer-employee relationship, they are comfortable enough around each other to engage in some banter. Nonetheless, it is always clear that Bennell is the dominant one in their relationship.

The next and probably most important relationship that is portrayed is the one between Bennell and Becky Driscoll. When they meet, they too engage in some flirtatious banter. During the course of their conversation, it is revealed that they have a history together and that Becky has recently been divorced. After Becky's divorce, she and Bennell had planned to meet in Reno for reasons unknown. However, this meeting did not take place - ostensibly due to schedule difficulties - and it is left unclear whether there is interest in a renewal of their relationship. Apart from their spoken dialog, their body language gives us quite a good insight into their relationship, for example, when they cross the street after leaving Bennell's office. It seems like whenever the two of them are walking beside each other, Bennell does not hold her hand, but places his own on her elbow, gently steering her, thereby controlling the direction in which she walks. Even though Becky Discroll's clothing, demeanor, and flirtatious manner clearly set her apart from Sally Withers (as does her past relationship with Bennell and the fact that she is not one of his employees) he, once more, represents the dominant part in the relationship.

It should be noted that nearly all the women Bennell encounters throughout the movie are portrayed as assuming the inferior role: Sally Withers is his employee, Becky Driscoll is his former girlfriend who, recently divorced, has moved back in with her father, and some other women are his patients. Towards many he acts paternally, fulfilling his role as a small-town doctor, to some - as one would expect from a handsome single doctor - he acts in a flirtatious manner. In several scenes, this is also reinforced by the way in which the characters are positioned during a conversation. In the doctor's office and in the garden of the Lentz family (Bennell makes a house call because Wilma Lentz is convinced that an impostor has replaced her uncle), the women are seated while Bennell is standing. As a gentleman he leaves the seats to the women, of course, but this also enables him to tower over them, which is why they have to look up to him while he, at certain times almost condescendingly, talks down to them. One might argue that all these 
relationships are common for the 1950s, but the degree to which the gender disparity is exaggerated and later turned around still make them important for this analysis.

The clear division along traditional gender lines can also be seen in the clothes the characters wear. Bennell is mostly shown wearing a suit, which he is not afraid to dirty, which can be seen when he gets out of the car on a dusty road and kneels down beside the boy in the beginning of the movie. Becky Driscoll on the other hand is usually wearing dresses and carrying fashion accessories like handbags or shawls which hinder her movement. While Bennell's hands are free to take action, Becky Driscoll's are clutching a purse.

When Bennell is called to a patient and takes Becky along with him, the way she is dressed is contrasted with the way the female patient is. Wilma Lentz, Becky's cousin, has become suspicious of a close family member, who seems to be acting strangely around her. Wilma's clothes are quite plain and she does not sport a particularly elaborate hairstyle either. Becky on the other hand appears almost overdressed. Her styling very much underlines her femininity, making her even more attractive than other women, which in turn reinforces Bennell's masculinity. The two of them therefore fulfill the stereotypical roles their respective genders are generally associated with.

When the plot reaches its climax in the scenes where there is open hostility between the alien invaders and Bennell, the gender roles are still firmly traditional. Bennell fears for Becky's safety, and drives to her house to pick her up. Because he is unable to awaken her, he simply carries her outside and to his car and takes her to his house. The next morning, Bennell is again in the foreground of the shot sitting on a table while in the background Becky is preparing his breakfast. Once more, a very traditional, almost archaic gender relation is depicted in this scene. Becky dutifully fulfilling her domestic role stands in stark contrast to Bennell's role as protector, having used his physical strength to carry her to safety the night before. When the two of them have to hide in Bennell's office for a night, it is heavily implied that they engage in sexual intercourse (Mann 60). The ability to seduce an attractive woman might serve as another reminder of how masculine, confident and successful Miles is. The fact that Becky later tells Bennell that she wants to be the mother of his children further strengthens the traditional gender relationship. When the alien invaders abandon secrecy and start taking ever more aggressive measures against the protagonists, Bennell and Becky have no choice but to try to escape Santa Mira. In their escape, it is Bennell who keeps both of them going. When Becky is physically exhausted from the strains of their flight, the doctor first has to drag her along, and later even carries her away from the town. Where he earlier was the dominant part of their relationship, he now is the only active one. Their survival depends solely on him, while Becky, physically and mentally exhausted, becomes utterly impassive. 


\section{The Small-Town Doctor}

Wilma Lentz is not the only character who is introduced as one of Bennell's patients. In fact, the reason why he has returned early from his conference is that his nurse, Sally Withers, has called him back in order to attend to the great number of people who have come to seek his advice. We later learn that these people had noticed strange behavior in their family members or peers. Yet at the time Bennell returns to Santa Mira, most of them have either been convinced that nothing is wrong or have been replaced by pod people. The few patients we see in Bennell's office seem to trust his opinion. It is also interesting to note that the change in behavior many of the film's characters seem to have noticed in others is not necessarily a medical problem - yet they still want to see Dr. Bennell about it, which demonstrates that his authority and the trust the townspeople have in him are not merely based on his status as medical doctor. It seems more like he is the one person people may come to for advice in an unusual situation, which clearly distinguishes him as a authority figure within the small-town society of Santa Mira.

However, there are also other characters Bennell interacts with, for example the psychologist Dr. Kauffman, whom he encounters when he is on a date with Becky. They talk in an informal manner about the patients Bennell has seen and to whom he refers to as a "mixed-up kid and a woman," making clear that he does not take their fears seriously. Kauffman reacts in the same indifferent manner, blaming psychological difficulties for the strange behavior of Bennell's patients. This scene also marks an instance of male bonding: Bennell and Kauffman seem to be old friends or at least old colleagues and talk about what to do about their patients' treatment out on the street in a very informal way. This symbolizes how they are in control and how they can execute power without any sort of accountability. Katrina Mann points out that Dr. Kauffman represents the "dubious postwar technocrat," a member of the "white patriarchal collective" (59). His friendship hints at Bennell's status in the social hierarchy of Santa Mira. This social hierarchy seems to be based on patriarchal structures, with men like Bennell and Kauffmann exercising power not only through their work but also through their positions as well-respected members of the Santa Mira society.

Combining the observations concerning behavior, relationships and social hierarchy in Santa Mira, Bennell's status in town becomes quite clear: He is portrayed as being very confident, especially around women. This can be seen in his demeanor when talking to Becky, Wilma or Sally. The townspeople trust him and come to him for medical and non-medical advice. Up until the very end of the movie, he plays the active part when together with Becky. This reaches its climax when he has to carry her into the tunnel in one of the last scenes. He sometimes seems to be quite condescending, especially towards women, on one occasion dismissing a woman's (justified) fears the same way he dismissed the ramblings of a hysterical child earlier in the movie. 


\section{The Deconstruction of Masculinity}

As I have shown so far, the picture of Dr. Miles Bennell as strong, confident and in control of both his life and most of the situations he gets into is strengthened. In the following section, I will explore to what extent this picture is deconstructed during the course of the alien invasion and how this in turn affects possible interpretations of the movie.

This changing portrayal of Dr. Bennell does not come about suddenly but in several steps. Some of them are rather subtle, some more obvious. One of the first signs can be observed when Miles finds out that Sally has been replaced by an alien. He watches from a window, then runs away in panic and jumps into his car. Becky, who is in control of the car, then speeds away. This is the first instance in the movie in which Bennell is in a car that he is not driving himself - thus, the first situation in which a woman is in control while he is merely a passive passenger. A few scenes later, he and Becky are hiding in a closet in Bennell's office, while a policeman - already turned into a pod person - searches the place.

The fact that Bennell hides here and does not fight the policeman serves to deconstruct the almost archaic former depiction of his masculinity. Later, he actually fights back - but he is subdued by the policeman and has to be saved by Becky, who manages to tranquilize the alien policeman with an injection. Here, Becky saves him, and the situation in which Miles saved Becky by carrying her out of her house is in fact reversed. The fight with the policeman is also interesting on the level of visual symbolism. The policeman, who has one of the most stereotypically male professions, of course carries a gun and a baton. Both are phallic symbols, underlining his masculinity. He manages to overpower Bennell because of his greater physical strength or determination, both attributes usually associated with masculinity. Thus in order to lose the fight, Bennell must be less masculine than the policeman, who in turn is defeated by a woman. This not only deconstructs traditional gender stereotypes, but also shows how Bennell is losing power vis-à-vis the alien invaders and also vis-à-vis Becky Driscoll.

But in the end, it is Becky who delivers the coup de grâce. When Bennell leaves her alone at their hiding place for a few minutes, she becomes a pod person. Bennell comes back, kisses her and realizes from her lack of reaction, probably caused by a lack of emotions, that she has been replaced: "I didn't know the real meaning of fear," Bennell can be heard in the voice-over, "until ... until I kissed Becky." Michael Hardin here notes the image of the womb that the tunnel in which they are hiding conveys (1). This imagery serves to put the already decreasingly masculine Miles in an environment strongly associated with the female.

Additionally, Miles notices Becky's replacement only when she does not respond to his kiss. Here he fails to seduce her, which again stands in contrast to his former success in doing so. In one of the earlier scenes we can also witness how the former Sally, Bennell's nurse, advises one of her fellow aliens where to place a pod to replace her small child. This behavior shows how all the motherly instincts 
Sally might have had are gone. The inability or unwillingness to mate and the loss of normal, protective behavior towards children further deconstructs the idea of biological sex and traditional, sex-based gender roles.

After Bennell has realized that his companion has become a pod person, he flees - and while he is running away we hear in a voice-over that he now is in exactly the same situation the young boy Jimmy was in at the very beginning of the movie. He now has become like the frightened child he refused to take serious before. Hence there is a parallel where before there was a contrast. Earlier on, Bennell was the one who calmed down those who panicked, mostly women, but now he himself is extremely fearful and has basically suffered a nervous breakdown.

It should also be noted that, due to the pod people replacing more and more people, he becomes increasingly isolated. In the beginning, he is an important part of the town. He is friends with many of the film's characters and many people come to seek his advice. In the end however, has become an outcast. For someone who is used to be as involved in the community as Bennell, this must be quite a difficult situation, one that adds to the pressure he faces and contributes to his breakdown. Before, the traditional gender-specific attributes of both Bennell and Becky had been strengthened. Now, however, they do not apply any more.

The depiction of Miles Bennell at the end of the movie differs greatly from the way he is depicted in the beginning. While at first he is successful in his endeavors, confident and in control, he later fails to save Becky as well as the population of Santa Mira. Bennell panics and eventually has to leave it to others to notify the authorities and fight the invasion. The fact that the movie systematically deconstructs the picture of a masculine Miles Bennell, together with its ambivalent ending, which does not clarify whether the humans will be able to fend off the invasion, will be the base for further interpretation.

\section{Conclusion}

At the end of the film, the once confident doctor becomes a scared child. The idyllic small town in California becomes the base from which a hostile alien race tries to invade the United States. What was once a romantic relationship turns into horror and fear. What was once a loving mother now is a cold and calculating alien who even plans to replace her own child. Don Siegel's Invasion of the Body Snatchers succeeds in portraying an unrealistically perfect world just to systematically destroy it afterwards. To achieve this, the movie works on several levels: The deconstruction of traditional gender roles leaves the protagonist a nervous wreck and the town of Santa Mira populated by basically genderless individuals hostile to the outside world. The destruction of the nearly perfect small town community of Santa Mira transforms a once happy and presumably prosperous place into a bridgehead of an alien invasion. 
I have already mentioned that the most prevalent interpretations of the movie see the alien invasion as representative of either the danger of infiltration of the United States by communist ideas or as criticism of McCarthyism. But we can go one step further and look at how the doom of Santa Mira came about. We clearly see a decline of male dominance in Santa Mira, since the Body Snatchers do not seem to have any gender-based hierarchy (as can be seen, for example, in the scene where Bennell's nurse, Sally, orders several male aliens to place a pod near her child). This can be seen as an analogy of the decline of patriarchy in the United States as a whole, especially when taking into consideration the picture of women as equal to men that was prevalent in communism. We can also see how Bennell becomes a less and less masculine character as the story progresses. A confident man in the beginning, he has now become childlike. In this context, the movie is also critical of the empowerment of women, since as soon as there is an emergency, women - here represented by Becky - have to rely on men to ensure their safety. The movie thus serves as political and social commentary. While the real United States are under threat from communist infiltration, measures were to be taken to ensure that the traditional American social roles prevailed to ensure that the American way of life survives. The fate that the population of the fictional town of Santa Mira suffers must not be the fate of American society as a whole. In order to ensure the safety of the American people, they have to behave differently than the people in Santa Mira. Men must take the initiative, because the movie clearly shows that women are unable to do so. And these men must act in a stereotypically masculine way, because if they do not, they will fail just as Miles Bennell does.

The movie seems to call upon the male population of the United States to repeat their effort and to defeat the communist threat. And this, as the movie shows, has to be done by making use of male virtues. The people of Santa Mira did not do so, and were defeated and destroyed as a result. Invasion of the Body Snatchers thus stands as a warning of a society that is not ruled by able men.

\section{Films Cited}

Invasion of the Body Snatchers. Dir. Don Siegel. Perf. Kevin McCarthy and Dana Wynter. 1956. Walter Wanger Productions, 1998. DVD.

The Truman Show. Dir. Peter Weir. Perf. Jim Carrey and Laura Linney. Paramount Pictures, 1998. DVD. 


\section{Works Cited}

Hardin, Michael. "Mapping Post-War Anxieties onto Space: Invasion of the Body Snatchers and Invaders from Mars." Enculturation 1.1 (Spring 1997): n. pag. Web. 16 Jul. 2009. <http://enculturation.gmu.edu/1_1/hardin.html>.

Jameson, Fredric. Signatures of the Visible. New York, NY: Routledge, 1990. Print.

Mann, Katrina. 'You're Next!: Postwar Hegemony Besieged in Invasion of the Body Snatchers." Cinema Journal 44.1 (Fall 2004): 49-68. Print.

Sanders, Steven M.. "Picturing Paranoia: Interpreting Invasion of the Body Snatchers. The Philosophy of Science Fiction Films." Ed. Steven M. Sanders. Lexington, KY: U of Kentucky P, 2008. 55-72. Print. 

Philipp Stückrath

\section{"What keeps us safe also keeps us free": State Control vs. Personal Liberty in Steven Spielberg's Minority Report and the Present-Day United States}

In our present-day society we sometimes get the feeling that our personal liberty is shrinking while the state control is increasing. In our everyday lives, we experience that the state knows nearly everything about us. It seems that the state has access not only to our personal data but also to our thoughts and opinions. This development may lead to the perception that governments of modern societies attempt to investigate their own people in order to achieve more and more control over them. The result is an increasing distrust and growing suspicion on the side of both the state and the people.

Theories and doubts about these state politics culminate in academic essays and scholarly articles on this subject as well in social criticisms laid down in novels, plays and movies. I would argue that movies have the potential to deliver the strongest critical impact because they are products of modern mass media and are often watched by several million people around the world. Scholarly articles either deal with the problems of increasing state control or analyze the movies as cultural products. In this chapter, I want to create a connection between these two ap- 
proaches in order to show the impact of state control in the present-day United States, and to point out how it is reflected in the movie Minority Report by Steven Spielberg (released in 2002 and based on a 1956 science fiction short-story by the author Philip K. Dick). I will therefore compare the tools of state control in the movie with a few examples of increasing state control in the United States, i.e. the actions of the Department of Homeland Security and the new modification of the law, the USA PATRIOT Act (Uniting and Strengthening America by Providing Appropriate Tools Required to Intercept and Obstruct Terrorism Act of 2001). These concrete examples are taken from the time following the terrorist attacks on the World Trade Center in 2001. Minority Report was filmed before 9/11 and consequently this chapter does not mean to interpret the movie as a direct response to the increasing state control after the terrorist attacks. Instead I will be more interested in analyzing Minority Report as a general social criticism of state control. The chapter concludes with a discussion of the question whether increasing state control is a blessing or a curse, whether we as citizens should give up more and more of our liberty and rights for increasing safety or if we should see these actions of modern states in a more critical light.

\section{State Control in Steven Spielberg's Minority Report}

There are several types of state control in the movie Minority Report such as general retina scanning and actions related to pre-emptive crime control. In the following, I will explore the differences of the controlling methods, show how they work and how they affect the freedom and privacy of every human character in the movie.

The experimental Pre-Crime system of Minority Report is a way to predict future crimes. Washington, D.C.: In the year 2054, the so-called Pre-Cogs - a mentally advanced form of human beings - dream of murders yet to come. These visions are projected on a large screen visible for the Pre-Cops, a specialized department of the Washington police. The Pre-Cops interpret the visions of the Pre-Cogs and interfere and arrest the suspects before the predicted murder happens. In the movie, not a single murder has occurred in three years. The people who are arrested are imprisoned without a trial or even a hearing and are kept in prison infinitely.

According to critics, the problem of Pre-Crime is that the actions of the government, which in the case of a predicted murder have a tremendous effect on the lives of the suspects, are based on interpretations of the Pre-Cops. Lester D. Friedman, for example, states that

... all mechanisms [of the Pre-Crime system], however sophisticated and refined, remain open to human interpretation and, by virtue of that fact, such devices are inherently susceptible to corruption and misuse. 
This shows the inherent danger of the Pre-Crime system: Despite the fact that the visions seem to be objective and real (which they are not, as is revealed at the end of the movie), humans are still interpreting the visions of the Pre-Cogs and running the system. Therefore, Pre-Crime is subject to human fallibility. Who knows whether the person who interprets a vision is objective or if personal experiences shape his or her view? A good example for this is the protagonist of the movie, Chief John Anderton, who works in the Pre-Crime unit because his son was kidnapped and possibly murdered some years earlier. In the words of Friedman "all the variables which constitute one's personal and social identity determine how, and even what, one sees."

Another flaw in the system is that the Pre-Crime system has lost its legitimation right from the beginning, because its founder Lamar Burgess committed murder in order to establish the system - a murder which remained undetected (Sutton 195). This means not only that the system can fail because of misinterpretations or ignored visions (so-called minority reports) as I have pointed out above, but that the system itself is based on a murder. While Pre-Crime is used to catch and imprison hundreds of people for future murders they will never commit, the one establishing the system is a murderer still walking free.

In other words, the Pre-Crime system has too many possibilities of misuse and fallibility. It is a system of an oppressive state used to control and suspect its own people. Everybody can become the state's target, even Anderton, one of the PreCops, who does not even know the person he is supposed to murder according to the Pre-Cogs' vision.

In Minority Report, the social environment is under permanent control by the government, the police, and private corporations. The tool to control the people is the retina scan. Everybody's eyes are scanned everywhere: when entering a building as well as when using public transport or when shopping. Every person can be identified and located wherever he or she is. These data are then used in various ways. On the one hand, the companies use the knowledge of what one buys, which shops one goes to, or which one's daily routes are to create personalized commercials. These commercials are not just adapted to the consumer's profile but they address the person directly. In my opinion, this is a sidekick to our present-day society. At the moment we are very concerned about what companies know about us, if our data is safe, or how the companies gain the knowledge about our needs to address us directly with their commercials. In the movie, nobody has any influence on how the personal data are raised or used. Every person constantly makes it possible for the state or companies to retrieve personal data simply by going outside the house and opening his or her eyes.

On the other hand, the data are used by the police to track people down. Especially for the Pre-Cops it is easy to find a suspect because the "omnipresent eye scans make hiding virtually impossible" (Sutton 196). When a suspect leaves his house he will sooner or later be scanned somewhere and the police will instantly 
know where to find him. To evade this, the main character in the movie, Chief Anderton, has his eyeballs removed and exchanged for new ones, so that the police will not be able to catch him with the help of the retina scan system. Friedman writes about this matter: "In the future [of Minority Report, the eyes are less the window to the soul than the path to the check book - or to jail. Such intrusions merely refine already existing devices now routinely used at airports and received via email."

Another area in which this dystopian vision of the state shows its controlling power is the prison system. The suspects are caught with the Pre-Crime system and the visions of the Pre-Cogs are evidence enough to imprison them. They are taken to prison without a trial or even a hearing. The correctional facilities resemble a storehouse more than a prison. The prisoners are kept comatose, their vital functions supervised by a computer. The punishment is infinite because the prisoners are not meant to be set free again. Geoff Bakewell calls this "the indefinite warehousing of the prisoners" (97).

With the prisoner control the future state in Minority Report has achieved one of its goals. The "technology creates a utopian state through the removal of unwanted elements ... and crime, rather than through the fulfillment of a positive ideal" (Atkinson 12). The unwanted elements, in this case "murderers" are removed from society and are imprisoned forever. The only reason why people spend the rest of their lives in a Pre-Crime prison is the Pre-Cogs' vision of a future of which nobody knows if it would have come true. That means the state simply imprisons people because they are likely to become criminals. This reflects actions of a totalitarian state and serves as a warning that exaggerated state control can lead to oppression and bondage as I will show later in the analysis of the state control systems of our own society.

Nevertheless, the oppressive future state is not satisfied with controlling the public sphere using retina scans. The police permanently infringe on the privacy of the people in order to assert control and ensure public safety. In search of the main character Anderton, for example, the Pre-Cops perform a thermal scan of a building in order to see where exactly everybody in the building is. Afterwards they send in spiders - little moving robotic creatures which can scan peoples' retinas. The spiders are very intelligent robots, which can gain entry to every corner of the building. The devices break into the privacy of every human being in the building, crawl on them and force them to let their retinas be scanned. Children, a couple making love and an old man sitting on the toilet - nobody can escape the scans (Friedman). The spiders again reveal the characteristics of a totalitarian regime that ruthlessly infringes on the privacy of the people in order to ensure the state's ideas of public safety. In the name of the law - in this case to catch a criminal - the privacy and liberty of innocent people is sacrificed.

The same happens when the police nearly detain Anderton on the street. The policemen have jet-packs on their backs which allow them to fly after Anderton 
and even track him through apartments. According to Mann, the result is a "police chase through family dinners and TV watching ... that exposes the hidden in the name of the law, while destroying the private, either by violence or by ridicule" (199-200).

The examples above show the dimension of the state control in the fictional world of Minority Report. The state controls its people in a very oppressive and ruthless way and is willing in the name of law to sacrifice nearly every individual freedom and the right to privacy and public safety. The people can do nothing about it and therefore the audience gets the impression that in the movie the state is a very authoritarian or even totalitarian one - a matter that I will discuss in detail at the end of this chapter.

\section{State Control in Today's Everyday Life}

Today, newspapers and TV news are full of articles and debates about safety and liberty. They often discuss the protection of our personal data and private sphere from intrusion by the government. Especially the internet has a tremendous influence on our lives and makes it much more complicated to keep control over our own data. Experts working for the police or intelligence agencies can reconstruct the curriculum vitae of a person only by using the Internet. The spread of information about ourselves has also made it easier for companies to supervise our consumer behavior and to drown us in personalized commercials. In all of these areas one can find many parallels between the movie Minority Report and our own society. To get a more precise image however, this chapter will only give examples from the areas of public security and, more precisely, the measures taken by the United States to enhance safety but also to confine privacy and personal liberty.

The terrorist attacks on the World Trade Center on 11 September, 2001 gave a significant, thought-provoking impulse to the public security debate. The question was raised whether citizens need to sacrifice more of their rights in the name of public security to make it easier for the police and the intelligence agencies to track down potential terrorists. During this time, the USA PATRIOT Act was signed by President Bush and the Department of Homeland Security was founded. Lester D. Friedman sees a coincidence in the release of the movie Minority Report and the security debate in the United States:

Though conceived, shot and edited long before the current crisis in domestic security spawned by the terrorist attack on the World Trade Center Towers, Minority Report hit movie screens at a time when questions about how much personal liberty Americans were willing to sacrifice for the promise of public security stimulated an ongoing national debate. Can we trust the FBI and the CIA to exercise appropriate restraints, to monitor only those who endanger our safety and not those who hold unpopular 
opinions, if given greater power to patrol our lives? Will President Bush's and Tom Ridge's Department of Homeland Security prevent violent activities or routinely engage in unjustified surveillance of our personal lives? ... It is also a time when ... prisons throughout the United States contain people arrested because the government suspects they would have committed future crimes.

Because of this national security debate during the movie's release, the following section will deal with the new policies of the PATRIOT Act and the Department of Homeland Security and how they pose a threat to the freedoms and liberties of our personal lives.

According to John Podesta, the terrorist attacks on 9/11 have started a "rapid reconsideration of the legal restrictions placed on law enforcement and the intelligence communities" (3). The new USA PATRIOT Act was signed by President George W. Bush and became operative on October 26, 2001. The PATRIOT Act consists of ten chapters and is basically a law that makes the work of the police and the intelligence agencies easier when hunting down suspected terrorists. Sounding like a good thing to do at first, the new law has turned out to be a great threat to the privacy rights of American citizens because, as Podesta has pointed out, "when we decide, however, to expand surveillance powers to track terrorists, all residents, not just the terrorists are affected" (3). The PATRIOT Act, despite introducing many innovations, has especially reduced the restrictions concerning surveillance. This affects in particular the so-called "Wiretapping," "Pen Register," "Trap and Trace" and "Search Warrants" (Pallasky 221).

Wiretapping describes the eavesdropping of every form of telecommunications by the police or the intelligence agencies. This includes email, cell phones and the conventional telephone network. Wiretapping is generally forbidden but there can be exceptions for the tracking of criminals or terrorists. Due to the PATRIOT Act, getting permission for Wiretapping was made much easier (221-22). Podesta states that " $[\mathrm{i}] \mathrm{t}$ is conceivable that all the pay phones in an entire neighborhood could be trapped if suspected terrorists happened to be in that neighborhood" (4). This means that now nearly everybody can be targeted by Wiretapping if there is only the slightest suspicion that the he or she could pose a threat to national security (Pallasky 221-22).

Pen Register and Trap and Trace describe the tracking of dialed numbers and the ensuing localization of the called phone. This possibility to track people was already there before the PATRIOT Act, but it was restricted to the conventional telephone network. Now, also cell phones, the access to internet sites, and emails can be tracked (222-23).

Search Warrants are permissions a judge or a court give to the police so that they can search private apartments or houses. Before the PATRIOT Act this was one of the last possibilities of the agencies to captivate a suspected criminal. Now, the permissions for a Search Warrant are much easier to obtain and there is even 
an addition to the old law. The so-called "Sneak and Peek Search Warrant" allows the agencies to search a house (and even seize items from the owner), and then leave without informing the owner that his/her house has been searched (223-24).

Especially this last modification of the law due to the PATRIOT Act shows how dramatically the privacy and the personal rights of every American are restricted. Now, the police or members of the intelligence agencies can tap telephone calls or emails, then track the person called and eventually search the house while the owner is away and without even informing him. Nobody knows if the gathered information about the suspected person is deleted when the government stops the investigations. Podesta points out possibilities of misuse:

[T] he government can learn a tremendous amount of information about you from where you shop to what you read to who your friends are through the use of so-called transactional records. The potential for abuse, for invasion of privacy, and for profiling citizens is high. (3)

This high potential for abuse is also visible in the adaptation of the PATRIOT Act by other countries. Beth Elise Whitaker states that "[i]n some countries the adaptation of anti-terrorism laws has provided leaders with the tools they need to silence critics and punish political opponents" (1017). She further found out that "the more authoritarian a country, the more quickly it enacts anti-terrorism legislation" (1021) because it turned out to be a perfect tool to encounter unwanted thoughts or ideas in a country. This way, she continues, "leaders in China, Egypt, Eritrea, Malaysia, Russia and Syria, among others, have justified recent crackdowns on political opponents as a necessary response to terrorist threats" (1028). In Zimbabwe, even journalists who merely wrote about political violence were labeled as terrorists (1028). This shows the abusive potential of new anti-terrorism laws like the PATRIOT Act. Authoritarian countries immediately seize the opportunity to establish such laws because they see the potential of the new laws to be used in domestic politics. They are an invitation for the police and the intelligence agencies to establish a system of repression and control over the citizens. This can pose a great threat to democracy and has to be watched very closely, especially by privacy activists and NGOs.

Another institution founded in the wake of $9 / 11$ that can possibly be abused by the government to manipulate and control its own people is the Department of Homeland Security (DHS). The department was created in the year 2002 and can be seen as a direct consequence of the terrorist attacks of 9/11. The new department was established as a combination of 22 agencies, which had operated separately before, and employs a total 179,000 people (Krauss 57). The intended function of this massive department was to gather experts from many different agencies at one location in order to make it easier to defend America from terrorist attacks. However, even during the creation of the new ministry, critics like Elishia L. Krauss asked "why do we feel that we need to create an enormous bu- 
reaucracy to meet our homeland security needs?" (57). As a matter of fact, the complexity of the DHS tasks is immense: it has to monitor " 5.7 million cargo containers and 600 million passengers on American aircraft every year" as well as to patrol "95,000 miles of coastline and 430 major airports" (57). Additionally, the department is now in charge of the preparation for and the prevention of terrorist attacks (57).

Krauss has also pointed out that the benefit of creating large bureaucratic agencies like the DHS is not really in making the country a safer place but in making the people think it is a safer place:

It seems the federal government has been spending more energy trying to make Americans feel safe by building up a bureaucratic organization for the future, rather than actually making America a safer place to live now. Establishing the agency itself creates a false sense of safety. There is a perception that something is being done and that America is more secure. (57-8)

According to Krauss and other critics, departments of the size of the DHS are highly inefficient and slow, and their only function is to calm the masses. Thus the DHS can be seen as a tool of state control over the people. The DHS even uses the so-called Homeland Security Advisory System (HSAS) to execute greater control. The HSAS is a color-coded alert system, based on the U.S. military's Defense Condition System, which is supposed to show America's protection from terrorist attacks (Shapiro/Cohen 127). There are five threat levels: low (green), guarded (blue), elevated (yellow), high (orange) and severe (red), which serve to predict the possibility and gravity of an attack (123). Yet, how these levels are set by the DHS remains unclear because there is no information as to what is required to raise the level to a certain color (124). Moreover, the descriptions of the threat conditions are misleading because everybody can interpret "low," "high" or "severe" differently (128).

There are several hints that the HSAS is used by the government in a manipulative way. In the years from 2002 to 2007, for example, the threat level never went below yellow, and was raised to orange eight times, even though none of these "high risks" was followed by a terrorist attack (126). Another action that caused distrust in the system occurred in the year 2003. Jacob N. Shapiro and Dara Kay Cohen state:

With the United States on the brink of war with Iraq in February 2003, the George W. Bush administration chose to reduce the threat level from orange to yellow so that it could raise the threat level once the war began. The decision was intended to avoid having to go to red alert. (128)

Although critics have pointed out that the system was used as a tool for domestic policy by President Bush, a rise of the threat level bound the media's attention to the possibility of a terrorist attack and during the election period the Presi- 
dent's approval ratings increased significantly following warnings about terrorism (130). It is not hard to see the possibilities of misuse of the HSAS by the government and the DHS. It can be used to control the media and to control the people by toying with their fears of a terrorist attack. These possibilities of political misuse have eventually led to a deep distrust in the American population and the system's complete marginalization (121-22).

In the next part of this chapter, I will compare my examples of state control in the United States with the techniques shown in the movie Minority Report. In my analysis, I will focus on similarities and differences and raise the question whether Minority Report can and should be read as a social critique.

\section{Minority Report: Social Criticism?}

The movie Minority Report reflects on many aspects of our present-day society. In the movie, the eyes give access to personal data and there is nothing that can be done except exchanging one's eyeballs for new ones. In our society, the Internet is our eye to the world and this eye is scanned, too. We also have little influence on what happens to our data. The companies profile us, overflow us with personalized commercials and if we do not buy anything, they sell our dataset to another enterprise. Though our retinas are not scanned yet, we have no influence on who knows what about us and how this knowledge is used.

Furthermore, the PATRIOT Act with its "wiretapping" and "sneak and peek" tactics is already present in Minority Report. The government profiles citizens and targets everybody in the name of anti-terrorist legislation. In the movie, nobody has insight into which knowledge is collected about him via retina scanning or the visions of the Pre-Cogs, but neither do we have insight into the records kept by the government - possibly for years. The government in Minority Report uses the people's fear of murder and crime to establish the Pre-Crime system - a system that, as I have argued earlier, is highly authoritarian and has many possibilities of misuse. It even made the people to accept an inhuman prison system like the PreCrime prisons. The state is successful in creating a utopia, i.e. a state without crime, by removing the unwanted elements, namely the criminals (Atkinson 12). I would suggest that the same is happening in our own society: American prisons contain people of whom the government thinks that they are likely to commit future crimes (Friedman). Furthermore, laws like the PATRIOT Act have the potential to eliminate unwanted elements - i.e. critics, dissidents or people leading an unpopular lifestyle. This can be observed in authoritarian countries where the law has been rapidly adopted. Like the police chase and the spiders in the movie, our own society knows hardly any privacy anymore. Everybody becomes transparent before the law - through data, registers, and telecommunications. Even houses can be searched, properties be seized, and the owner is likely to not even notice it. 
Institutions like the Department of Homeland Security and its tool the Homeland Security Advisory System are foreshadowed in Minority Report in the form of the Pre-Crime system. The DHS gives the people the feeling that the government is active. The HSAS is used by the government as a tool of domestic policy that toys with the citizens' fear of terrorism and sidetracks the attention of the mass media. The same "false sense of safety" (Krauss 58) is created in the movie Minority Report by the Pre-Crime system. The people think the visions of the Pre-Cogs are infallible not knowing that there can be "minority reports" and that especially the Pre-Cops are likely to miss something, so that there is still the possibility of murder.

Considering the tremendous similarities between the world presented in Minority Report and the present, I think that the movie is meant as a social criticism. Minority Report is not set far in the future and therefore facilitates seeing parallels to our present-day society. The movie shows us what can happen if we do not question the ambitions of the governments to gain a greater control over our lives and to see through tactics of the state or the mass media, which are often trying to persuade us to give up parts of our freedoms and our privacy for a greater public security. Private choice does always contain the possibility of making the wrong choice - to choose wrongly does not mean that we have to eliminate the choice at all (Mann 201).

Minority Report, then, is a social criticism and a warning for us that "uncritically trusting in any system whatsoever inevitably leads to disastrous consequences" (Friedman). According to Friedman, the movie encourages us to question actions of our governments which confine our liberties because scepticism is the only safeguard that we have against human frailty and desire. Minority Report exemplifies this by showing that doctrinaire conviction in a system creates oppression and not freedom. Or, as Lester D. Friedman aptly puts it:

[T] he surrender of our liberties in a quest for security is seen as far too high a price to pay. Ultimately, then, Minority Report warns us that, even during times of wide-spread public anxiety [like our current fear of terrorism], the motto of the Pre-Crime unit - 'That Which Keeps Us Safe Also Keeps Us Free' - must be reversed: that which keeps us free also keeps us safe. 


\section{Works Cited}

Atkinson, Paul. "The Visualization of Utopia in Recent Science Fiction Film." Colloquy: Text Theory Critique 14 (2007): 5-20. Print.

Bakewell, Geoff. "The One-Eyed Man Is King: Oedipal Vision in Minority Report." Arethusa 41.1 (2008): 95-112. Print.

Friedman, Lester D. “Minority Report. A Dystopic Vision.” Senses of Cinema 27 (Jul.-Aug. 2003): n. pag. Web. 19 Mar. 2009. < http://archive.sensesofcinema.com/contents /03/27/minority_report.html>

Krauss, Elishia L. "What the Department of Homeland Security Won't Do." The Public Manager 32.1 (2003): 57-58. Print.

Mann, Karen B. 'Lost Boys and Girls in Spielberg's Minority Report.” Journal of Narrative Theory 35.2 (2005): 196-217. Print.

Minority Report. Dir. Steven Spielberg. Perf. Tom Cruise, Colin Farrell, Samantha Morton. 20th Century Fox and DreamWorks, 2002. DVD.

Pallasky, Angsar. "USA PATRIOT Act: Neues Recht der TK-Überwachung." Datenschutz und Datensicherheit Vol. 26, No. 4 (2002): 221-25. Print.

Podesta, John. "USA Patriot Act: The Good, the Bad, and the Sunset." Human Rights Magazine 29.3 (2002): 3-7. Web. 22 Sep. 2009. <http://www.abanet.org/irr/hr/ winter02/podesta.html>

Shapiro, Jacob N. and Dara Kay Cohen. "Color Bind: Lessons from the Failed Homeland Security Advisory System.” International Security 32.2 (2007): 121-54. Print.

Sutton, Brian. "Sophocles's Oedipus the King and Spielberg's Minority Report." The Explicicator 63.4 (2005): 194-97. Print.

Whitaker, Beth Elise. "Exporting the Patriot Act? Democracy and the 'war on terror' in the Third World." Third World Quaterly 28.5 (2007): 1017-32. Print. 

Moritz Emmelmann

\section{Religion in Soylent Green}

Based on Harry Harrison's dystopian novel Make Room! Make Room! (1966), Richard Fleischer's Soylent Green (1973) is set in New York in the year 2022. As police officer Robert Thorn and his roommate Solomon (Sol) Roth investigate the assassination of William R. Simonson, an executive of the world's largest food corporation "Soylent," they gradually unveil a much larger criminal plot. Although Thorn fails to retain information from a priest to whom Simonson had confessed shortly before his death, Sol acquires classified information revealing that the widely consumed food surrogate Soylent Green is made from dead people. Sol reacts to this revelation by ending his life in a semi-religious euthanasia facility, while Thorn decides to continue his investigations. He follows a corpse transport, finds proof for his theory and, badly wounded by contract killer Tab Fielding, manages to inform his chief officer of the scandal at the end of the film.

The living conditions in the world of Soylent Green are characterized by massive overpopulation, environmental destruction and extensive crime. The fictional New York of 2022 is chronically underserved with respect to food, housing, sanitation and electricity. Its inhabitants have to face corruption, police brutality and the unrivalled monopoly of the Soylent Corporation that fixes prices and produces food from its deceased customers. These outrageous circumstances are a call to arms for helpers of the "poor and orphaned" (Psalms 10,14). When learning that 
the food substitute Soylent Green is made from the dead, the Christian Church, with the priest as its representative, becomes involved in the film's central conflict. This dramatic situation provides a test case for the church's charitable and moral ambitions. The conduct within the ambit of the church, which extends to the church building and its members, differs starkly from the procedures in the outside world, which is controlled by the government and the Soylent Corporation. In fact, it creates the impression of a religious sphere with an inside that acts as a sanctuary opposing the moral decay in the society shown in the film. By these means, the film draws attention towards the depiction of religion and especially of the Christian Church.

Few works have been published on Robert Fleischer's 1973 film Soylent Green and none of them have discussed the topic of religion in great detail. When the film receives scholarly attention - usually in the context of more encompassing studies on science fiction film - religion is typically featured as one component among many. Furthermore, analyses of Soylent Green vary considerably: They provide a number of conclusive readings, yet generally neglect to consider the film as a piece of art in its own right. In Screening Space: The American Science Fiction Film, Vivian Sobchack, for example, has provided a short discussion of the filmic devices in Soylent Green in which she focuses solely on how the dystopian film communicates the people's alienation from nature and their dehumanization (131-32). The film's final revelation that "Soylent Green ... is ... PEOPLE!," on the other hand, serves as the title and guiding metaphor of Ronnie D. Lipschutz's article on "Labour, Bodies and Capital in the Global Political Economy." In his assessment of our present-day economy, Lipschutz links fact and fiction by arguing that the horrible cycle Soylent Green envisions for future food production and consumption can already be detected on today's labor markets where the laboring body is constantly consumed and recreated (573-76). Finally, Pat Bereton briefly reviews the film as one example of her larger survey on the theme of ecology in the American cinema, and points out an exceptional explicitness of both the film's environmental dystopia and a utopian alternative of pastoral harmony. She aptly calls the latter a vision of "(post)secular spiritualism" and mentions in a footnote that main actor Charlton Heston appeared repeatedly in stories of biblical or spiritual content (169-70). The widespread neglect of instances of religion, then, is all the more surprising as religious elements, characters and institutions occupy central positions in the film and together provide much material for interpretation. Numerous interrelations created through means of plot development, symbolism and contrast form a thoroughly crafted discourse that deserves consideration in the evaluation of the film.

In this chapter, I will show that in the context of an extreme social, economic and moral crisis, Soylent Green presents the Christian Church as a charitable institution offering both spiritual leadership and moral integrity. Regardless of its limited factual capacities, hope for positive change centers on the efforts and services of 
the church. Certainly, my background as a student of theology helped me to develop interest in this specific aspect. Nevertheless, this chapter is not meant as a theological review of the film, but as a film analysis that focuses on the religious elements in Soylent Green. ${ }^{1}$

\section{Instances of Religion}

The fictional world of Soylent Green is not dominated by religion, not ruled by religious leaders and not characterized by spirituality. And yet, a number of peculiar incidents, comments and character relationships draw attention to its religious dimension, adding a number of subtle yet dramatic linkages between the morally corroded reality of Soylent Green and religious practices and traditions. The religions featured in the film are Judaism and the Roman Catholic denomination of Christianity. Even though the society portrayed appears to be very multicultural, there are no instances of other world religions. However, we do find an important third party to the spiritual world of Soylent Green: a fictional, semi-religious death cult that is located around euthanasia facilities maintained by the ever-present Soylent Corporation. This cult incorporates certain elements of both Judaism and Christianity within a heathenish ritual, but it never abandons its central theme and purpose of assisting in suicide.

I will now turn to a more detailed analysis of those instances in the film in which religions play a role. With this, I seek firstly to gain access to the religious discourse in the film and secondly to evaluate the religions' respective functions.

\section{Judaism}

The representative of Judaism in Soylent Green is the old man Solomon Roth. His affiliation to the Jewish religion first becomes clear shortly before the dinner scene, when he says the Hebrew toast "Le Chaim" before drinking the whiskey that his friend Robert Thorn has brought home. Also, his first name is not an unusual one for a man with Jewish ancestors. In the biblical tradition, Solomon is the name of one of the great kings of Israel. His regency is said to have been a time of peace and prosperity as well as political stability. Under his successor, the unity of the twelve tribes was lost and the faith in Jahveh deteriorated (2 Chronicles 9 18-27; 12). Solomon Roth makes no specific comments about his religious beliefs and does not appear to practice his religion in terms of prayer, service attendance or study of the scripture. He frequently makes exclamations like "Oh God"

\footnotetext{
This paper was written in the context of a seminar titled "Of Body Snatchers and Cyberpunks" at the University of Göttingen in the summer term of 2009, held by Kathleen Loock. Its content, structure and mode of argumentation have been both developed and criticized throughout the course and therefore owe credit to the participants of the course and the teaching staff.
} 
and at one point tells Thorn to "go with God," which seems to be a habit or a tradition rather than a calling upon God or a blessing. In this context, it is very remarkable how he comes to undergo the death ritual of the euthanasia cult. As he once more exclaims "Oh God" upon the shocking discovery that Soylent Green is made from the dead, the head of the information exchange takes him by his word and eerily poses the question: "What God, Mr. Roth? Where will we find him?" In the face of his devastating knowledge, this question becomes relevant to Solomon and he answers: "Perhaps at home. Yes, at home." The expression "at home" refers to voluntary execution in a euthanasia facility and indicates that Roth is able to project his personal spirituality onto the ritual of the euthanasia cult, although the latter does not relate itself to the Jewish God in any way. Rather the cult serves as the projection surface for individual religious longings. This becomes clear in the scene following Roth's resolution to go home, in which we see him walking through a dark and empty street towards the brightly illuminated euthanasia facility. Its basic features of light, warmth and cleanliness as well as the video show of nature scenes, impressive lighting and music during the dying ceremony allow people to have a spiritual experience regardless of their actual religious background. In Solomon's case this apparently bridges the discrepancy between the ritual and the Jewish law forbidding murder and suicide.

As Roth is the only representative of the Jewish religion in the film, it is licit to draw conclusions from his attitude towards Judaism about the film's portrayal of it in general. The religion's chief function here is to serve as a hoard of tradition and as a connector to a better past. Therefore, the film does not portray Jewish practices or sacred buildings, but instead associates it with books, knowledge and narration. For example, Solomon himself is referred to as "the book" because of his job as police assistant and the center of his professional life is the "exchange" that resides in the public library. Roth's first name relates to a grand past and so do the stories he tells Thorn of a better time before the age of Soylent. In a very literal sense, Judaism is portrayed in the film as a religion of the book, which corresponds with its focus on religious documents and the command to pass on knowledge as given in the Jewish creed "Shema Yisrael" (Deuteronomy 6, 4-9).

\section{Christianity}

In Soylent Green, instances of Christianity are present in the form of utterances, characters, rituals and specific localities. Such connections are remarkably numerous and call for a serious consideration of the religion's role and function in the film.

The church building is one example of the church's involvement in the conflict over secrecy or publication of the fact that Soylent Green is made from corpses. It is host to a number of scenes including parts of the investigation and the final battle between hero Robert Thorn and his antagonist Tab Fielding. This 
repeated use of the building as a setting may be read to indicate an understanding of the church as a relevant factor in moral issues. The church's counterpart is a euthanasia facility, which forms the religious center of the euthanasia cult and therefore may also be described as a temple. However, their purposes are altogether different: The church provides housing and some medical care - the facility is the site of mass homicide. It is also noteworthy that the film shows no Jewish synagogue and gives no explanation for this gap. In my opinion, speculations on this topic have no basis in fact and run the risk of inappropriately transferring historic events to a work of fiction.

Another instance of Christianity is the church personnel, represented by an African American priest named Paul. The very engagé clergyman heads the church's charitable activities and becomes intertwined with Thorn's investigation when the Soylent Green manager William Simonson confesses that his company's products are not harvested from the ocean as the public is told, but in truth are made from the dead. With the priest gaining the same knowledge as Simonson - and later on Solomon and Thorn - the church joins the small group of people who know the secret of Soylent Green. Because of this entanglement via its very own practice of confession, the church is forced to react. Upon learning about the production of Soylent food, the church neither takes the initiative like Thorn, nor is it forced into resignation like Solomon. The church's resolution is to continue its service to the poor and sick, although it is questionable whether the priest will be able to fulfill his duties effectively in the future. This reaction is bound to be compared with that of other characters as the viewer's attention turns towards the moral assessment of different ways of dealing with the most appalling truth: that, in the words of Robert Thorn, "Soylent Green is people."

Christian rites and traditions are also present with some of the minor characters, hinting at some awareness of a Christian heritage in the society of Soylent Green. Simonson, apprehending his near assassination, confesses to the priest. Simonson's former concubine later expresses her regret at the lack of a traditional funeral for him, which indicates that she is still familiar with the religious dimension death used to have in former times. Furthermore, the homeless masses sheltered within the church make frequent use of the offer of confession. This sign of religious earnestness is probably caused by the danger of death that is present throughout the film and might occur at any time due to disease, malnutrition or the violent environment. These examples show a strong association of the church with rites and ceremonial actions as well as a general understanding of the church as something not quite obsolete but rather traditional. At the same time, the use of the church building as setting for important scenes denotes its significance for the events. 


\section{Euthanasia Cult}

A third religious element in the film is a death cult involving the euthanasia of people seeking to escape life in the world of Soylent Green. In a ceremony reminiscent of heathenish rituals, these people are placed on a stretcher, given a toxic drink and then granted a video show of nature scenes accompanied by music and special lighting. This procedure results in the death of the person, after which the corpse is quickly removed from the ceremonial room and then brought to factory grounds to be processed into Soylent Green.

On a spiritual level, this cult centers around the notion of "going home," meaning the act of voluntary execution. While there is no further theological or esoteric foundation to this idea in the film, the existence of a place called "home" seems to be a common thought. No certain destination or spiritual goal is announced in order to promote "going home." The devastating living conditions evidently are enough to create escapist longings in vast parts of the general public. Strikingly, the conditions of the procedure - no pain, a twenty-minute video show with shots of nature scenes and a choice of music - are widely known and hardly need to be mentioned again in the facility itself. Because no applicant for "going home" lives to tell others about the ritual, it can be reasoned that there must be some form of advertising to inform people about the procedure. Solomon Roth's comment "I should have gone home long ago" may be read to imply that suicide had already been suggested to him earlier, maybe at a certain age or with the decline of his working power.

The "priests" of this cult are employees dressed in long white gowns who act with great dignity and thereby create the impression of actual religious procedures taking place. They are the most important factor in making euthanasia appear as something religious and represent the facilities to the public. This lets me conclude that the creators of the cult - probably executives of the Soylent Corporation or of the government - seek to quench the religious thirst of people with these ceremonies. Since they are the representatives of this governmental institution for the public, it is reasonable to conclude that the society leaders in Soylent Green seek to quench the religious thirst of people with these ceremonies. Should there really be other motives besides economic interest for maintaining the facilities, this would point at a competition between the religions. However, I believe my earlier observation that the cult acts as a projection surface for individual religious feelings points away from a direct competition and towards a function as an outlet for spiritual wants. Instead of proposing a certain belief system of its own, the euthanasia cult lends itself to a diverse set of religious ideas. As the operators of the cult are the only authority with the power to grant people to "go home," they are in control of yet another instrument of power. Since their work directly assists the production of Soylent, we can assume they belong to the Soylent Corporation and receive payment and supplies from corporate funds. Nevertheless, they certainly do not know what becomes of the dead bodies. The Soylent facto- 
ries are heavily guarded and even the drivers of the garbage trucks are exchanged at the gates. Because, as Robert Thorn tells us, work on the so-called waste disposal plants is a sentence for life, no word of the conversion of corpses into food reaches the outside world.

Throughout the film, we see that power resides with those who have work and who can thus afford access to resources like room, food and other basic commodities. The poor are generally treated cruelly and contemptuously as illustrated by the practice of "scooping" them into trucks to end riots. Power is frequently accompanied by corruption and nepotism, for example in the police department or within the board of the Soylent Corporation.

The buildings that house the euthanasia cult are very modern, clean and spacious and are open to the public. In stark contrast to the general treatment of people by the government and the Soylent Corporation, officials here are very friendly and courteous. This certainly helps to attract new victims, but it also sheds light on a hypocritical and sinister attitude towards people. The sequence of scenes displaying Solomon's death in the euthanasia facility reveals how, instead of bringing salvation, the ceremony plays a fatal trick on the poor. Most obviously, the ceremonial rooms are called "theaters," indicating that the ritual is understood as an enactment. During the video show, the buoyant music takes away the gravity of the moment and the intense orange light lends Solomon a healthy complexion. However, before the last note has faded away, the lighting abruptly changes back to standard and an extreme close-up forces the viewer to look at Solomon's dead face in all its bluntness. This shows that the warmth and dignity of this scene is a masquerade disguising the cruelty of the procedure. As far as can be judged from the information given in the film, the euthanasia cult is very popular and attracts people from various religious backgrounds.

\section{The Depiction of the Christian Church}

As I have shown, the three groups in the religious world of Soylent Green have differing human and institutional representatives and unequal levels of popularity. The fictional euthanasia cult deserved special attention in the description above and, a corporate or governmental institution is assumedly the largest religious unit among the three. Nevertheless, I believe the Christian Church serves an even more complex function in the film's moral discourse. I will therefore proceed to further examine and interpret its depiction in the film, bearing in mind the context of a social, economic and moral crisis. My argument is that the Christian Church acts as the lone practitioner of long abandoned virtues such as altruism and magnanimity and provides helpful, if not vital services under the hostile circumstances. The evidence for this outstanding position among the institutions and characters can be grouped into three central functions fulfilled by church and clergymen: charitable actions, spiritual leadership and defense of morality. 


\section{Charity}

Given the city's massive overcrowding and lack of food supply, the necessity of help is obvious. This causes the church in Fleischer's Soylent Green to react in a very direct way. The church building itself becomes a refuge for masses of homeless, poor and sick people. In various scenes the viewer can observe the altruistic work of a number of nuns and the priest. They nurse the sick, set up and repair beds and continue to accommodate newly arrived people seeking help. At one point, Thorn finds an orphaned child and quite naturally takes it to the church for care. Apparently it is known to offer reliable support for those in danger.

A further characteristic of the church in this context is its lack of security devices and guards. The doors are unlocked, open to anyone wishing to enter, as there are no contracts to be negotiated and no payments to be made. This forms a sharp contrast to other scenes, in which we see for example the house entrance of Robert Thorn guarded by an armed watchman, who sends away people longing to sleep on the already crowded staircase. Such details underline the importance of charitable action and draw attention to the difference in attitude between the general public and the church. While accessibility is also a characteristic of the euthanasia facilities, these require an application and are of course interested in profiting from their clients rather than serving them. When Robert Thorn first visits the church to speak with the priest, he steps into a crowded, messy room with clouds of haze drifting through the air. By contrast, the euthanasia facilities are particularly spacious, clean and have a pleasant odor, which causes Solomon Roth to take a deep breath when stepping inside. All of this exemplifies that the material offers of the cult surpass those of the church by far. However, one must keep in mind that the church's offering is life sustaining while the cult's is life destroying.

Furthermore, the priest Paul is presented as a highly engagé, even altruistic laborer - working until mental and physical exhaustion. The knowledge of the true ingredients of Soylent Green, in his own words, "is killing" him and it truly does when Tab Fielding sneaks into the confessional to shoot him. This illustrates how the priest dedicates his work, health and his life to the cause of charity. The actions of both church and clergy appear as positive, commendable examples of reacting to the dramatic social circumstances. It must be acknowledged, however, that regardless of the considerable efforts described above, the church is not capable of vanquishing the social hardship of the Soylent Green society in its entirety. This is illustrated on a filmic level by the weariness of the priest, which intensifies to a near paralysis after he finds out the truth about Soylent Green. Also the small number of church workers in relation to the millions of homeless and unemployed people allows no other conclusion than a failure of the church to effect extensive change. But at the same time, the church's actions are singular in the world of Soylent Green. Nowhere else do the poor encounter genuine compassion, ingenuous amicability and unconditional readiness to help. As we can also see from the portrayal of Robert Thorn's investigations, the film is more interested in 
effort, commitment and perseverance than in the factual results of the struggle against injustice and immorality. Thus, the value of the church's actions and its moral integrity is not diminished by the irrefutable incapacity to overcome the unrighteousness present in the Soylent Green society.

\section{Spiritual Leadership}

But the agent of Christianity does not exhaust itself with practical help alone. The Roman Catholic Church in Soylent Green also takes the role of spiritual leadership for its members and guests, which is made most explicit by the administering of Catholic sacraments.

The sacrament of confession initiates the priest's involvement in Thorn's investigation and later provides the setting for his assassination. In this particular scene, long lines of people have formed in front of the confessional, showing that the act is nothing unusual and widely appreciated. The means of camera movements and shot selection employed in this sequence shed light on the effects of the difficult working conditions of the priest. Beginning with a panning medium shot that captures the amount of people waiting, the short scene continues with a shot inside the confessional. In contrast to the noise and the voices accompanying the first shot, the audio line to these pictures only contains Fielding's voice and the report of his gun. The camera is now absolutely stationary, conveying only Fielding's movement and the motionless priest in a close-up shot on eye-level. This selection of filmic devices emphasizes how the minister is almost paralyzed by his work, which he tries to pursue with great dedication. We must also take into account that confession is not simply a means of small talk or personal relief for the believer, but a religious necessity for absolution. Since the priest is the only one able to accept a confession, his role as a spiritual leader is eminent even in spite of the unsoundness of his mental and physical health.

For that matter, the priest himself is evidence of another sacrament, namely the ordination. This special kind of blessing is endowed by the spiritual authority of the church and enables him to effectively administer sacraments. His presence therefore hints at a higher, functioning ecclesiastic authority.

A sacrament that is not directly present in the film is communion. There is no celebration of communion and none of the characters mention it directly. It is reasonable to believe that communion cannot take place in the world of Soylent Green, because of the horrendous price of bread and wine. But perhaps featuring communion in this film was avoided purposefully since it might mock Christian beliefs and thus compromise the generally positive depiction of Christianity. In a world in which people eat food made from the dead everyday, the somewhat similar procedure of communion would be hardly bearable. As if to close this gap in the set of religious rituals, the euthanasia procedure involves a perverted version of communion. The priest-like executioners hand the poison to the Jew Solomon 
Roth in a large goblet, much like the ones used in Mass. It remains unclear whether the theological implications of this are meant to suggest a conflict between Judaism and Christianity, or whether they are just a side effect of the imitative elements in the cult.

\section{Stronghold of Morality}

In view of the dysfunctional society of Soylent Green and in opposition to the barbaric business scheme of the corporation, the church becomes a veritable stronghold of morality. I have chosen this admittedly strong expression, because the idea of defense and safekeeping inherent in the word "stronghold" is similar to the institution's function in the film. The priest and his affiliates do not attack or openly confront the moral failures surrounding them, but rather act as a refuge to those in difficulties and provide a moral safe-haven.

Most tellingly, the church is repeatedly presented as a trustworthy place where moral issues are concerned. Soylent manager Simonson, seeking to relieve himself of his knowledge about the food substitute and to come to terms with his immoral deeds in the past, turns to the church. In his desperation for moral righteousness, this is the place where he wants to go to even at the cost of his life. In the eyes of this defector, the church is the institution that is the farthest away from the debauched corporation. At the same time, it is open and accessible.

Another detail supporting the claim that the church is a stronghold is the use of the church building as the setting for the final battle between Thorn and Fielding. After the wounded Thorn has escaped from the Soylent factory into the church, the crowd within gives him coverage and he is finally able to decide the fight in his favor. As it is a battle between truth and lie, between morality and immorality, this choice of location is significant. It indicates that the building is home ground to the hero and a helpful ally against his opponents. Again, the church has a considerable impact on the course of events. While it remains unclear whether Thorn's investigations are going to provoke profound changes, he has done everything in his power to contribute to a good cause. This is exactly what the priest and the church are doing as well and it shows an attitude of persistent courage, which is most benevolently portrayed by the makers of Soylent Green.

\section{Criticism}

Following the presentation of my paper in the seminar and at the undergraduate conference in June and July of 2009, fellow students stated some criticism. It mainly concerned the question of whether or not to consider the activities of the priest and the church as lasting accomplishments and thus arrive at a positive reading of their depiction - as this chapter claims. Arguments brought up against 
this reading are the limited effects on society in general, and an understanding of the priest's exhaustion as incompetence. I appreciate these remarks and recognize that they do form a legitimate interpretation. Yet the outstanding position of the Christian Church and its representatives in the context of multiple crises is so strongly emphasized that it is able to refute the counter-arguments. The depiction of the priest, the church and even Robert Thorn is based on a simple and plausible conclusion: The scale of the challenge does not compromise the value of moral behavior and altruistic help.

\section{Conclusion}

In view of the scarce amount of works published on the film Soylent Green, every paper on this film requires some initiative to begin and investigate a certain topic. In this case, the opening observation was the frequent appearance of religious elements throughout the film. Analyzing and describing the instances of Judaism, Christianity and a fictional euthanasia cult in the story, my attention then turned towards the depiction of the Christian Church. There, I paid special attention to the critical circumstances of social, economic and moral downfall under which it makes its efforts. The thesis tested here stated that it occupies leading positions on the fields of charity, spirituality and morality. Various instances of such depiction found on the levels of plot and scenic realization supported this reading, for example, the reliance of multiple characters on the church in moral issues or the choice of the church building for the final battle. The sum of these arguments outweighs remarks that are critical of such a reading of the film and opens up new questions concerning the relations between the different religious groups. With my argumentation, I hope to have shown the relevance of religious institutions for the film and to have sharpened the perception of the moral and religious discourse. 


\section{Works Cited}

Bereton, Pat. Hollywood Utopia: Ecology in Contemporary American Cinema. Bristol: Intellect, 2005. Print.

Evangelische Kirche in Deutschland, ed. Die Bibel: Nach der Übersetzung Martin Luthers. Stuttgart: Deutsche Bibelgesellschaft, 2001. Print.

Harrison, Harry. Make Room! Make Room! 1966. New York: Tom Doherty Associates, 2008. Print.

Lipschutz, Ronnie D. “'Soylent Green ... is ... PEOPLE!': Labour, Bodies and Capital in the Global Political Economy." Millenium 34 (2005). 573-76. Print.

Sobchack, Vivian. Screening Space: The American Science Fiction Film. New Brunswick, NY/London: Rutgers UP, 1999. Print.

Soylent Green. Dir. Richard Fleischer. Perf. Charlton Heston, Leigh Taylor-Young, and Edward G. Robinson. 1973. MGM, 2003. DVD. 


\section{Part III}

Themes and Motifs of Science Fiction Films 

Dennis Kogel/Iris Schäfer

\section{The Doppelgänger Motif in Science Fiction Film}

\section{Introduction}

When the word doppelgänger appears in science fiction or fantasy it tends to denote a creature, whether alien or demon, that can take on the shape of another person, usually to achieve an evil end. However, the concept of the doppelgänger in science fiction is not at all limited to these creatures. Derived from the Gothic double, the doppelgänger has been a part of science fiction since its very inception and has developed into several recurring motifs, such as clones, robots, virtual avatars or parallel selves, that can be found throughout science fiction film. John Herdman defines the doppelgänger as:

a second self, or alter ego, which appears as a distinct and separate being apprehensible by the physical senses (or at least, by some of them), but exists in a dependent relation to the original. By 'dependent' we do not mean 'subordinate', for often the double comes to dominate, control and usurp the functions of the subject; but rather that, qua double, it has its raison d'être in its relation to the original. Often, but not always, the subject and his double are physically similar, often to the point of absolute identity. (Herdmann 14) 
Unquestioningly, the doppelgänger motif is an important theme appearing in many literary and scientific works from Socrates and Plato to the German Schauerroman and psychoanalysis. Even today many stories and movies are centered around pairs of contrasting or complementing figures (e.g. Palahniuk's/Fincher's Fightclub), often subtly presenting variations on the doppelgänger motif as introduced by Jean-Paul Richter and E.T.A. Hoffmann. The discourse surrounding the double in literature and film, though, is mostly concerned with its use in Gothic literature and modern adaptations, where it mainly serves to portray the dualism of the self. However, one of the earliest works of science fiction is also considered a Gothic classic: Mary Shelley's Frankenstein. ${ }^{1}$ In it a young scientist named Victor Frankenstein creates a monstrous creature out of spare human parts, brings it to life and is haunted by it. The story introduces the Gothic doppelgänger into science fiction in the shape of the relationship between Victor Frankenstein and its creation, who appear to mirror each other's actions. Therefore it is important to examine the doppelgänger not only as a motif of nineteenth-century Gothic literature, but also as a motif inherent in science fiction.

Although today science fiction has its place as an important social and scientific commentary, it first became mainstreamed through mass publication and without the respect of critics. ${ }^{2}$ The equivalent of science fiction pulp novels of the past are today's blockbuster films and series aimed at commercial success. Within these genres, certain thematic conventions concerning the doppelgänger motif have been established through commercial or critical success. Frank Dietz identifies three so-called "stages" of the Double in science fiction: the "mechanical doppelgänger" (the double in the purest sense), the "allohistorical doppelgänger" (meaning parallel worlds or histories) and "wetware" (the dissolution of the self in digital form) (Dietz 209-210). But little has been said about the effect of the doppelgänger and its forms in science fiction film and series. We want to expand Dietz' three categories of doppelgänger (mechanical, allohistorical, virtual) to five distinct motifs used in film and serial TV (clones, artificial intelligence, time travel, parallel universes, virtual identities). By applying those motifs to films discussed in the 2009 Undergraduate Conference "Of Body Snatchers and Cyberpunks" such as Invasion of the Body Snatchers, Blade Runner or The Matrix as well as to films we consider key works for the doppelgänger motif in science fiction such as 12 Monkeys, Ghost in the Shell or the Star Trek series we hope to show how the idea of the self is both presented and challenged in contemporary film, how it relates to the

1 " $[\mathrm{M}]$ uch science-fiction criticism talks about the origins of SF in the nineteenth century ... [science-fiction author and critic] Brian Aldiss sees Mary Shelley's Frankenstein (1818) as the first SF text" (Roberts 48).

2 "Both [Jules] Verne and [H.G.] Wells were writing deliberately popular fiction and working within the traditions of popular publishing of their day ... In America, the popular market also dictated the beginnings of SF as a serious market. In particular, this is connected with the cheap magazine format known as 'Pulp"' (Roberts 67). 
challenges and issues of modern capitalism in an information society and what it tells us about the shifting values of human life and identity.

\section{Clones}

A clone is an exact genetic replica of a living creature that exists independently of its original and usually with an agency of its own. Due to the physical similarity and the resulting ability to easily and unnoticeably stand in for or replace the original, the human clone is one of the most obvious and formulaic manifestations of the double in science fiction. Because of the clone trope's focus on replacement, Dietz assigns clones as well as robots and AIs to his category of the "mechanical doppelgänger." He writes that

the mechanical doppelgänger usurps the role of the original self. This tradition of the mechanical double extends from Frankenstein to the numerous stories in which robots, androids, or clones attempt to replace humans. (209-10)

A single clone or a small number of them may often be a direct threat to the original's existence, either by planning to remove it or by demanding a share of the original's previously unquestioned identity. Science fiction plots with a limited number of clones show the most similarities with the Gothic doppelgänger as they usually involve a direct confrontation between the original and the usurper and question the validity of the original's identity. A single clone may also serve as a dark mirror to the original, reflecting only its negative attributes and thus creating a duality of the self. ${ }^{3}$ This motif is often found in Gothic stories.

An uncountable multitude of clones, of which the clone army in the Star Wars prequels is the most popular example, confronts not only the originals but humankind as a whole with the idea that human beings are just another massproducible commodity. In their number, mass-produced clones usually represent an expendable working class: The clones in Star $W$ ars are used exclusively as soldiers and are immediately replaced upon their death. Therefore, they are not encouraged to develop an identity of their own, and their identical bodies reflect their identical functions and absence of a self. For Dietz, the mass-produced clone depicts a society constructed around the idea of Taylorism.

3 See, for example, Jean-Luc Picard's “evil” clone in Star Trek: Nemesis (2002). 
Clones ... signify the ultimate triumph of mass production ... The clone ... represents the introduction of Talyorism to human reproduction. ... The notion of the original individual, still visible in the conflict between human and robot is now almost entirely lost. Duplication has resulted in anonymity. ... (Dietz 212)

A clone army or clone labor force does not only mirror the existing human working class and the struggle with corporate identity, but also reflects the fear of a devaluation and destruction of an "original" identity and the displacement of human workers in favor of mass-produced machinery.

The mere existence of clones as such raises the question to what extent a human being can be duplicated, i.e. to what extent the original's identity may be reproduced and which parts of its identity constitute the original. If a clone possesses the same body and the same hereditary traits, how can it be distinguishable from the original? Can the original prove its originality or the duplicate be unaware of the fact that it is a copy? The action movie The $6^{\text {th }}$ Day (2000) features a protagonist who tries to uncover a cloning conspiracy to eventually find out that he and not the assumed doppelgänger is the clone. But does the fact that he is a copy mean that he has no claim to the identity that he feels is his? The 6 th Day affirms the superiority of the original by letting the clone relinquish its claim, but at the end of the movie the clone nevertheless stands before the task of creating a new, original identity for itself. Its first step to achieve this is to put physical distance between itself and the original by taking off to Argentina, adopting the assumption that in order to create its own space it must not in any way come in contact with the original's space. Thus it appears that both the original and the copy have a need for an identity and existence unique to themselves - a conflict that can be resolved either violently or peacefully.

In the 1956 film Invasion of the Body Snatchers, the small-town doctor Miles Bennell returns from a medical conference to discover that the inhabitants of his town are being replaced by hollow duplicates originating from alien seedpods. While strictly speaking these duplicates are not clones because they do not share the original's DNA, they fulfill similar functions as the clone trope: both are indistinguishable copies of a human original. Like clones, the seedpods threaten the concept of identity as something secure and inalienable. In fact, they plan to erase all notions of identity and personhood. In this context, it is important to note that the film has been interpreted as both anti-communist and anti-McCarthyist. As Steven M. Sanders writes:

nobody has established whether Invasion is a protest against the political and social conformity called for by right-wing anti-Communists or that demanded by pro-Soviet collectivists ... . (59) 
Both communism and the corporate structure of capitalism as they were seen in the climate of the 1950s United States include the threat of identity loss and assimilation into a culture that consists of mere copies. As the body snatchers and the clone trope personify this attack on personhood, they can be understood as stand-ins for any ideology that is perceived as a threat in the same sense.

However, unlike the clones or the Gothic doppelgänger, the pod people simply want to do away with identity altogether. They neither question our understanding of the concept nor force us to redefine the term. Due to the film's adherence to a strict "us" versus "them" mentality, Invasion of the Body Snatchers defends the notion of identity as a stable unity even while the pod people seem to gain the upper hand. During the early stages of the invasion, Becky Driscoll's friend Wilma Lentz insists that her (already-snatched) Uncle Ira “isn't Uncle Ira." Despite the fact that he looks like him, acts like him and has the same memories, she has revealed him as a fake and could not be fooled to confuse him with her uncle. This suggests that even when all facets that constitute an identity have been copied, there can only be one "true" Uncle Ira that the copy can neither measure up to nor authentically replace. It can merely attempt to create a superficial illusion of being the same person. The only moment of genuine doubt occurs when Bennell finds a number of unfinished pod people in a greenhouse. When looking at the seedpod transforming into the body of his love interest Becky, he hesitates and cannot immediately bring himself to kill it. But when he passes Becky's pod to move on to a copy of himself, he immediately lifts the pitchfork he carries to destroy it. While there may be a surface confusion between a copy and another person, apparently no moment of confusion between the copy and the self arises: Bennell does not fear to hurt himself by destroying his seedpod. Even without the "happy ending" frame narrative 4 , the film would have a much more unifying message than most modern films working with the clone trope: you can either keep your identity or lose it but it cannot be torn into parts.

\section{Artificial Intelligence}

The concept and function of the AI in science fiction film is similar to that of the clone, but differs in significant ways. An AI or artificial intelligence is a humanlike machine, created for a certain purpose (e.g. service or warfare). AIs are usually built as a double of a specific human being (e.g. its inventor) or they are constructed with the idea of a human being in mind. Famous examples are AIs like the murderous HAL 9000 in 2001: A Space Odyssey, Data, the android who devel-

4 In the original cut of Body Snatchers, the film ends with a horrified Dr. Bennell standing on a highway shouting: "You're next!" As it was believed that such a bleak ending would be too disturbing for a contemporary audience, a frame narrative was added that shows a more hopeful possibility of Bennell escaping to the city and notifying the authorities (LaValley 125). 
ops feelings in the Star Trek: The New Generation series, the NS-5 robots struggling for equal rights in the blockbuster I, Robot based on the Asimov story of the same title, or the replicants in Blade Runner.

The common question in most science fiction stories centering around or involving AIs of various sorts is the examination of identity. What constitutes an identity? Is it the programmed function of the AI that determines all aspects of its existence, or is it possible to create an individual identity based on experience with the outer world? Through mass-production AIs become a new, mechanized working-class struggling - like clones - for an identity and a space of their own.

In contrast to the clone, however, the AI has no clear-cut original. It is not a doppelgänger of one person, but rather mirrors a concept of a person or a stereotype. The AI is, to use Baudrillard's terms, a "sign" of "real" humanity and in science fiction usually threatens to become its own "pure simulacrum" without an origin (Baudrillard 169). The replicants in Blade Runner are a good example: Pris is designed as a "pleasure model," Roy Batty for combat and Rachael as an assistant. They are what Herdman, borrowing a term from Joseph Frank, calls "quasidoubles":

Quasi-doubles come in various forms, but always have an unambiguously independent existence within the fictional scheme. Frank cites 'characters who exist in their own right, but reflect some internal aspect of another character in a strengthened form.' ... Quasi-doubles may also, however, be complementary opposites, whether Platonic soul-mates or, more often, characters whose unlikeness and contradictions reflect hostility and conflict, yet at the same time mutual dependence and interlocked destinies. ... Such characters are sometimes inaccurately referred to as 'mirror-images.' (14)

The "complementary" or "reflecting" attributes can also be found in the replicants of Blade Runner. Batty's combat prowess reveals Deckard's physical weakness, while Rachael's sensibility contrasts with his cold-heartedness. According to Dietz, androids and robots confront the viewer with concepts of "alienated labour" (211) and pose both "capitalist menace to mankind" and "socialist threat to the middle classes" (211). The struggle of the AI to be accepted as part of the society doubles the struggle of the working classes for equality and power. Or, as Dietz argues, "the robot as the worker represents the part of human experience excluded from the intergalactic and imperialists plots of space operas" (212).

Similar to the clone in science fiction narratives, films dealing with AIs seldom deal exclusively with the AI as a mass, but often incorporate the struggle of an individual machine to be recognized not as a copy, but an original. HAL 9000 claims individuality and differentiates itself from the identical HAL 9000 on Earth, and the replicants in Blade Runner strive to leave behind their predestined life as automatons with a brief lifespan and finally become "more human than human." Blade Runner not only shows androids fighting to emancipate themselves from 
their status as mere doubles of human beings, but also questions our distinction between human and artificial doppelgängers. Dietz states that "Deckard's job as a bounty hunter makes him become more detached and less emphatic, that is more what an android is supposed to be" (214). The supposedly human characters in Blade Runner seem less human than the replicants. Their status as those who are left behind on planet Earth further strengthens the impression that what is left of humanity on Earth is not what is associated with being human. At the end, when it is implied that Deckard might escape from the city with Rachael, and when he shows emotions towards her, there is even a possibility that he himself might be the last missing replicant. Blade Runner thereby blurs the lines between what we perceive as human or artificial, and it shows that our robot doubles might indeed become "more human" than ourselves and that the line dividing original identity from reproduced identity is arbitrary.

\section{Time Travel}

When time travel plots deal with a journey into the more or less recent past or near future, they become relevant for the doppelgänger motif, since this type of plot at the very least enables and usually involves a meeting between two or more different versions of a person. Unlike clones or AIs, these different selves all occupy a legitimate and uncontested position in their respective space-time frame. Neither can be seen as a copy of the other. Nevertheless, the time travelers create an equally significant contrast between each other as the clone or AI and its original. As the kind of contrast depends very much on the type of time traveling plot, the time travel doppelgänger can be used to address a wide range of themes. In respect to their depiction of the timeline, time travel stories can be divided into three basic types.

The first type treats time as a predetermined constant, where the past can be visited but the chain of events cannot be changed. While time travelers can take actions, they can only do so because they have already - albeit unknowingly taken them in the past of their own timeline. More so, usually their own actions in the past lead up to the events which make them travel through time in the first place, creating a causal time-loop that repeats itself infinitely.

This sort of story is called a time-loop paradox because cause and effect are not only reversed but put into a circle: the later events are caused by the earlier events, and the earlier by the later. (Penley 119)

In this deterministic timeline, doppelgängers meet one another at different stages in their lives, exhibiting contrasting attributes and thus exemplifying the effect of time and outer circumstances on the person. In the film Twelve Monkeys, the protagonist Cole is a little boy when he sees himself die as a grown man who has just failed to prevent the catastrophe that is about to take place. At that moment, Cole 
stands both at the beginning and the end of his own story. He is entirely ignorant and innocent, and at the same time the only person who knows exactly what is going to happen. While this appears to be contradictory, the two versions of Cole merely constitute two opposing poles in the span of his personal development. Their coexistence in this moment of time highlights the magnitude of this development, revealing that the same person can have opposing qualities through time.

Thus while from the objective perspective of external time it may appear that there are two different persons, when we focus on personal identity from the objective perspective of personal time, there is only one Cole, who happens to exist at a certain external point in time twice. (Devlin 109)

This moment is also the first and last time that Cole sees Kathryn Railly. This becomes important for their love story as Railly becomes aware of the younger Cole's presence and the fact that he is watching her kneel over the older Cole's his dying self's - body. For Railly, this moment becomes a farewell at the same time as it is a greeting. She mourns Cole's death at the end of their story, but when she notices the young Cole, she smiles at him in recognition, remembering what the dying Cole had said about seeing a woman at the airport before the viral outbreak. Cole thus becomes a double for Railly as well, since she now realizes that their story has ended and begun at the exact same time and that even though the Cole she knows is dying, his younger self will see her again. While time travelers in a deterministic time travel story will meet a doppelgänger who is a younger or older version of themselves, a time traveler in any of the other types of time traveling stories can only meet a doppelgänger that is not quite them and thus can only reflect what they are not but could have been.

In the second type of time travel plot the timeline is a highly vulnerable construct, so that any meddling with the past can create a completely new present and erase the old one. This concept is most famously realized in the Back to the Future series, where in the first film the protagonist Marty McFly travels to the past and threatens the likelihood of his own conception by accidentally making his mother fall in love with him instead of his father. Marty carries with him a photograph of himself and his siblings and the more unlikely their future becomes, the more translucent the people turn in the photograph. This type of story suggests that while there is only one timeline, its direction can be changed from any given point. Thus, when Jennifer meets her future self in Back to the Future II (1989) she only meets a possible version of herself, one that will never exist since Marty changes the direction of the timeline in the present. This type of story often features the intervention of dystopian future selves in the present in order to prevent their own existence. The doppelgänger here becomes a possible future version of a strongly contrasting present self, but one that is regarded as highly negative and thus must and wants to be prevented in favor of a preferred outcome. In the TV show Heroes 
(2006), for example, the character Hiro is visited by a future self that he must not become.

The third and last type we consider here is based on Hugh Everett's relative state or many-worlds interpretation, which claims that for every possible outcome there is a separate world in which this outcome takes place. For a time traveler this means that when he travels back in time he will arrive and make changes in a timeline parallel to his own. Paul J. Nahin describes it as follows:

According to this idea, if a time traveler journeys into the past and introduces a change (indeed, his very journey may be the change), then, as Gardner stated, reality splits into two versions, with one fork representing the result of the change and the other fork being the original reality before the change. (295)

Therefore a time traveler can make any possible changes without threatening his own existence because his original timeline has been split from the universe he now occupies from his first differentiating action onwards. When the time traveler meets his parallel self he may interact with it freely, quite unlike the predetermined interaction in the deterministic timeline or the possibly fatal interaction in the variable timeline. We can see this kind of unconcerned interaction between the two Spocks at the end of Star Trek (2009), where the older Spock, knowing his parallel self's potential but recognizing him as a separate individual, takes the role of an adviser to his younger counterpart.

\section{Parallel Universes}

In science fiction, time travel is not the only way to access a parallel universe. A time traveler like the older Spock in Star Trek may create a parallel universe through his changes in the past, but others, not from the past or future but from a parallel present, may visit it at any time after its creation. While Spock encounters a universe similar to his own, as the changes have only begun with his journey, a person traveling into this universe a hundred years later will likely encounter something that he does not recognize at all. Although according to the manyworlds interpretation, the universe splits "at every microinstant" (Nahin 295) and therefore causes an infinity of minimally different worlds, the parallel universes visited in science fiction are almost always extremely different from the "original" universe. Similar to the dystopian future self, the doppelgänger from a parallel universe shows us the potential for personal development that lies within us only that the dystopian future self has been altered by events that have taken place between its present and the present of the self it visits, while the parallel self has diverged from the "original" from birth onwards by being brought up in a different society and under different circumstances. Dietz states that "the allohistorical 
double liberates alternative selves repressed by the dominant society and personality. Allohistorical fiction deals with the question of what might have been" (214).

A particularly crass example of the doppelgänger from the parallel universe is the Star Trek franchise's mirror universe first introduced in The Original Series' episode "Mirror, Mirror" (1967). Star Trek's humanist utopia is met by a fascist dystopia in which each of the Star Trek characters occupies the exact same position (which is highly improbable but serves its purpose) but handles it with the cruelty and egotism that is encouraged by the mirror universe society. However, the characters are not the only ones who have duplicates in this parallel universe: every facet down to the crew's spaceship and their very mission has been duplicated and inverted, so much so that the mirror universe itself appears as a doppelgänger. Or to put it in Captain Kirk's words: "It's our Enterprise. But it isn't!" Both crews want the resources of the planet they are orbiting, but while the Federation crew attempts to find a peaceful solution, the Imperial crew threatens to annihilate the protesting natives.

In the episode "Mirror, Mirror," a landing crew consisting of Captain Kirk, Dr. McCoy, Uhura and Mr. Scott are exchanged with their mirror counterparts during their attempt to transport back to the ship and find themselves on the Imperial Enterprise instead. The scene of stepping over the threshold borrows much of its audiovisual effects from the Gothic with unnerving music and thunder and lightning (here caused by an ion storm) recalling the monster's creation in Frankenstein (1931). The image of the Enterprise in orbit flickers, interjected with green and red lights, before it is flipped around to represent the mirror universe. The spirit of the mirror universe itself recalls Dr. Jekyll's Mr. Hyde: it is impulsive, sadistic and sexually indulgent. Uhura's uniform becomes even more revealing in the mirror universe and she has to fight off the crude sexual advances of crewman Mr. Sulu. The conflict between the "civilized" Starfleet officers and their "barbarian" counterparts follows the Gothic dualism between good and evil or, in Freudian terms, superego and id, but instead of depicting that dualism in one split person, the use of a parallel universe allows this dualism to be portrayed through the interactions of several individually whole people.

However, even though both universes and the opposing personalities within them occupy valid positions in their own spaces, "Mirror, Mirror" negates the deconstruction of identity as a constant and a "true" versus "false" mentality in a parallel universe by letting the members of the "original" Star Trek universe gain superiority over the universe of the "other." Not only do the Starfleet crew members attempt to intervene in the Imperial plans according to their own standards and thus impose their values upon the foreign universe, but they also manage to convert the mirror version of Spock to their value system through argument:

Kirk: I submit to you that your empire is illogical, because it cannot endure. I submit you are illogical to be a willing part of it.

Spock: You have one minute and twenty-three seconds. 
Kirk: If change is inevitable, predictable, beneficial, doesn't logic demand that you be a part of it?

Spock: One man cannot summon the future.

Kirk: But one man can change the present! ... What will it be? Past or future? Tyranny or freedom? It's up to you. ... In every revolution there is one man with a vision.

Spock: Captain Kirk, I shall consider it.

This argument and Spock's reaction to it suggests that the only reason for a parallel self to differ from the "original" is a lack of information or logical thinking and thus a flaw in that version of the self that keeps it from realizing its full (the "original's") potential. "Mirror, Mirror" thus reinstates the superiority of the normative self and undermines the threat to the self posed by the parallel doppelgänger.

While Star Trek takes a still very regressive stance towards the existence of multiple independent selves in the 1960s, its view on the universe has become much more complex when it revisits the mirror universe in the Deep Space Nine episode "Crossover" (1994). The universe is still a dystopia - the human totalitarian regime has been replaced by an alien one in which the humans are now enslaved - but Star Trek now very darkly reflects on its own converting message voiced through Kirk in "Mirror, Mirror" by making it the cause of the current distress. Due to Spock's attempts to reform the Empire according to Kirk's vision, the Empire was overthrown and enslaved by alien races who now rule in an equally cruel way. The characters in the mirror universe are no longer simply dark copies of those from the Star Trek universe, but constitute personalities in their own right who are not simply dismissed as inferior or unfavorable by the crewmen passing over the threshold. The mirror selves' divergences are attributed to their different environments and experiences and stress the importance of nurture for the character development and present identity as something fluid and changeable. As their attributes are not seen as universally good or bad (despite the conflict between Major Kira and her doppelgänger, Kira finds character traits in her double she admires) and they inhabit a space separate from the Starfleet crewmen, they become equal and dynamic counterparts to the characters from the Star Trek universe and in many instances complete rather than threaten their identity by showing them what they could have been.

\section{Virtual Identities}

With the rise of the Cyberpunk sub-genre in the 1980s, Dietz also sees the rise of "wetware" as a model of the self. "Wetware," a popular Cyberpunk term, describes something that is tradeable, exchangeable, fluid, and - most importantly digital. As Dietz writes: 
If we are only wetware, then duplication loses its terror. The free roleplaying of multiple selves has replaced much of the anxiety over the loss of selfhood exhibited in traditional science fiction. ... The figure of the doppelgänger has therefore lost much of its mystical awe. In a sense, the word double is no longer accurate, as many recent texts have transcended the duality of protagonist and alter ego by envisioning the self as infinitely fluid. (218)

Instead of fighting to be accepted as an original in its own right, an individual separate from other individuals, we can embrace a multiplicity of selves. This is the third stage of Dietz' understanding of the doppelgänger motif in science fiction and probably the most positive depiction of the double. Without fear of being usurped by the double, it is finally possible to go beyond traditional notions of the self and use a multitude of doubles as an extension of the self, a hive mind. The self, Dietz contends,

is now seen as a mere part of the technological landscape in which the oppositions of self and other, or organic and mechanical, are seen as meaningless. By depicting the sale and purchase of artificial personalities (if the term artificial is even applicable here) in an economy dominated by interplanetary corporations, these cyberpunk novels gone (sic.) beyond the concept of alienation, as they presume character as a commodity. In a world where huge corporations not only own the products of labor, but also the copyright for personalities of the workers, the old concept of the self no longer exists. ... the central position of the self has vanished. ... (218-19)

With Dietz' praise for "wetware" comes a cautionary warning against the self as a commodity possessed by multinational corporations. However, he cites many positive examples of the Virtual Identity in science fiction literature. Among these are Rudy Rucker's Wetware and Michael Swanwick's Vacuum Flowers.

But if the concept of "wetware" and the multitude of selves has caught on in science fiction literature, it is still a rare occasion that science fiction film embraces or even touches upon it. The most recent addition might be Joss Whedon's TVseries Dollhouse (2009), which is set in a near future and features so called "dolls," regular humans, who exist in a "blank state" after their memory was downloaded onto hard-drives, and who are used to embody various roles from callboys and girls to hired goons by having the personality needed for the job "uploaded" onto them. The series' main protagonist Echo keeps certain memories, even after new personalities over-write the used ones, and thereby develops a personality comprised of a multitude of selves. Dollhouse certainly features the self as a commodity, but ultimately depicts the loss of the original self as ethically questionable. It is therefore no surprise that the show revolves around Echo's quest to develop her self and stop remaining in a fluid state. 
The most positive rendition of a "wetware" self is to be found not in a liveaction film but in the anime Ghost in the Shell directed by Mamoru Oshii and based on the manga by Masamune Shirow. Members of a government special unit in a cyberpunk version of Hong Kong where people are bionically enhanced, security robots roam the streets and corporations hold the power, are hunting the hacker Puppetmaster, who is able to "ghosthack" actual people, use them as he sees fit and access their personality, memory and experience. In the course of events, the film's protagonist Motoko Kusanagi finds out that the Puppetmaster used to be a government AI called 2501 that has developed a consciousness and subsequently gone rogue. Motoko decides to "merge" with 2501, as it wants to experience human emotions, life, death and birth and in exchange grants Motoko an extension of the self and freedom from the limitations of a traditional identity. She sheds her old body and transcends traditional identity.

A similar, yet more negatively depicted character in recent science fiction film is Agent Smith from The Matrix Trilogy (1999-2003). Smith is a sentient program, a so-called Agent who protects the Matrix from intruders and whose main goal it is to destroy the rebels' hideout Zion. As an Agent, Smith is able to use other humans in the Matrix as an extended self. He can use their senses, read their minds and possess their bodies. After his defeat by Neo in The Matrix, Smith becomes a virus detached from the Matrix' control, further develops his personality and gains the ability to copy himself over other beings both in the Matrix and the outside world. This results in a massive Smith "infection" in The Matrix Revolutions. Smith becomes legion, a virus comprised of a multitude of people all overwritten by himself. Instead of being able to tap into the hive mind of the world, he erases any notion of individuality in the Matrix. He becomes the perfected version of a body snatcher and much like his clone "cousins" he stands for the attack on the self this time not by capitalist corporations, socialist ideology or bio-engineering but by technology's rapidly growing reach.

Smith thus becomes the ultimate enemy of Neo and the Matrix alike and is ultimately destroyed. The Matrix Trilogy takes a very regressive stance towards technology. The digital "evil" Smith, who is in fact less useful and able than his former Agent self, has to be defeated to keep Zion, a crude mix between technology and tribalism, safe. Here, wetware is considered not as a next step towards transhumanism, ${ }^{5}$ but as an attack on individuality. Smith is presented not as a machine that has discovered its own self or an entity with a fluid identity but as a corporate, viral and "evil" identity that threatens to "overwrite" the free world. Zion's fight for survival is the fight against technology (or, in the language of The Matrix, "the machines") and for the perseverance of the individual self.

5 Transhumanism refers to the belief that it is possible to enhance mankind, overcome its limitations through technology, and progress to a not clearly defined state of post-humanity. See also A History of Transhumanist Thought by Nick Bostrom. 


\section{Conclusion}

While many articles have been written on the double in science fiction literature, doppelgängers in science fiction films have not received the same amount of attention. With this chapter, we hope to have shown that while in many ways similar to Dietz's "three stages of the double" in science fiction literature, science fiction film has developed its own language and routinized forms of the double. Most importantly, the doppelgänger in science fiction film illustrates a development of the notion of identity from fixed personalities closely linked to status and power to a more open concept that allows for the development of identity and eventually a multi-voiced identity.

Following Dietz's theory we can identify several examples for each "stage." The first stage, the "mechanical double" consists of clones and AIs and shows a struggle to define identity. Films like Invasion of the Body Snatchers, which depict a clone attack, show identity as something solid and fixed, as a possession of the individual self that can be lost and has to be defended. On the other hand, more recent films focus on the struggle of clones to have an identity in their own right, showing that identity is something that has to be created, fought for even, but cannot simply be copied. AIs undergo a very similar struggle. On the one hand, they are a threat to the traditional notion of identity as something organic and human. On the other hand, AIs with developing identities struggle to be accepted as autonomous beings, rather than to be considered mere machines as is demonstrated in Blade Runner.

Doppelgängers of the second, or "allohistorical," stage appear in films featuring time travel and parallel universes. Within a time travel plot the protagonist can encounter three different types of doppelgänger: If it is a "closed loop"-story, the doppelgänger illustrates certain developmental stages in the life of the time traveler. If it is a changeable timeline, the time traveler often has to deal with a dystopian self. If a story follows the many-worlds interpretation, no changes can be made while traveling through time, because traveling through time here equals traveling to a parallel universe. In this kind of story, the double poses no threat but can be an aide to the protagonist. When they are not encountered through time travel, parallel universes differ starkly from the "original" universe in significant ways. This depiction is used to show characters who look the same in very contrasting roles. It emphasizes nurture over nature. It is also one of the few doppelgänger motifs that acknowledges an autonomous place for the doppelgänger.

The third stage, the virtual identity, might be the most controversial topic for science fiction film. While many cyberpunk ideas of a fluid, downloadable and changeable identity have become mainstreamed in science fiction literature through now famous novels like William Gibson's Neuromancer (1984) or Neal Stephenson's Snow Crash (1992), its use in film has been rather limited. Film characters that can possess a wetware kind of personality are often a threat to the notion of individuality. Like Agent Smith from The Matrix Trilogy they are feared for 
being able to erase individuality and replace it with conformity. The promise of a multi-voiced, non-traditional identity is only seldom realized. We would argue that science fiction films defend a traditional, fixed, singular construct of identity. This one-sided depiction of virtual identities seems to become more common. Films like Avatar (2009) or Surrogates (2009) undermine the perception of a unity of mind and body. Jake Sully in Avatar is using an artificial body to communicate with the alien $\mathrm{Na}$ 'vi and subsequently becomes more Na'vi than human, but stays both Jake Sully and Na'vi. Surrogates shows a society in which everybody uses a so called "surrogate," to interact with the outside world. Those surrogates are an exchangeable extension of the user's self and while they are often seen as a danger to individuality, they carry the promise of transhumanism. Ultimately, doppelgängers in science fiction films show the rapid changes in the perception of identity that have taken place in the last 50 years and that are pointing to a future in which what constitutes an identity is not something fixed, but extendable, changeable, fluid and even more than the sum of its parts.

\section{Films Cited}

12 Monkeys. Dir. Terry Gilliam. Perf. Bruce Willis, Joseph Melito, Madeleine Stowe, Brad Pitt. Universal Studios, 1995. DVD.

2001: A Space Odyssey. Dir. Stanley Kubrick. Perf. Keir Dullea, Gary Lockwood, William Sylvester, Douglas Rain. MGM, 1968. DVD.

Avatar. Dir. James Cameron. Perf. Sam Worthington, Zoe Saldana, Sigourney Weaver, Stephen Lang. Twentieth Century Fox, 2009.

Back to the Future. Dir. Robert Zemeckis. Perf. Michael J. Fox, Christopher Lloyd, Lea Thompson, Crispin Glover. Universal Studios, 1985. DVD.

Back to the Future Part II. Dir. Robert Zemeckis. Perf. Michael J. Fox, Christopher Lloyd, Lea Thompson, Thomas F. Wilson. Universal Studios, 1989. DVD.

Blade Runner (The Director's Cut). Dir. Ridley Scott. Perf. Harisson Ford, Rutger Hauer, Daryl Hannah, Sean Young. Warner Home Video, 1982. DVD.

"Crossover." Star Trek Deep Space Nine - The Complete Second Season. Dir. David Livingstone. Writ. Gene Roddenberry, Rick Berman, Peter Allan Fields. Perf. Avery Brooks, Alexander Siddig, Colm Meaney, Nana Visitor. Paramount, 1994. DVD.

Dollhouse: Season One. Writ. Joss Whedon. Perf. Eliza Dushku, Harry Lenix, Fran Kranz, Tahmoh Penikett. Twentieth Century Fox Television, 2009. DVD.

Frankenstein. Dir. James Whale. Perf. Colin Clive, Boris Karloff, Mae Clarke, John Boles. Universal Studios, 1931. DVD.

Ghost in the Shell. Dir. Mamoru Oshii. Perf. Atsuko Tanaka, Richard Epcar, Akio Ôtsuka, Iemasa Kayumi. Palm Pictures, 1996. DVD. 
Heroes Season 1. Dir. Lisa Jackson, Jeff Weinstock. Perf. Hayden Panettiere, Masi Oka, Ali Larter, Adrian Pasdar, Milo Ventimiglia. Universal Studios, 2006. DVD.

Invasion of the Body Snatchers. Dir. Don Siegel. Perf. Kevin McCarthy, Dana Wynter, Larry Gates, Carolyn Jones. Republic Pictures, 1956. DVD.

I, Robot. Dir. Alex Proyas. Perf. Will Smith, Bridget Moynahan, Alan Tudyk, James Cromwell. Twentieth Century Fox, 2004. DVD.

"Mirror, Mirror." Star Trek: The Original Series - Season Two. Dir. Marc Daniels. Writ. Jerome Bixby, Gene Roddenberry. Perf. William Shatner, Leonard Nimoy, DeForest Kelley, George Takei. Paramount, 1967. DVD.

Star Trek. Dir. J.J. Abrams. Perf. Chris Pine, Zachary Quinto, Leonard Nimoy, Karl Urban. Paramount Pictures, 2009. DVD.

Star Trek: The Next Generation - The Complete First Season. Writ. Gene Roddenberry et al. Perf. Patrick Stewart, Jonathan Frakes, LeVar Burton, Brent Spiner. Paramount, 1987. DVD.

Star Wars Episode II - Attack of the Clones. Dir. George Lucas. Perf. Ewan McGregor, Natalie Portman, Hayden Christensen, Christopher Lee. Twentieth Century Fox, 2002. DVD.

Star Wars Episode IV - A New Hope. Dir. George Lucas. Perf. Mark Hamill, Harisson Ford, Carrie Fisher, Alec Guiness. Twentieth Century Fox, 1977. DVD.

Surrogates. Dir. Jonathan Mostow. Perf. Bruce Willis, Radha Mitchell, Ving Rhames. Touchstone Pictures, 2009.

The 6th Day. Dir. Roger Spottiswoode. Perf. Arnold Schwarzenegger, Michael Rapaport, Tony Goldwyn, Michael Rooker. Sony Pictures, 2000. DVD.

The Matrix. Dir. Andy Wachowski, Larry Wachowski. Perf. Keanu Reeves, Laurence Fishburn, Carrie-Ann Moss, Hugo Weaving. Warner Bros., 1999. DVD.

The Matrix Reloaded. Dir. Andy Wachowski, Lana Wachowski. Perf. Keanu Reeves, Laurence Fishburn, Carrie-Ann Moss, Hugo Weaving. Warner Bros., 2003. DVD.

The Matrix Revolutions. Dir. Andy Wachowski, Lana Wachowski. Perf. Keanu Reeves, Laurence Fishburn, Carrie-Ann Moss, Hugo Weaving. Warner Bros., 2003. DVD.

\section{Works Cited}

Baudrillard, Jean. "Simulacra and Simulations." Jean Baudrillard, Selected Writings. Ed. Mark Poster. Stanford: Stanford UP, 1988. 166-84. Print.

Bostrom, Nick. "A History of Transhumanist Thought." Academic Writing Across the Disciplines. Eds. Michael Rectenwald, Lisa Carl. New York: Pearson Longman, 2011. Print. 
Devlin, William J. "Some Paradoxes of Time Travel in The Terminator and 12 Monkeys." The Philosophy of Science Fiction Film. Ed. Steven M. Sanders. Lexington: UP of Kentucky, 2008. 103-18. Print.

Dietz, Frank. "Secret Sharers: The Doppelgänger Motif in Speculative Fiction." The Fantastic Other: An Interface of Perspectives. Eds. Brett Cooke, George E. Slusser, and Jaume Marti-Olivella. Amsterdam/Atlanta, GA: Rodopi, 1998. 209-20. Print.

Herdman, John. The Double in Nineteenth-Century Fiction. Edinburgh: Palgrave Macmillan. 1990. Print.

LaValley, Al. Invasion of the Body Snatchers. Rutgers University Press, 1989. Print.

Nahin, Paul J. Time Machines: Time Travel in Physics, Metaphysics and Science Fiction. New York: Springer, 1999. Print.

Penley, Constance. "Time Travel, Primal Scene and the critical Dystopia." Alien Zone: Cultural Theory and Contemporary Science Fiction Cinema. Ed. Annette Kuhn. London: Verso, 1990. 116-27. Print.

Roberts, Adam. Science Fiction. New York: Routledge, 2000. Print.

Rucker, Rudy. Wetware. New York: Avon Books, 1997. Print.

Sanders, Steven M. "Picturing Paranoia: Interpreting Invasion of the Body Snatchers." The Philosophy of Science Fiction Film. Ed. Steven M. Sanders. Lexington: UP of Kentucky, 2008. 55-72. Print.

Shelley, Mary Wollstonecraft. Frankenstein or the modern Prometheus. London: Oxford UP, 1971. Print.

Swanwick, Michael. V acuum Flowers. New York: Ace, 1988. Print. 

Stefanie Schwarz

\section{"Can you see?": The Importance of Vision and the Eye Motif in Steven Spielberg's Minority Report}

Minority Report shows the audience a utopian vision of the future: A special police unit called 'Pre-Crime,' under the lead of Chief John Anderton, can foresee crimes with the help of so-called Pre-Cogs and prevent them before they are actually committed. The new crime prevention system seems to be impeccable until the chief himself has to experience what it means to be adjudged by an unreliable method. Vision is not only the basis for the plot but also appears in many components of the movie. While watching Minority Report, the eye motif forms one of the most important images (Friedman). It appears in various ways and builds up one of the leitmotifs in the film. In this chapter, I want to analyze the dominance and extensive interpretatory potential of the eye motif. I would argue that in a world depending on vision, blindness can be an advantage. "Sight is power" but this power is limited (Bakewell 102). Minority Report shows the "unreliability of human vision" and that the interpretation of future images can lead to false conclusions (107). Therefore, John Anderton has to lose sight in order to see (Friedman).

First, I will focus on the appearance of the eye motif in Minority Report, for example when and where it is actually occurring in the movie. In addition, I will provide some examples where vision and sight are also addressed in the dialogs. Then, I will turn to my two main points. They are both based on two quotes 
which are essential for the movie. More precisely, I will discuss the statement of the blind drug dealer Lycon - "In the land of the blind the one-eyed man is king" - and how this quote applies to Anderton, and concentrate on the proposition of Mrs. Hineman, one of the Pre-Crime founders: "In order to see the light, you have to risk the dark." I will then explain why everything depends on interpretation and give an example for the failure of the Pre-Crime system, before I end with my conclusion.

\section{The Eye Motif as a Key Element in Minority Report}

Eyes evidently play an important role in Minority Report since there are many scenes in the movie which deal directly or indirectly with eyes. Their steady appearance seems to hint towards a special message which is essential to the film. In the movie, there are many ways in which vision, sight, and eyes are referred to. There are references in the language as well as direct and indirect emphasis on eyes (Friedman).

In a scene at the beginning of the movie, for instance, the son of the future criminal Howard Marks cuts out a mask and, as Lester D. Friedman writes, "plunges a pair of scissors through the eyes of a cardboard picture of Abraham Lincoln." Since the scene is primarily focusing on the conversation between Marks and his wife, the stabbing of the mask's eyes is only an indirect reference to the motif. Yet it is important because it foreshadows the fact that the Pre-Cogs later provide a vision in which it looks as if Howard Marks is going to stab his wife and her lover with a pair of scissors (Friedman).

Another scene which contains a more direct reference to the eye-motif is the meeting of Anderton and the blind drug dealer Lycon, who lost his eyeballs. All that is left are two holes in his face, which he first covers with sunglasses (Bakewell 101). At first, the reason for his missing eyeballs remains in the dark. Yet, as Friedman points out in his article, it becomes clear that Lycon chose to be blind once the fact is revealed that eyes serve as identification marks.

In Minority Report, eyes have replaced the old personal identity cards. Friedman observes that every person is identified many times a day by retina scans, when leaving the subway, for example, or when entering a store. More than that, Geoff Bakewell adds, retina scans are also used to personalize advertisements and required to enter buildings. In addition to this, there are also so-called spyder scanners which work with heat flow sensors. They are used to locate and identify persons in buildings (104). This means a total control by the state and the usage of spyders makes it sheer impossible to avoid being located and identified by the authorities. Therefore, it is no wonder that Lycon does not have eyeballs anymore. According to Friedman, "[t] he drug dealer ... has no eyes so he cannot be identified." 
With its excessive references to vision, Minority Report does not only make use of the eye-motif superficially but, in Friedman's words, "fundamentally questions our sight: How does one see? What does one see? How do we understand what we see - or think we see?"

These questions are very important especially concerning the Pre-Crime system which depends on vision(s) and which is the basis for the movie. The PreCogs can foresee murders before they actually occur. They have visions, which they transmit through pictures of the future crime. The Pre-Crime cops then have to arrange and interpret these pictures. They have to respond and act to what they have made up out of the pictures and right there is the problem of the system, as both Friedman and Bakewell have also noted (107). Minority Report presents a system which depends on visions of "unreliable guides" which leaves a lot of space for mistakes and doubts (Bakewell 110).

\section{References to the Importance of Sight}

The eye motif also occurs in the dialogs of the movie through what Friedman terms "a vast array of spoken references to ... eyes." Howard Marks, for instance, says that he is blind without his glasses when he returns to his house to get them and finds his wife together with another man. Here sight is connected with understanding. Marks is enabled to 'see' that his wife has been unfaithful to him. Things become clear for him and he recognizes that his wife has been cheating on him for a long time.

Friedman also hints at an even more interesting, short statement by Pre-Crime director Lamar Burgess: "The eyes of the nation are upon us." Burgess wants PreCrime to become the national security program and therefore cannot risk that there are any mistakes, flaws or scandals connected with Pre-Crime (Friedman). He knows that Pre-Crime is under permanent observation and that the government focuses on his company. This puts a lot of pressure on Burgess because when people know they are watched they try to avoid mistakes and carefully think their actions through. In this context, then, "sight is power" (Bakewell 102). Sight is an instrument of putting people under pressure. The one who is watching is more powerful than the one who is being watched. Western society makes an enormous usage of this phenomenon. People like to watch others - for example in TV shows like Big Brother which enable the viewer to take the role of a voyeur. Watching others is always a form of power because it deals with the value of knowing more about a person than is desired by them.

The title of this chapter alludes to Pre-Cog Agatha's "physical as well as metaphysical question" "Can you see?" which - as Friedman notes - "she asks Anderton several times throughout the film." Agatha wants him to see that Anne was her mother and imitates her drowning when "she slides back into her own pool" (Bakewell 102). Of course, the Chief has eyes but he does not understand that 
Agatha leads him to the murderer of her mother and that she basically warns him of Burgess and the future events (102). At this point, Anderton almost appears to lack vision, a fact that comes literally true during the movie. Several times, Anderton is basically shown one-eyed. As Bakewell explains, the spectator cannot really see the second eye because "features of Anderton's face are shrouded in darkness" (107).

"In the land of the blind the one-eyed man is king" is a sentence from the blind drug dealer Lycon whose eyeballs have been completely removed from the orbits. He says it at the end of his conversation with Anderton. In this scene, Anderton is searching for his drug 'neuroin' and says that he is seeking for some 'clarity.' It is revealed that the Pre-Crime cop Anderton, a man of the law, uses drugs. Moreover, he thinks that this drug will 'clarify' things even though drugs are usually taken to experience a distorted perception of the environment. Naturally, drugs have a similar effect as narcotics and reduce clear sight. Drugs are taken to escape the real world, to experience a state of trance, or, in some cases to provoke visions.

Even though Anderton is able to see, he seeks clarity from a blind man (Bakewell 102). Therefore, "sight is power" but power is limited as Bakewell argues (102). Anderton is capable of seeing but this does not "guarantee" that he actually understands. This makes him unlike the blind Lycon, who may actually have insight as he understands much quicker and maybe more than the seeing Anderton (103). In this context, Lycon demonstrates that although he may be (physically) blind in this moment, Anderton is also blind because, according to Bakewell, "even a sighted king may be partially blind" (102). Therefore he indicates that "the one-eyed man" actually is the king - king in the land of the blind because he may have the ability to see like a two-eyed man but also to understand and interpret things like a blind man.

In addition, Lycon's quote is a prediction of what will happen to Anderton in the future because according to Bakewell he will become "a one-eyed man twice" $(102,104)$. The first time he becomes one-eyed is after the operation, when "he lifts the bandage over one eye just enough to let the spyder shine its brilliant light into his new orb" before the time of recovery is up (104). He does so in order to let a spyder scan his newly replaced eye preventing arrest by his former colleagues. This blindness, then, is voluntarily and it saves him from greater evil (104). The second time Anderton becomes one-eyed is when he drops one of his removed eyeballs - which he carries in a plastic bag - while trying to enter the Pre-Cog Temple in the Pre-Crime unit (104). Bakewell states that once more "the destruction of the protagonist's sight is voluntary" and will lead him later to a greater vision because he can see more clearly each time he reduces his sight (104). He can enter the Pre-Crime department, get to the Pre-Cog Agatha, and find Leo Crow whom he thinks to be his son's kidnapper, and the story takes its course. This would not have been possible had Anderton kept his original eyes and not 
followed Mrs. Hineman's advice: “In order to see the light, you have to risk the dark" as the Pre-Crime founding member tells him when he visits her in her greenhouse. With this sentence she implies that Anderton has to get his own eyeballs removed before he will be able to move on and enter the Pre-Crime unit to find his own minority report (Bakewell 103). But why does she make this suggestion?

In 2054, everywhere in Washington, D.C. retina scans are performed to identify people. This makes it impossible for Anderton to enter the Pre-Crime unit because he would already have been detected on his way to the building. Therefore, he decides to have the suggested eye operation (Bakewell 103).

The eye surgery is undertaken by the surgeon and former criminal Dr. Eddie, who had been arrested by Anderton some years before (Friedman). Still, Anderton depends on him because there is no other way "to pass undetected through the ubiquitous retinal scans" (Friedman) than removing his own eyeballs. According to Bakewell, the eye operation itself means a change of identity for Anderton. He changes from a police officer and much respected authority in the beginning to an inferior position because of his eyes. Anderton becomes "Mr. Yakamoto" and as an Asian he belongs to a minority group in Washington, D.C. (Bakewell 106; Friedman). The change of his identity is permanent, because the identity, as said before, depends on the eyes. Anderton's social rank is now lowered and he will never again become the John Anderton he has been before. Therefore, I would argue, his whole perspective changes and he sees his society and Pre-Crime in a completely new way. Or, as Friedman writes:

Though he survives, Anderton never looks at the world in the same way: the veil of certainty which surrounded his faith in the Pre-Cogs has been ripped away, replaced by a tattered and uncertain cloth which reveals the world as a more ambiguous and less trustworthy place.

Through his new eyes Anderton is finally able to find the solution to his problem and, related to this, he also learns about the weaknesses of the Pre-Crime system. $\mathrm{He}$ is able to enter the Pre-Crime headquarters and the Temple where he finds Agatha. Realizing that he has no minority report, Anderton panics and holds on to Agatha. He finally finds Leo Crow and for the first time his faith in Pre-Crime is shattered because he notices a failure of accuracy in the prediction. Anderton learns that Pre-Crime cops only get one fixed point of view and that what is really happening could be understood in completely different ways if seen from a different angle (Friedman). Furthermore, he recognizes that the Pre-cogs' individual visions of a future event are edited to produce one coherent vision of the event. This edited version is the one the Pre-Crime cops see. In this moment, he understands that all he did in his time as a Pre-Crime cop was to invent future crimes.

Therefore, "functioning eyes" do not always "guarantee ... understanding" and insight (Bakewell 103). Anderton learns that the future is not predestined but 
that one can always choose. Thus, when he is about to kill Leo Crow he decides not to do so (Friedman). His temporary blindness, caused by the operation, has served to open his eyes. He gets a deeper insight and begins to understand why Pre-Crime is not the best solution for fighting high crime rates. In this context, Anderton really has to go blind in order to see (Friedman).

\section{It Is all a Matter of Interpretation}

Vision always depends on interpretation. Pictures themselves can only show what things look like but what they really are like is a matter of interpreting the images. Therefore, it always depends on the person who interprets and evaluates the images and not only on the person who provides the visions. Friedman states:

[T] he Pre-Cogs function as authors - or at least transmitters or channellers - of the text, the images as the physical text itself and Anderton as its reader, the one called upon to fashion the disjointed images into a coherent story, identify the scene and prevent the crime. (Friedman)

There are many scenes in Minority Report in which what John Anderton actually sees is not shown very clearly. Mostly this lack of clear vision appears when Anderton is standing in front of the board in his office and interprets the bits and pieces of pictures he receives from the Pre-Cogs. While watching Anderton shuffling the images on the translucent board, the spectator is also able to see what is behind the board. Therefore, Anderton, too, can always see what is behind the board and what is on the board at the same time. Images are overlapping and it becomes basically impossible to focus entirely on just one impression.

Furthermore, the spectator receives a good view of Anderton's position in these scenes. Shown from various camera angles, he is standing in front of visual fragments and has to solve a puzzle but is in fact seen through a screen of confusing images - fragments he actually receives and sees. All of the cases he is solving are not really depending on facts. Their solution is always connected to Anderton's point of view. In this case it applies that "we inevitably see what we have been trained to understand and, sometimes, what we want to see" (Friedman). No one will ever know if the Pre-Crime cops interpret the pictures right because no one really knows if the future would have happened just as the Pre-Crime cops see it. Clearly Pre-Crime workers have eyes, but are they really able to see the meaning of the images?

Friedman points out that the best example for a "misinterpretation" is the case of Anderton himself. The Crow murder shows that the cops always just see the worst-case scenario. They come up with absolute horror stories but they do not include "alternative visions" (Friedman). Furthermore, they are actually trained to ignore certain things, for example "echoes," which are supposed to be just a repetition of earlier visions (Bakewell 110). In reality, however, there can actually be 
two murders which just look alike but are not the same. Here the seeing persons are left in the dark. They just do not make use of their eyes but depend on what they are told by the authorities. As a result, they are basically blind because they simply rely on what others say and do not take a closer look at things or question them (103).

Furthermore, the Pre-Crime cops and the Pre-Cogs are not cooperating. In the movie, the workers never enter the Temple where the Pre-Cogs are. This further strengthens the idea that there is much room for "misinterpretations" (Friedman). Solutions are not drawn together with the Pre-Cogs, who provide the images, but only by the cops.

Minority Report clearly shows that the interpretation of visual material is precarious and that it can easily lead to false conclusions (Bakewell 111). "Sight is power" as it can be used to improve knowledge but power is limited (102). Therefore, sight is limited too. The ones who are seeing may not have the necessary insight blind people have (103). Therefore, blindness can be an advantage. Vision and interpretation have to be seen as two separate components and eyes are just the mediators that connect them.

Anderton is the best example to understand that sight and interpretation may not be linked as easily as one would think. He does not understand the failure of the Pre-Crime system until he has a new perspective through new eyes and becomes himself a victim of the system (106). He has to lose sight before he can discover that Pre-Crime is not impeccable and may not be the best solution in order to prevent crime. Furthermore, he learns that future visions may not always come true, because one can always have a choice (Friedman).

The use of the eye-motif makes way for various interpretations. Clearly the vision and the eye-motif are of great importance for Minority Report but there is more to it than one might think. It serves as a warning of total state control and inspection (Friedman). Furthermore, the eye-motif hints to the question of predestination. Can the future really be predestined if there are cops who stop a future murder which will never happen in the end (Friedman)? 


\section{Works Cited}

Bakewell, Geoff. "The One-Eyed Man is King: Oedipal Vision in Minority Report." Arethusa 41.1 (2008): 95-111. Print.

Friedman, Lester D. “Minority Report. A Dystopic Vision.” Senses of Cinema 27 (Jul.-Aug. 2003): n. pag. Web. 19 Mar. 2009. <http://archive.sensesofcinema.com/contents /03/27/minority_report.html>.

Minority Report. Dir. Steven Spielberg. Perf. Tom Cruise, Collin Farrell, Samantha Morton. Twentieth Century Fox and DreamWorks. 2002. DVD. 
Solveig Burfeind

\section{Becky Driscoll as femme fatale? Elements of film noir in Don Siegel's Invasion of the Body Snatchers}

The 1956 movie Invasion of the Body Snatchers, which depicts a small town community that is invaded by an extraterrestrial force, is usually regarded as a classical science fiction film. Moreover, popular readings of the film suggest that it reflects the Cold War paranoia of its time: the fear that communists, represented in the movie by the Body Snatchers, would infiltrate the American society and turn Americans into communists, or emotionless pod people as they are called in the film.

But there are other readings of the film that at first glance seem less obvious. Steven Sanders, for example, perceives Invasion of the Body Snatchers as a film noir. This interpretation is especially interesting because the movie is said to belong to the genre of science fiction. How does Sanders arrive at this conclusion? What features of film noir can be found in the movie? Narrowing down the scope of the film noir elements in Invasion of the Body Snatchers, in the following chapter I will focus on the leading female protagonist, Becky Driscoll, and in how far she can be seen as a femme fatale, one of the most popular features of film noir. I will set Becky in contrast to the conservative role model of American women in the 1950s and point out various aspects of her character that make her a film noir's femme fatale. 
The United States in the $1950 \mathrm{~s}$ - the time period in which the film is set were on the one hand influenced by economic prosperity as an outcome of World War II and on the other hand by the constant threat of the Cold War. Regarding the private life of the Americans the "decade came to seem a time of pervasive affluence and consumerism, of cheap gasoline and big cars, of new suburban homes and family togetherness, of conservatism and conformity" (Boyer 844). This emphasis on conservative values already indicates that her "suburban home" and family defined the role of the woman. During World War II many women were important work forces at the home front while their husbands fought in the war. After the war however, these women were supposed to return to domesticity, housekeeping and family. This idea was also promoted in the media. According to Paul S. Boyer "[p]opular culture ... glorified marriage and parenthood more than ever before" and "television invariably pictured women as at-home mothers" (861). But the perfect housewife shown on television also had its counterpart in Hollywood movies, as Susan George points out. She claims that "besides doing its part to promote the 'proper' role for women in the public and private spheres, 1950s Hollywood also produced cautionary tales regarding what could happen if female sexuality and ambition were not contained" (3).

In contrast to the positive, happy family life portrayed by American pop culture, the experiences of World War II and the constant threat of the Cold War were reflected in the genre of film noir. Roger Westcombe notes that "America's movies were growing darker" (3, emphasis in the original) as a result of its "dark" experiences with war. Especially the visual effects reflect the "desperation and hopelessness" ("Film Noir") of real life with its play with shadows and darkness. This can already be seen in the French term noir meaning 'black' or 'dark' as opposed to 'light'. Filmic elements such as "low-key lighting" and "chiaroscuro effects" (Horsley 1), meaning the contrast between light and dark, are important in this respect.

Apart from these devices, the genre also depicted certain themes and character constellations. The main protagonist or "noir hero" often had to realize that things were completely different from what they appeared to be and had to deal with the consequences (Horsley 2). Another important character of the film noir is the femme fatale. Femme fatale is a term frequently used to describe a certain type of woman.

This woman is usually extraordinarily beautiful and an object of desire for many men. But she can also become a dangerous seductress, or "a siren-like figure of desire whose distinctive characteristics, compared to previous female archetypes, were her independence, strength and ruthless desire" as Roger Westcombe phrases it (4). Famous examples of classical noir actors that come to mind are Marlene Dietrich, Rita Hayworth and Ava Gardner as femme fatales and Humphrey Bogart and Dick Powell as the noir heroes. More recent examples of noir characters could be Sharon Stone in Basic Instinct and the newest Batman movies by Christopher Nolan with Christian Bale as the dark superhero. 
The femme fatale of the film noir was to seduce the hero, often with dangerous consequences for him. The cinematic journal Images compares the character to "black widows who slowly drew in the heroes with come-hither looks and breathless voices ... the femme fatale knew how to use men to get whatever she wanted" ("Film Noir"). The depiction of the femme fatale can also be seen as a reaction of male anxieties towards emancipated working women. The fact that many men who returned home after World War II found their wives working and independent created a "new male anxiety" and as a result the image of the femme fatale (Westcombe 4). Her characteristics, the independent and sexually emancipated identity, were opposite to those of the traditional, loving housewife.

How are these noir aspects visible in Invasion of the Body Snatchers? As mentioned earlier, Steven Sanders reads the movie as a film noir and presents different elements of the film to support his thesis: "Its flashback structure with voice-over narration, unusually angled shots, scenes of claustrophobic darkness, crisply rendered dialogue, and a sense of sinister purpose and impending doom" (55). This sense of "impending doom" is reflected in the film's storyline, dealing with the invasion of extraterrestrial forces, called pod people, which take over the form of human beings turning them into emotionally dead creatures.

In an important scene of the movie, the main protagonist, Miles Bennell, discovers four pods that are coming to life in his greenhouse; the room is dark and seems claustrophobic. In addition to this, the camera angle is estranging, showing the whole scene from an upper corner of the room. Moreover, Miles himself has features of the noir hero: On the one hand, Miles realizes that things are different from what they seem. He finds out that many people in his town have been turned into pod persons. On the other hand, his character development is similar to that of the noir hero, who changes from a self confident, respected doctor to a haunted person, full of anxiety: "the movement of the protagonist from one role to another constitutes key structural elements in noir narrative" (Horsley 1). In the final scene of the movie, Miles has escaped the pod people but finds himself in a mental hospital and his rapid speech and body language indicate his deep fear and confusion.

When looking at the movie Invasion of the Body Snatchers as a film with classical noir elements and Miles as a potential noir hero, it only seems logical that his female counterpart Becky Driscoll represents a femme fatale. The first time she appears in the movie, Becky is wearing a pretty dress and her hair and make up are carefully done. She is a beautiful, attractive woman and it does not take long for her and Miles to refresh their old romantic feelings for each other. Becky's looks can be compared to that of a classical noir femme fatale, the curly hairdo, shaped eyebrows and a make up that accentuates her seductive eyes and sensuous lips. Apart from her appearance, the fact that she was recently divorced is equally important. The 1950s ideal of a woman was a married mother, a housewife. Contrasting this ideal, Becky's marriage has failed, and she does not have any children. Having been married also implies that she is sexually experienced. Katrina Mann 
points out that "Becky's divorce culturally resonated as evidence of her unrestrained sexuality. The female divorcee ... was presumed to be more sexually available than unmarried women ... [and] had increased awareness of herself and her desires" (60). Moreover, a sexually emancipated woman was seen as a danger to society by attracting and seducing men, thus representing the opposite of the traditional housewife: "Writers ... were warning that female desire and sexuality, if not properly contained, could distract men, destroy families and make the nation weak and ripe for Communist infiltration" (George 2). In the movie, Becky eventually turns into a pod person and through this transformation she becomes a danger to Miles' life, like the femme fatale to the noir hero.

The first scene in which Becky appears is set at Miles' office. As soon as she enters the room, a light, seductive music sets in and her soft voice seems to resemble the tone of the music. She is wearing a pretty dress that shows her bare shoulders and, as already mentioned, her hair is done and she wears make up and jewelry. Her face is illuminated and highlighted by a spotlight. We see Becky in an over-the-shoulder shot from Miles perspective and it is obvious that he is stunned by her appearance, smiling at her and joking. He closes the door behind her as if he was seeking intimacy. A mutual attraction becomes obvious to the viewer as Becky seems flirtatious with Miles. When she sits down to talk to Miles we see her from a bird's eye perspective, she is looking up at Miles and especially her eyes seem very large and sensual. At the same time she is giving the impression of a self-confident woman. In this scene, Becky clearly shows attributes of the femme fatale, being beautiful and seductive, attracting Miles.

Farther into the movie, Becky is cooking breakfast in Miles' kitchen, after he had rescued her the night before from being transformed into a pod person. At the beginning of the scene the soft, seductive music sets in again. The fact that Becky stands in the kitchen cooking for Miles might imply that she does have traditional housewife qualities. But Becky's clothes speak a different language. She is wearing a large man's shirt and jeans, the opposite of what one would expect from a 1950s housewife. These clothes make her look like an emancipated woman, another feature of the femme fatale. Miles seems very much in love with her, dedicated to please. When she asks him how he likes his eggs, he says that he wants them the same way she makes hers. He also makes remarks about how he liked to rescue and take her home in the middle of the night. Becky on the other hand seems more rational and in charge of the situation.

In another scene at the office, Miles hides with Becky from the pod people, which had been trying to find and transform them. Miles and Becky decide that they need to stay awake the whole night in order to withstand a transformation into a pod person while sleeping. Before the camera fades out, the two kiss passionately, and music is playing in the background. Katrina Mann observes that the next picture, which shows the scene in the morning, displays a full ashtray, which she interprets as a "postcoital commemoration with a macabre twist" (61). Taking this as an indicator for a sexual encounter between Miles and Becky it can be as- 
sumed that Becky got what she wanted. She succeeded in seducing Miles. After this it does not take long for her to be turned into a pod person, endangering Miles' life, like the femme fatale endangers that of the noir hero.

Later in the scene, the music becomes more dramatic and the room seems somewhat claustrophobic, because of the dark shadows that were not there in the first office scene; these are clearly elements of film noir. Miles is trying to think of a way to battle their persecutors and he takes two knives from a cabinet: "No. It wouldn't work. I might get one or even two, but I couldn't get three." And Becky replies: "You're forgetting something, darling - me. It isn't three against one. It's three against two. Give me a knife." Miles presumes that he has to fight the pod people by himself and that Becky, being a woman, is not capable of this. She on the other hand appears to be very strong and self-confident when she tells him that she can fight, too. She takes his hand with the knives in it with a strong and determined grip. She "takes action," which, according to Westcombe, is another distinctive feature of the femme fatale, who "is not passive ... she takes action to get what - and whom - she wants with a directness and aggression previously reserved for male players" (4).

One of the last but probably most crucial scenes is where Becky is being transformed into a pod person. She and Miles have run from their persecutors, the pod people, and hide in a cave. Miles leaves Becky alone for a moment to find help and when he comes back he discovers that she has fallen asleep. He takes her into his arms and kisses her passionately. In this moment, dramatic music sets in and we see a close up of Becky's face. When she does not kiss Miles back with the same passion he realizes that she has been transformed during his absence. Becky opens her eyes and stares at him coolly, her hair is messed up and her face covered in dirt. She lifts one of her eyebrows in an almost cynical way. She appears wild and dangerous with her white teeth clenching, almost animal-like. This shot is followed by a close-up of Miles' horrified face. It is obvious that the beautiful, flirtatious Becky that he fell in love with is completely and irreversibly gone and he is shocked. When he starts to run from her, Becky calls out for the other pod people to get him.

In his voice-over, Miles states that he has never been so afraid in his whole life. Becky has become his ultimate threat: "I didn't know the real meaning of fear ... until I had kissed Becky. A moment's sleep, and the girl I loved ... was an inhuman enemy bent on my destruction. That moment's sleep was death to Becky's soul." In this scene, Becky can again be perceived as a femme fatale, because she betrays and endangers Miles by shouting out for the pod people to get him. Although her appearance has changed from the beautiful and carefully styled woman she was in the beginning of the movie to a dirty, scary face she still fits the image of the femme fatale.

Susan George writes in her essay on the "Science Fiction Vamp," where she compares the former to the femme fatale, that stories about this kind of seductive and dangerous woman serve "as a cautionary tale for the unsuspecting men they 
may seduce and as a warning to women to stay in their place or they will, literally, turn monstrous and be dispatched without mercy" (14). Becky, too, has turned truly "evil" and she even appears somewhat "monstrous" with her widely opened eyes and clenched teeth. Moreover, it can be argued that she is a seductress because of her attractive appearance and the fact that it did not take long for Miles to fall for her. When Becky has become a pod person, her body is still alive but Miles realizes that her soul is dead. "Death was usually the fate of the SF Vamp" (George 3) and the same could be said for the femme fatale. One might argue that Becky in the end does not resemble a femme fatale anymore, because she is a pod person without emotions or sexual desires. On the other hand, Becky's transformation can also be perceived as a final act to "pull the hero down" ("Film Noir"). At the same time Becky succumbs to the fate of the femme fatale, because her "soul dies" ("Film Noir").

In conclusion, Becky shows various features of the femme fatale. According to Richard Westcombe, the three "key components" of the femme fatale are her "independence", "strength" and "ruthless desire" (4). All three components can - to a certain extend - be found in the character of Becky. She is divorced from her husband, no longer depending upon him. She shows self-confidence and strength, and insists on taking up a fight against the pod people. She shows desire when she flirts and kisses Miles. She also stands in contrast to the traditional role model of American women in the 1950s.

Yet Becky does not give a fully homogenous picture of the femme fatale. In the second office scene, right before she tells Miles that she can fight the pod people, too, she breaks down crying and telling him that she does not want to live in a world where there is no love, a world where there are only emotionless pod people, and that she wants to have Miles' children. This seems contradictory to an independent and dangerous femme fatale and it shows that Becky's character has further components than mentioned in this chapter, e.g. the longing for love and children. But when looking at the 1950s Italian movie poster of Invasion of the Body Snatchers the image of Becky as a femme fatale is somewhat taken to an extreme, showing her tanned and naked, voluptuous lips and breasts, her hands seem like sharp claws - a truly wild and dangerous femme fatale. In my opinion, it is this impression of Becky that lasts because this is what her character has become at the end of the film, and though the picture of her as a femme fatale is not fully homogenous, it can be concluded that Becky does more than just sharing certain characteristics with the film noir's dark heroine, the femme fatale. 


\section{Works Cited}

Boyer, Paul S., et al. The Enduring Vision. Boston: Houghton, 2004. Print.

"Film Noir: An Introduction." Images Journal 2 (25 Feb. 2004): n. pag. Web. 3 Jul. 2009. <http://www.imagesjournal.com/issue02/infocus/filmnoir.htm>.

George, Susan A. "Pushing Containment: The Tale of the 1950s Science Fiction Vamp." Reconstruction 5.4 (Fall 2005): n. pag. Web. 8 Mar. 2010. <http:// reconstruction.eserver.org/054/george.shtml>.

Horsley, Lee. "Definitions of Film Noir." Crimeculture.com. 2002. Web. 28 Apr. 2009. <http://www.crimeculture.com/Contents/FilmNoir.html>.

Invasion of the Body Snatchers. Dir. Don Siegel. Perf. Kevin McCarthy and Dana Wynter. 1956. Walter Wanger Productions, 1998. DVD.

Mann, Katrina. “'You're Next!': Postwar Hegemony Besieged in Invasion of the Body Snatchers." Cinema Journal 44.1 (Fall 2004): 49-68. Print.

Sanders, Steven M. "Picturing Paranoia: Interpreting Invasion of the Body Snatchers." The Philosophy of Science Fiction Film. Ed. Steven M. Sanders. Lexington, KY: U of Kentucky P, 2008. 55-72. Print.

Westcombe, Roger. "What is this thing called film noir, anyway?" Crimeculture.com. 2003. Web. 28 Apr. 2009. <http://www.crimeculture.com/Contents/RW ThingCalledNoir.html>. 



\section{Part IV}

(De)Constructing Bodies and Identities 

Benjamin Ryan Ulonska

\title{
Human Monsters: The Function of the Horror Motif in Don Siegel's Invasion of the Body Snatchers and Its Remakes
}

\author{
In retrospect, it's usually pretty easy to look \\ at horror movies and see the influences of the time. \\ - Wes Craven, director
}

As director Wes Craven states, films - and horror movies in particular - reflect contemporary socio-cultural events by commenting on the political climate of certain decades. Quite often, the horror story relies on gloomy atmospheres, underlined by distracting images of fear and terror, and features the confrontation of the hero with the ultimate evil that takes shape in devilish figures such as Michael Myers, Freddy Krueger or the Alien. In any case, the evil force embodies a dangerous threat to human life as it wants to mercilessly eliminate those who are good at heart.

It is exactly that aspect of menace which draws a connection between the horror and the science fiction genre. The representation of a threatened society in a most often - dystopian world is a classical aspect of twentieth-century science fiction literature and can be found in Jack Finney's The Body Snatchers (1954) and 
Richard Matheson's I am Legend (1954) as well as in their cinematic adaptations and remakes. Thus, the question arises whether there exists something like a metagenre of both Horror and science fiction, and if that is the case: How can it be identified and what are its key aspects?

In this chapter, I will discuss these questions by focusing on the cinematic construction of the alien-invaded human body in two film versions of Jack Finney's novel The Body Snatchers. Therefore, I will give a definition of the horror genre before I make a distinction between horrific elements and elements of terror. Following, I will briefly summarize the plot and give some basic information about the first Body Snatcher film by Don Siegel and its three remakes. Thereafter, I will elaborate on the different socio-cultural backgrounds of each film and place the horrifying corporal construction of snatched bodies in context to the contemporary influences of their time. To conclude, I will briefly summarize the crucial points of my research and point out the overall function of SciFi-horror films as medium that is critical of society.

\section{Playing with Fears: The SciFi-Horror Genre}

In order to argue that the genre boundaries of films such as Invasion of the Body Snatchers are fairly ambiguous and that Science Fiction movies can under certain circumstances be regarded as horror films as well, I will briefly outline some genre specifications: The term "horror" is derived from the Latin "horreo," which means "shudder at" or "bristle" ("Horror"). In order to create a frightening effect, horror fiction communicates the emotion of fear by making use of horrific and terrifying elements. As Georg Seeßlen and Fernand Jung write in Horror: Geschichte und Mythologie des Horrorfilms, the Gothic Novel originated the horror movie:

Das moderne Horror-Genre im Film und in der Literatur verdankt seine Thematik und seine Ornamentik vor allem drei Quellen: Das ist der klassische Schauerroman als spezielle Form der Gothic Novels, das ist der Vampirroman mit den Verarbeitungen seines Motivs in Vers-Epen und in der Lyrik, und das sind die Gespenstergeschichten und ihre Vorformen im Drama. (49-50)

Thus, horror fiction plays with shudder and thrill and takes up myths of horrific as well as of scientific character which can be presented in either horrid or terrifying ways - and it is useful to make a distinction between horror and terror at this point because, according to Devendra Varma, the difference lies within the recipient's "awful apprehension and sickening realization" (Varma qtd. in Cavallaro 3) with the term horror implying an instantaneous shock and the term terror meaning the process of building up emotional anticipation for what is seen. Thereby, the "awful" is most often fantasized as a monster. But what exactly is a monster? 
Primarily, there are six types of monsters: the artificial human, the creature, the undead, the animal, the doppelgänger and the witch (Seeßlen and Jung 46-48). All Body Snatcher movies contain such images of monsters - in the 1993 version for example, the snatched mother is not only the creature but also becomes the witch (Brenez 94-96). Despite the fact that these implementations might be mistaken for typical characteristics of horror films, Fred Botting manifests that "[ $\mathrm{t}]$ he conjunction of two hybrid genres composed from diverse literary and mythical precursors breeds monstrosities: strange beings and disturbing other" (111). In Invasion of the Body Snatchers, the "alien" is of course the strange being as it resembles an unknown species that wants to invade humans. Thus we can say it is a monstrosity, a creature threatening human life.

With regard to the Body Snatchers and its remakes, Botting's definition is just as easily applicable as Sobchack's: In all remakes, the alien liquid snatching human bodies comes from outer space. Sobchack even defines the Sci-Fi-Horror genre as a "Monster or Creature film" in her book Screening Space. According to Sobchack,

the horror film is primarily concerned with the individual in conflict with society or with some extension of himself, the SF film with society and its institutions in conflict with each other or with some alien other. ... There are ... frequent cases of congruence between the SF and the horror film; there are films in which it is not so easy to distinguish whether the chaos is moral or civil. ... The films ... are what we commonly call the Monster or Creature film. (29-30)

Sobchack then continues that those science fiction monsters either fell from outer space to threaten the planet, or they invaded or destroyed it (29).

\section{The Corporeality of the Alien}

Just like horror, the term corporeality is also of Latin origin (Lat. corporalis) and means "relating to or being characteristic of a person's body" (Hawker, Soanes and Spooner 191). Thus it is used in a physical rather than spiritual way. Hence, I will observe the physical appearance, the corpus of the alien, and, moreover, the alien-invaded human body according to features that can be interpreted as metaphors for contemporary societal issues. It is important to accomplish this analysis in two parts, since the alien semen or alien liquid and the alien-invaded body are different from each other in their function. From now on, I will use the terms alien, monster or creature interchangeably to describe the bodily version of a snatched human. On the other hand, the term alien source will stand for the shape of the outer-space alien.

Aliens demonstrate what is not human, the better to exemplify that which is human. Difference and otherness are the essence of aliens ... for only 
then can they stiffen the sense of self and self-defence that completes the chain of science fiction as a normative genre. (Sardar 6)

Ziauddin Sardar's definition of the alien's otherness comes close to psychological theory about the categorization process of the human mind. Therein it is said that humans categorize everything they fear as "strange" and "unknown." Thus it is interesting to observe the alien in Body Snatchers on two levels: the corporeal construction according to applied features of societal fear and the reception of the creature as "the other" (Zimbardo 137).

\section{The Body Snatchers}

Perhaps we can say that the title of the first Body Snatcher film called Invasion of the Body Snatchers (1956) exactly mirrors what had happened ever since the story based on Jack Finney's novel was first turned into a movie: it has prepared the ground for a worldwide invasion of Body Snatcher films. These primarily tell the story of an alien invasion on earth and the simultaneous equalization of humans.

Whereas the 1956 version (directed by Don Siegel) is still a black and white movie set in an idyllic small town, an anti-communist area underlining the danger brought to society in shape of colossal outer space semen, the cinematographic composition of the 1978 version appears much darker. Director Philip Kaufman not only gave a blunt and merciless portrayal of post-Vietnam War society, he also hit the ravages of time. ${ }^{1}$ With its gloomy atmosphere and the permanent presence of a terrifying yet elusive alien power, Invasion of the Body Snatchers follows the typical sort of late 1970 s mystery thrillers. ${ }^{2}$ Especially the unexpected ending contains one overall message: don't trust any BODY. Another 15 years later, right after the Gulf War, Abel Ferrara directed another version of the story set in a military base. The movie seems to be a combination of both previous movies, as it takes up numerous elements (such as familiar lines or characters) from its predecessors. Moreover, we notice a certain similarity in the scene structure, which is a typical characteristic for a Body Snatcher film; one that can also be found in the 2007 adaptation by Oliver Hirschbiegel. His The Invasion is the latest remake of Siegel's film. Although certain scenes ${ }^{3}$ recall earlier versions, the theme of "sleeping" has a

1 The film, for example, stars Donald Sutherland, Jeff Goldblum and Leonard Nimoy - all of them famos actors in the 1970s.

2 Another example is Peter Weir's The Last Wave (1977), which is set in Australia and takes up Indigenous Australian themes. It is quite interesting to compare the audio-visual storytelling techniques used in both films as there are similar motifs such as a pulse beating that only the viewer is able to hear.

3 See, for example, the scene in which Tucker Kaufman tries to convince his former wife Carol Bennell of the beauty that lies within being snatched. 
whole different meaning after the events of September $11 .{ }^{4}$ Also, the atmosphere conveyed in this movie has changed into a terrifying one: whereas Kaufman and Ferrara both strongly implemented uncanny elements in their works, Hirschbiegel almost went back to the roots of the 1956 Body Snatchers, as his movie focuses on terrifying components rather than horrific ones.

Thus we can say that when considering the film's release years it seems as if almost each decade has its own Snatcher movie that reviews contemporary sociocultural issues and comments on the fears of society by encoding them into metaphors of communism (1950s), war (1970s) and terrorism (2000s). These metaphors, as I will argue, are not only psychologically manifested in the characters of the films but also in their outer appearance. The corporeality of the snatched body is the visualization of a whole generation's fear projected on the other, the alien. Furthermore, the altered bodies also hint at a popular feature of the science fiction genre, which is the implementation of horrific elements such as the monster or the alien. If these films include horrific elements, to what extent, then, is it possible to strictly distinguish between horror and science fiction movie? Looking at different examples such as Stuart Gordon's Re-Animator (1985) or David Cronenberg's The Fly (1986), we clearly see that there is something like a meta-genre to be called SciFi-Horror. ${ }^{5}$

\section{Invasion of the Body Snatchers (1956)}

When the first Body Snatcher movie, Invasion of the Body Snatchers, was released in 1956, the United States was facing a problem that had occurred after the end of World War II: the Cold War. During this period, the Soviet Union opposed the United States (and their Western allies). The tension between them was expressed through a high level of espionage, invasions, technological competition and above all the space race. The intensity of the conflict and its medial representation can be interpreted as making a boogeyman out of the Communist, who became the fear of a whole generation.

Regarding Siegel's Invasion of the Body Snatchers, the alien serves as a stand-in for this fear. It presents the perfect boogeyman of the Communist, already in its outer appearance. The first time we see the snatched creature in Siegel's film, it is lying motionless on a pool table. The leading characters Miles Bennell and Betty Driscoll have been called to the Belicec's house where Jack and Teddy are already waiting outside. They invite them in and Jack talks to Miles and Betty in a secre-

4 In all of the Body Snatcher versions, humans are snatched while they are asleep, thus the "sleeping" becomes one of the films' key motifs. On the other hand, after the events of September 11, 2001, terrorists leading their everyday life in the United States society became known as "sleepers" - they invade society from within without being recognized.

5 A definition hereof has previously been given according to Vivian Sobchak, author of Screening Space. 
tive manner, not revealing what the point of their invitation is. Inside the house, Jack tells Miles to walk over to the pool table. The atmosphere is gloomy, as only parts of the bar room are lighted. The pool table in the foreground is completely shady. Miles walks over and switches on the ceiling light. His body is silhouetted against the wall. Something indefinable is lying on the table, covered with a blanket that makes it look like a body bag. Miles is shocked when he discovers a body below. Being a doctor, he examines it, and then asks Jack who the man was. The cuckoo clock counts down scaring Betty, who moves over to Miles quickly. She glances at the supposedly dead body and remarks that its facial expression is "vague." Jack adds that it looks like "the first impressions of a stamp on a coin" it is not finished. Miles, taking a closer look at the body, finds out that even though facial features are given, the details and lines characteristic for a human face are missing. The group discusses whether the body might be a human corpse or not. Then Miles asks for an ink-pad to take the body's fingerprints. Just like the unfinished face, they are characterless, blank. Teddy wonders whose body replica it might be. The four of them go to the bar and discuss it. Teddy remarks that it has Jack's height and weight, which surprises her husband so much that he injures himself in this moment of shock. Miles wonders whether there might be some connection between Jack and the body. A short time later, he and Becky leave. Teddy and Jack stay at their place. When Jack falls asleep for a moment, Teddy examines the corpse again and recognizes that it has a wound at the same spot where Jack hurt himself. She wakes her husband in fright and both of them hurry to Miles's place.

In this sequence, both characters and audience are confronted with the alien during its growth. We neither know where it came from nor have we seen the alien source before. However, the corpus is presented to us through the descriptions the characters give. Even though we barely get a glimpse of it, an exact idea of what it must look like is manifested on our mind: the creature under the blanket looks like a dead man. It is motionless, has vague facial expressions, and lacks details and lines. It appears to be unfinished and characterless. Later in that sequence, when we briefly see the creature's face in a close up shot, we clearly notice the lack of detail: the emotionless facial features strengthen the impression that it must be dead. This image of death and its hiding under the body bag-like blanket which indicates the deadness triggers the reception of the alien as a monstrous being: Not only is it an unknown creature and thereby according to Sardar identifiable as alien (because it is different from the other characters who are alive, have mimics, features and emotions which are recognizable through the lines on their faces), but it can also be regarded as the monster since we are presented with Jack's doppelgänger, his motionless replica which disturbs the characters because of its strange otherness. And at this point it must be mentioned that the dead body is not the frightening aspect but rather its features which remind the characters of Jack. 
Moreover, the discourse on the Cold War conflict and the fear of Communist invasion contemporaneous to the film's release is metaphorically manifested in the alien's outer appearance. It is described as characterless and blank yet as still looking human. This picture conveys the idea of the perfect spy as a neutral figure, a blunt instrument and anonymous person who simply functions for the state. The spy's task was to gain information from the opponent in order to foster the Communist regime. Thus, he worked undercover and apparently became friends with the political "enemy" to transmit secret information (cf. Quiring).

In Siegel's Invasion of the Body Snatchers, this picture of the undercover spy is deployed several times. It is most explicitly used in the medical office scene when Jack's doppelgänger takes advantage of the friendship with Miles in order to convert him to the league of aliens. To quote a famous line from the movie, Jack "looks the same but he has changed - his emotions have changed," as Miles and Betty agree. Jack's alien-invaded body tries to invade Miles's thoughts in preparation for a bodily invasion. Thereby the doppelgänger wants to prepare the ground for a societal change, since the aliens distinguish themselves from humans by their lack of emotions.

This idea of a hierarchical system in which the participants work as they have been ordered - the famous Saturday morning street scene viewed from Miles's office in which the snatched people unpack new pods from trucks to further the snatching in town - very much reminds viewers of the principles of Communism: Individuality is lost due to the fact that all people are forcibly equated. Thus, the missing fingerprints of the alien body in the encounter sequence at the Belicec's house are a beautifully encoded example of this contemporary US American fear: The fear of losing what makes people unique, being invaded and becoming a Communist by force. Regarding the socio-cultural background of the United States during the Cold War, this image of Communist invasion is the horrifying part of Siegel's film, as it becomes obvious in the above mentioned scenes in Miles's office and Jack's house.

\section{Invasion of the Body Snatchers (1978)}

Twenty-two years later, the Cold War was still continuing and the United States was still facing a Communist opponent. But times had changed: The United States had won the space race with Neil Armstrong and Buzz Aldrin being the first men on the moon. On the other hand the shadow of the Vietnam War, which was fought between 1959 and 1975, laid heavy on people's minds. US American society tried to find its way back to normality and to get on with everyday life. Only now they knew that technology had turned another direction: The chemical war- 
fare had reached a new dimension in the battles of Vietnam (Simkin). Defoliants, also known as the Rainbow Herbicides (including Agent Orange, an herbicide that had dioxin as a by-product in it) were used to fight the enemy. However, the use of such chemicals had not just caused changes in the ecological system but also the people residing in these areas - along the Ho-Chi-Minh trail - had been affected. The American society was now confronted with consequential issues of guilt and fear and the return to daily routine was not as easy as expected (Monsterland).

In 1978, Philip Kaufman's remake of Invasion of the Body Snatchers was released. The film depicts exactly the situation of people trying to re-integrate into society. The fear factor deployed in the movie, however, went through an alteration: Whereas in Siegel's film the horror motif basically rests on the idea of a Communist invasion, Kaufman establishes a more complex fear which functions on three additional levels. Firstly, the power of the other: After the effects of the Vietnam War, people were well aware that if their country was able to use chemical warfare, other nations could do so, too, and the effects would probably be unpredictable. Secondly, the ethic pitfalls of scientific progress: In 1971, surgeon Robert J. White had been the first scientist to transplant the head of a monkey to another monkey's body (cf. White et al.). There is a direct reference to that in the Body Snatchers movie when a man-headed dog crosses the street. Thirdly, the ecological effects: They had triggered a change in climate and poisoned food chains for example.

In order to point out how Kaufman produced two types of creatures in his remake, the alien source and the alien corpus, which embody the disturbing other in an even more horrifying way, I will now focus on the cocoon scene in the 1978 Body Snatcher movie. In this scene, the alien source tries to snatch Matthew Bennell and his friends Elizabeth Driscoll, Jack and Nancy Bellicec. It produces their doppelgängers and feeds from their bodies while they are asleep.

Matthew, Elizabeth, Jack and Nancy are at Matthew's place. It is late at night; Elizabeth and Jack have fallen asleep. Nancy is still awake, whereas Matthew tries to resist fatigue. While sitting outside in the front yard, however, he gets tired and finally falls asleep. Now the alien source starts the snatching process by spreading its roots across the yard towards Matthew. The string-like looking roots softly entangle his hand and a giant seed pod, which is in the garden, starts moving. The sound of a heartbeat can be heard. The pod opens up and pops out its fleshycolored petals. The deeper Matthew dreams, the faster it grows. The heartbeat turns louder as the pod fully opens, revealing in its center a reddish, muscle-like, slimy receptacle. The petals decay and eventually fall off. Disturbing sonar sounds underline the growing of Matthew's doppelgänger: the pod pops out a degenerated alien embryo covered in slime. The disproportioned body of the embryo is gasping for air. It expels bird-like sounds as if it was calling for its mother. Two 
more pods grow their embryos. Matthew's doppelgänger grows to his size: it now appears to be the almost perfect replica since its hair and facial features are a copy of the human original. The gasping for air gets heavier and the body starts twitching, trying to break free from the pod. The other embryos develop the features of Elizabeth and Jack. Suddenly, Nancy stands on the porch calling for Matthew. He wakes up and hurries inside. The twitching of his alien doppelgänger gets heavier as if it was dying.

This sequence is a key moment in the movie as it shows the growing process of the replica. At first, there is only the seed pod which later develops into a plant and then literally gives birth to the alien. The alien and its source are therefore connected not only with each other but also with their human host. However, the growing process takes place on two levels, which differ in their depiction of the horrific: the evolution of the alien source and the growth of the alien itself.

Whereas the alien source appears almost peacefully in the beginning, softly spreading its tentacle-like roots to invade Matthew, the alien embryo is introduced to the story at a point of unbearable tension. At first the pod seems to develop only into a plant. There is nothing frightening about it, nothing scaring, just the connotation of "nature's beauty." However, the image of an ordinary growing process taking place is an illusion. As soon as we then notice the disturbing core of the plant, an unpleasant feeling of terror sets in: we are unaware of what is going to happen next. Following, the heart-like pistil and fleshy petals instigate a feeling of disgust. Terror changes into horror after the embryo has popped out. The process reminds the viewer of a delivery and thereby causes confusion and repulsion when the plant disturbingly grows human look-alikes. Even worse than that, evolution has taken another direction, a horrifying, disgusting one that even foreshadows a dystopian world. The question now is which metaphors does the sequence contain and how can they be interpreted?

On the one hand, we are presented with the horrifying image of the other again: just as in the original version, the alien in Kaufman's remake embodies the dystopian vision of the Communist enemy, but the film's focus is changed in so far that the idea of a Communist invasion is not the most frightening point anymore. Rather, the vision of dystopia is intensified by the awareness of the Communist military power that became evident during the Vietnam War. Thus, the corporeal construction of the alien in Kaufman's remake is slightly different: whereas the creature in Siegel's film is monstrous because of its blank and motionless facial features, Kaufman's alien is horrifying because it becomes a nearly perfect replica of Matthew within short time, which indicates the opponent's ability to strike back mercilessly.

The transformation process of Kaufman's alien is quite fast and thereby also hints at the rapidly changing society and its moral values. If the alien in the film is able to quickly turn from a slimy, degenerated embryo into a human look-alike while the humans are sleeping, changes might be happing in real-life without anyone noticing them. In this case, the transformation resembles the process of 
changing directions in everyday life, whereas the sleeping character stands for the ignorance of society - quite often we don't see what is right in front of us because we don't question much. The fear of being ignorant is most of all illustrated in this sequence by the use of extraordinary special effects such as the slimy surface of the alien, its twitching moves and the bird-like cry.

On the other hand we must observe which meaning is conveyed by the idea of a plant giving birth to an embryo. The use of defoliants in the Vietnam War had left its marks: a functioning ecologic system had been widely damaged and in the aftermath people were confronted with poisoned food chains, changed landscapes and birth defects. Thus, the idea of the plant delivering an embryo signifies the unpredictability of the effects caused by chemical warfare. The wide use of newly developed scientifically enhanced products obfuscated the inexperience with longterm damages. Consequently, the deformed alien embryo metaphorically reflects popular discourses on birth defects that occurred after the Vietnam War. Thus, we can say the film warns against the careless use of new scientific products. Not only the unpredictability of effects but also the possibility of the opponent using chemicals in war, too, was a fear society had to deal with. Therefore, Kaufman's mise-en-scène in Body Snatchers is a remake which thoughtfully adjusted contemporary societal issues by reflecting a wider range of frightening aspects. However, the message of Siegel's film is still recognizable. Only the fear of the enemy invasion has switched to a fear of the enemy's powerful influence.

\section{The Alien as a Mirror of Our Contemporary Time}

This chapter has sought to discuss Siegel's Invasion of the Body Snatchers and its remakes as a hybrid genre that mixes with certain Horror elements. Drawing on Seeßlen, Sobchack and Varma, I argued that the corporeal construction of the alien in the 1956 and 1978 versions reflects contemporary socio-cultural issues. More precisely, the horrifying aspects could be identified as societal fears that are metaphorically manifested in the outer appearance of the alien in the Body Snatcher films. Yet in Kaufman's version, the alien neither only mirrors the enemy stereotype nor simply resembles the fear of "the other" as it does in Don Siegel's version. It functions as a socio-critical metaphor revealing similarities between the self (in that case the civilian) and the other (the Communist enemy) who can adapt to American culture, operate as a spy and make use of Western technologies which, in turn, can be of inhuman impact.

The commentary function of the SciFi-Horror meta-genre hence plays a crucial part. If the cinematic enemy is a natural product - the plant delivering the replica - and nature has been damaged by Western powers using new technologies and chemicals, the conclusion would be that the enemy is a self-generated problem, similar to the proverb, "What goes around, comes around." The Western powers had started chemical warfare and by now the Communist enemy was able 
to make use of it, too. When comparing Kaufman's film to Ferrara's remake, we see that the tendency of portraying the enemy as a danger that strikes back from within society has become more and more popular. In the 1993 version (Body Snatchers, Dir. Abel Ferrara), the U.S. military falls victim to its own chemical inventions, whereas the 2007 version (The Invasion, Dir. Oliver Hirschbiegel) conveys the image of terrorist sleepers (an ex-husband trying to persuade his wife to be invaded). Thus, the critical aspect of the alien body in these movies lies in its reflection of society and the contemporaneous questions it raises, which are whether or not the enemy - to a certain extent - was brought on by one's own fault.

\section{Films Cited}

Body Snatchers. Dir. Abel Ferrara. Perf. Gabrielle Anwar, Terry Kinney, Forest Whitaker. Warner Bros. Pictures, 1993. DVD.

Invasion of the Body Snatchers. Dir. Don Siegel. Perf. Kevin McCarthy, Dana Wynter, Larry Gates. Walter Wanger Productions, 1956. DVD.

Invasion of the Body Snatchers. Dir. Philip Kaufman. Perf. Donald Sutherland, Brooke Adams, Jeff Goldblum. Solofilm, 1978. DVD.

Monsterland. Dir. Jörg Buttgereit. Perf. Rick Baker, John Carpenter, Kim Newman. Avanti Media. 2009. DVD.

Re-Animator. Dir. Stuart Gordon. Perf. Jeffrey Combs, Bruce Abbott, Barbara Crampton. Empire Pictures, 1985. DVD.

The Fly. Dir. David Cronenberg. Perf. Jeff Goldblum, Geena Davis, John Getz. Brooksfilms, 1986. DVD.

The Invasion. Dir. Oliver Hirschbiegel. Perf. Nicole Kidman, Daniel Craig, Jeremy Northam. Warner Bros. Pictures, 2007. DVD.

The Last Wave. Dir. Peter Weir. Perf. Richard Chamberlain, Olivia Hamnett, David Gulpilil. The Australian Film Commission, 1977. DVD.

\section{Works Cited}

"corporal." Oxford Paperback Dictionary: Thesaurus \& Wordpower Guide. Eds. Soanes, Catherine, Alan Spooner, and Sara Hawker. New York: Oxford UP, 2001. 191. Print.

Maloney, Paul. Utopia and Dystopia: Visions of Alternative Societies. Berlin: Cornelsen, 2008. Print.

Botting, Fred. "'Monsters of the Imagination': Gothic, Science, Fiction." A Companion to Science Fiction. Ed. David Seed. Malden, Oxford: Blackwell Publishing, 2008. 111-126. Print. 
Brenez, Nicole. "Die abscheuliche Vertrautheit der Familie. Body Snatchers von Abel Ferrara." Unheimlich Anders: Doppelgänger, Monster, Schattenwesen im Kino. Ed. Christine Rüffert. Berlin: Bertz- und Fischer, 2004. 93-103. Print.

Chancellor, Henry. James Bond: The Man and His World. The Official Companion to Ian Fleming's Creation. London: John Murray, 2005. Print.

Cavallaro, Dani. The Gothic Vision: Three Centuries of Horror, Terror and Fear. New York: Continuum, 2002. Print.

Finney, Jack. Invasion of the Body Snatchers. 1954. New York: Scribner Paperback Fiction, 1998. Print.

Kristeva, Julia. Powers of Horror: An Essay on Abjection. New York: Columbia University Press, 1982. Print.

Matheson, Richard. I Am Legend. 1954. London: Orion Publishing Group, 1999. Print.

Quiring, Manfred. "Putin ehrt Star-Spion des Kalten Krieges." Welt Online 4 Nov. 2007. Web. 17 Dec. 2010. <http://www.welt.de/politik/article1330155/Putin_ ehrt_Star_Spion_des_Kalten_Krieges.html>

Sardar, Ziauddin, and Sean Cubritt. "Introduction." Aliens R US: The Other in Science Fiction Cinema. London: Pluto P, 2002. Print.

Seeßlen, Georg, and Fernand Jung. "Typologie der Horror-Mythen." Horror: Geschichte und Mythologie des Horrorfilms. Marburg: Schüren, 2006. 44-57. Print.

Simkin, John. "Chemical Warfare." Spartacus Educational. Spartacus Schoolnet, n.d. Web. 15 Dec. 2010. <http://www.spartacus.schoolnet.co.uk/VNchemical.htm>.

Sobchack, Vivian. Screening Space: The American Science Fiction Film. New York: Ungar. 1987. Print.

White, Robert J., et al. "Cephalic Exchange Transplantation in the Monkey." Surgery 70.1 (July 1971): 135-39. Print.

Zimbardo, Philip. Psychologie. 1992. 5. Auflage. Berlin: Springer, 1995. Print. 
Gina Ziebell

\section{Why Does the One Only Exist in Cyberspace? Obsolescence of the Body, Construction of a Virtual Subject and the Question of Control in The Matrix}

\section{Introduction: Why Identity Matters in Virtual Reality}

Not so long ago, the future of the science fiction film was considered bleak by some of the most important scholars in this area (Sobchack qtd. in Landon xxii). Even cyberpunk, celebrated by some for its unprecedented engagement with postmodern issues (Barnett 6; Landon xxiv) and seen critically by others (Bould 228), had lost much of its creativity. Barnett summarizes that cyberpunk works had become "restrained, commercialized, and mimetic" (360) since, according to Fredric Jameson, it had turned into "mere 'realism' and an outright representation of the present." Jameson continues his criticism with more detail, pointing to the limitations of a representative form in a genre that lives from its innovations (qtd. in Barnett 361). "Based on this criticism," Barnett concludes, "if the cyberpunk aesthetic is to be resuscitated, it must regain its Bohemian edge, return to its underground roots and present a more accurate depiction of the postmodern sublime that is multinational capitalism" (361). Consequently, what Barnett calls for 
are new ways to put the dark and dirty noir-inspired world of cyberpunk back in touch with nowadays' increasing tendencies towards world monopolies that have become a real possibility instead of the culmination of mere imagination. It is such a world that challenges traditional assumptions of selfhood and pushes it towards postmodern fragmentation and decenteredness. And it is cyberpunk with its dangerous dystopian imaginings that is best fit to depict such changes. Yet despite Barnett's call for "resuscitation," such a revival of cyberpunk did not happen until the end of the 1990s when The Matrix (1999), directed by Andy and Larry Wachowski, caused a "resurgence of and improvement on the same cyberpunk aesthetic (only now in visual form)" that "brought a ... smart postmodern aesthetic back to cyberpunk" (Barnett 362).

This "postmodern aesthetic" is influenced heavily by some of the most prominent aspects discussed in postmodern theory. As Veronica Hollinger summarizes: "In virtually every description of 'the postmodern' developed in the past two decades, the increasingly pervasive influence of science and technology on human life has been cited as one of its constitutive features" (232). The consequences of such an augmenting impact eventually lead to a questioning not only of the role of technology in our daily lives, but also of the position humans hold in society. Postmodern theory and art concern themselves with the technological dominance over the human, and cyberpunk takes up a special stance in this context. As Barnett asserts: "[C]yberpunk is the most likely source for answers to questions regarding the machine-human dynamic in multinational society" and "concerns itself most directly with the implications of cyberspace, virtual reality, and a host of technologies that place real human forms at risk of extinction" (360, emphasis in the original).

What cyberpunk does is to show us a world where humans are no longer at the center but where machines have come to take control instead (Barnett 367). Moreover, cyberpunk fiction depicts a world where human subjectivity becomes fragmented as it is no longer grounded in bodily experience. While bodily experience involves interactions of the human body with the physical reality, cyberpunk introduces an interaction between mind and virtual reality in cyberspace. The postmodern present is characterized by simulations, virtual realities, cyberspace and simulacra which no longer require physicality to function. According to Bukatman, we are facing

a postmodern crisis of a body that remains central to the operations of advanced capitalism as sign, while it has become entirely superfluous as object. ... Simply put, the body is not a requisite for the survival of the technocratic system. In cyberpunk science fiction the body finds and occupies a new space; a realm in which a control over the dataspheres of capitalism is restored. Within the intersecting planes of cyberspace, the body is re-placed and subject's autonomy is resurrected. (16, emphasis in the original) 
It is cyberpunk science fiction, and as such also The Matrix, which addresses the implications of this "technocratic system" for its human inhabitant. The film considers the "ontology of cyberspace" (Barnett 360) by taking the viewer into a simulated, digital world where subjectivity can literally be put together out of data fragments. The self is depicted as a construction, and we are in the course of the movie introduced to a subject that no longer needs physicality and unity of self in order to develop a sense of self-identity. Rather, we are presented with a subject whose mind itself becomes embodied and defines itself through agency in an electronic (cyber)space. It is the example of the protagonist Neo that shows us this development, and through him the movie reassures us that even in the Information Age of cyberspace and virtual reality, the human subject will in the end also control this new spatiality.

\section{Mr. Anderson and Reality: Identity and Physical Experience}

Right from the beginning of The Matrix, the viewer gets the feeling that things are not quite normal in this world - our world - as it is presented to him. Although we recognize the tall buildings and rundown streets as any Western city by night and the Agents with their dark suits and radio cables as the standard image of a federal agent, there are some elements in this sequence that throw us off. It is not only the ominous music which accompanies the opening of the first scene through a set of numerical codes on a black screen, but also the following fight and chase sequence of about five minutes where Trinity and the Agent perform movements which seem impossible. Trinity is only later revealed as part of a rebel group that wants to free humanity from the Matrix, the virtual reality they are imprisoned in without their knowledge, while the Agent is introduced as a hunting program encoded into the virtual reality to prevent its destruction. Even with the suspension of disbelief, which the introduction asks us to perform, we are left in the same situation the male protagonist is in when we are introduced to him in the next scene. The setting is recognized as "our world," despite the chase sequence and the greenish filter which gives the shots a gloomy atmosphere, yet there is something odd about it.

Consequently, this first sequence is important in more than one way. It not only presents the technique of "bullet time," which is central to the movie's unprecedented aesthetics, but moreover it leads the viewer to a point where he or she can immediately identify with the protagonist as he is introduced on his search for an answer to explain this strange feeling he has about his world.

In a telling way, the male protagonist is first presented to us as a hacker who goes by the alias Neo, and we get to know him as a person who likes to spend his time in the electronic world of cyberspace. It is this activity which has led him to the ultimate question that Morpheus, the rebel leader and Neo's future mentor, formulates for him: "What is the Matrix?" Yet not long after this encounter, our 
protagonist is revealed to have another identity, which Agent Smith describes as that of "Thomas A. Anderson, program writer for a respectable software company," leading a life in which he is firmly grounded in "reality" - paying taxes, helping an old lady to take out her garbage. Despite his double life, Thomas Anderson's sense of self is clearly bound to a physical experience of the world, even though he often works with computer programs and networks. He is presented to us as someone who uses - or of whom we, up until a certain point, believe he uses - his body to control his actions and, to a degree, his surroundings.

"The self, of course, is embodied" (56) is how Anthony Giddens begins a section on "Body and Self" in his book Modernity and Self-Identity: Self and Society in the Late Modern Age (1991). For Giddens, this section is part of a query into ontological and existential issues that are of importance for a consideration of (post)modern self-identity. Here, he not only describes self-identity as being based on discursiveness (54), but also goes on to discuss the central role of the body for the self in daily life. He specifically links the development of subjectivity to bodily experience: "A child does not learn that it 'has' a body, because self-consciousness emerges through bodily differentiation rather than the other way around" (56). Modern subjectivity, according to Giddens, is built through interaction with the world - meaning both objects and other people (56) - for which one needs a body:

Reality is grasped through day-to-day praxis. The body is thus not simply an 'entity', but is experienced as a practical mode of coping with external situations and events. ... To learn to become a competent agent ... is to be able to exert a continuous, and successful, monitoring of face and body. (56, emphasis in the original)

This is how Neo's identity is shown in this first part of the movie in which he, along with the viewer, does not know that his "reality" is only the Matrix, a virtual reality taking the shape of the world as it was in 1999 and to which every human being is connected. The sense of self that is portrayed here works with the idea that the subject can control his surroundings to a certain degree (follow the rabbit or not, climb out the window or not), but not completely so. The subject is limited by such things as laws of nature and physical constraints - the Thomas Anderson presented to us cannot jump from rooftop to rooftop to avoid the Agents. At least one half of Neo's double life is based on such assumptions. Paying taxes and taking out the landlady's garbage are repeated actions that say something about who Thomas Anderson is since they are results of his agency in a (supposed) reality, a self which he himself constructed.

All this is expressed by what Giddens concludes about the self in his considerations of existential questions: "Self-identity, in other words, is not something that is just given, as a result of the continuities of the individual's action-system, but something that has to be routinely created and sustained in the reflexive activi- 
ties of the individual" (52). Using these assumptions as starting point for the further development of Neo's identity in the course of the movie, I will subsequently focus on the protagonist's loss of a subjectivity based in physicality, and furthermore examine the Construct and its importance for Neo in constructing a new subjectivity.

\section{Uploading and the Construct: Fragmentation and Dislocation of the Subject}

The viewer, just as curious as the protagonist, joins Neo on his path as he sets out to find out what the Matrix is. We share his feelings of disbelief when he - and the audience - finds himself in a world that despite all allusions to Alice in Wonderland and The Wizard of $\mathrm{Oz}$ feels more like an inversion of wonderland than anything else. The distorted camera angles, the pans and tilts shot from Neo's point of view in the cramped space of the Nebuchadnezzar convey a feeling of alienation which we think he must be feeling in this 'real' reality outside the Matrix.

The shock Neo experiences after having been physically and mentally disconnected from the Matrix by the rebels, though, is not only that of learning that his whole life so far has been an illusion, but also the loss of his identity. He was living in a virtual reality without resemblance to the reality that exists outside of it and therefore the control over his seemingly physical surroundings was a lie. He has held no control, no power of agency whatsoever - at least that is what it looks like in the beginning. For someone whose sense of self for his whole life has been based on the idea of physicality and a degree of control over concrete objects, this is a disorienting blow. While this view presupposes a certain measure of physical and geographical unity, these factors are now lost for Neo. About the place where he lived he learns that it does not physically exist at all, and about his concrete surroundings and own body he realizes that they have only been a simulation created by a machine. These realizations result in the "death" of Thomas Anderson that part of his double identity that has been grounded in factors now revealed as non-existent. It is "Neo" who remains because this hacker part of his self has mostly existed in cyberspace anyway. ${ }^{1}$

What follows now in The Matrix is not only a part that shows the training Neo undergoes to be prepared to enter the Matrix as a sort of guerilla fighter, but also a redefinition of his subjectivity which is closely connected to what he learns. Important for this process is what the crew calls "the Construct," a "loading program," as Morpheus explains to Neo when they first enter it after Neo has been disconnected from the Matrix: "We can load anything from clothes, to weapons, to training simulations. Anything we need." Moreover, they can upload parts of

1 This might have to do with the fact that the name "Neo" was chosen by himself. Concerning the relation between the act of naming and identity, see Ravichandran 34-35. 
themselves - or at the least that part which Morpheus calls the "residual selfimage."

The Construct is introduced as a blank space where things can appear and disappear at the will of someone who is controlling the upload from outside. We also get to see it as a Japanese style dojo in which Neo and Morpheus train, as a "jumping program," as a simulation that looks like the Matrix and is filled with rows and rows of weapons. Computer screens inside the hovercraft allow the crew to observe what is happening inside the Construct. It is the operators who control the make-up of the Construct and decide what to load - as Tank, the operator in control of the Construct, tells Neo: "We are supposed to load all these operations programs first, but this is some major boring shit. Why don't we start with something a little fun?" In the Construct, Neo learns all the skills which allow him to survive in the Matrix in his encounters with the Agents. It is in this space where he first shows promise of being someone special when he fights Morpheus.

These points seem to be the basic features of the Construct as far as they are explained in or can be inferred from the movie. Apart from these basic facts, the role of the Construct for Neo's redefinition of subjectivity is hard to point out. In the following paragraphs, I will therefore attempt to examine the Construct's properties within the framework of my argument and to point out possible consequences for Neo's identity.

When entering the Construct, the subject enters an electronic space just as if being plugged into the Matrix since both are computer programs. This process dislocates the subject not only in a geographical sense - because cyberspace is everywhere and nowhere at once - but also concerning a fixed sense of selfidentity. As Bukatman writes:

Subject dislocation is enacted by a movement through an excruciatingly technological, decentering spatiality. The site of origin of the subject passes first outside the body and then inside the terminal. ... [T] he subject is broken down in the zones of cyberspatial simulation, there to await its reconstitution amidst these fields of data. (180, emphasis in the original)

This explanation makes it clear that through subject dislocation, the self is removed from an actual space, such as the one which Thomas Anderson perceives as "reality," in which the body works as the center of agency. Instead, it becomes located in cyberspace where the conditions for the construction of subjectivity are different because cyberspace is not physical and as such denies the self a stable reference point for its identity.

Yet it remains unclear to what extent being in the Construct has different effects on the subject than being in the Matrix. Both are electronic spaces where some outside force determines the subject's surroundings so that the subject can control them only to a certain degree, although this manipulation is different from bodily control in physical reality. The Construct, though, might be different from 
the Matrix in that it is ultimately a human being who is in control of determining the contents of the computer program, not a machine. Because of this it could possibly be considered as a sort of in-between space between the Matrix and physical reality - a humanitarian cyberspace. This idea of a cyberspace in which humans are in control - as in opposition to the Matrix which is controlled by machines - though, is connected strongly to the figure of the operator as someone who delivers the objects and skills necessary for the protagonists to defeat the Agents, and not to the properties of the Construct itself. Any characteristics of human control could be linked back to the fact that the operators, who were born outside the Matrix, are "one hundred percent pure, old-fashioned, home-grown human."

The fact that in the Construct Neo first catches a glimpse of his abilities as the One prophesied to be able to control the Matrix as he wishes, gives this space a degree of importance. Still, the actual impact of the Construct for the refashioning of his identity remains uncertain since it is both similar to the Matrix in its technological properties and different from it as it is controlled by a human.

\section{Plugging Into the Matrix: "Terminal Identity" and the Virtual Subject}

When Neo realizes that what he perceived as "reality" is nothing more than a digitally constructed illusion, he has to come to terms with the fact that his body has never been the center of agency as he thought it was. The only way for him to rebuild a sense of self now lies in creating a routine, a continuity of actions in the way Giddens remarks on the construction of self-identity (52). The Construct, however, with its state in between actual space and cyberspace might give him a first insight into the possibilities of fashioning a new identity for himself. In the following paragraphs, I will examine what impact Neo's entrance into the Matrix has on his sense of self, the relation of his physical and his phenomenological body, and his ability to act.

As Morpheus enters the Construct together with Neo to explain to him how the Matrix works and what reality actually looks like, he describes the way the machines use humans to create energy as "fusion." This kind of combination is usually termed "interface" today, defined as "the boundary of two bodies or spaces," or, as Bukatman writes, "as existing between a body and a space" (192, emphasis in the original). In Terminal Identity, he argues that science fiction presents us with a new form of subject that overcomes this boundary between body and space, or more precisely makes the boundary vanish. By fusing with technology, this new subject becomes able to occupy cyberspace (8-9).

This subject is characterized by what William S. Burroughs calls "terminal identity": "an unmistakably doubled articulation in which we find both the end of the subject and a new subjectivity at the computer station or television screen" 
(Bukatman 9). The terminal identity is the end, the termination, of the sense of subjectivity based on physical reality and geographical unity - the end of the embodied subject Thomas Anderson. On the other hand, this gives rise to the possibility of a subject dislocated from its physical form, one that exists in electronic space, as Neo does in the Matrix.

"Virtual subject" is the term Bukatman uses to define this latter form, "a new subject capable of inhabiting the bewildering and disembodied space of the electronic environment" (118):

$[\mathrm{R}]$ ecent SF frequently posits a reconception of the human and the ability to interface with the new terminal experience - as in cyberpunk - and thus a uniquely terminal space becomes a fundamental part of human (or posthuman) redefinition. ... [W] hat is involved is a projection or transmission of the human into 'the infinite datascape' and the concurrent construction of a spatial simulacrum of the invisible circulation of information. These narratives literalize McLuhan's vision of a prosthetic extension of the human nervous system into the new fields of the electronic environment, granting the process an important spatiality which represents a simultaneous grounding and dislocating of human bodily experience. (118, emphasis in the original)

This projection into cyberspace is what happens to Neo. His consciousness is connected to the technological data spheres of cyberspace, his "residual selfimage" is loaded and supplemented by skills, clothing and other necessities that the operator can digitally create for him. But not everything about this cyberspatial $\mathrm{Neo}$ is the result of data manipulation, since he also possesses his abilities as the One which appear to be inherently his own. He loses his identity as Thomas Anderson but fully inhabits that of "Neo" in the process of (re)constructing his sense of self. His new sense of subjectivity is no longer located in a physical reality and limited by the rules of the system. Instead he understands the fact that what he sees is only an illusion which in the end allows him to at once see the image created by the Matrix and the codes that operate behind it. This makes it possible for him to manipulate the Matrix and thus work against its system.

By entering the electronic space, Neo gains a new sort of experience in that (for him) it is no longer his physical body that "experiences" and connects him to his surroundings and functions as center of his self-identity. Rather, his brain is the new center of his experience as it sorts through the electrical signals sent to it by the electronic system to create a surrounding phenomenal cyber-world: "Virtual reality represents an attempt to eliminate the interface between user and information - by 'transforming data into environment"' (Bukatman 191-92). In a similar fashion, Morpheus asks Neo in The Matrix: "What is real? How do you define real? If you're talking about what you feel, taste, smell or see, then real is simply electrical signals interpreted by your brain." When Neo is plugged into the Matrix and his brain starts constructing an illusion of physical reality from the 
signals it receives, it is these "real" surroundings that allow the mind to become the center of experience.

To be installed into such an apparatus would be to exist on two planes at once: while one's objective body would remain in the real world, one's phenomenal body would be projected into the terminal reality. ... [W]orld and body comprise a continually modifying feedback loop, producing a terminal identity without the terminal - a cybersubject. (Bukatman 187, emphasis in the original)

The screen, which in today's human-machine interface functions as frontier between physical and virtual reality (Bukatman 108), has therefore become nonexistent as border: human and machine merge directly by connecting human nerves to electronic appliances. The construction of a new subject in electronic space creates a new double existence, but not necessarily a double identity, since the sense of subjectivity can be detached from physicality and be connected only to the "phenomenal body," as Bukatman calls it.

For Neo, it thus becomes possible to (re)fashion his new sense of self in electronic spaces such as the Construct and the Matrix, and still retain it even if he is in physical reality. Yet the fact that in order to be able to enter this space he needs to merge with a machine and enter a realm where technology seems to determine his surroundings raises a problem of control. If identity in one of its senses means "an agency," as Ravichandran (6) has pointed out, and according to Giddens (52), the individual's actions are important for creating and retaining it, then it is necessary for the subject to have a certain degree of control which the virtual reality does not offer. In the next section, I will examine this problem in further detail.

\section{Controlling the Matrix: The Question of Agency in Electronic Space}

What The Matrix does is creating for us a visible version of electronic space something that is usually invisible to us. Considering this connection between phenomenology and science fiction, Bukatman writes:

A phenomenology of science fiction helps us to understand the strategies of these works: specifically, their attempt to redefine the imperceptible (and therefore absent to consciousness) realms of the electronic era in terms of the physically and perceptually familiar. The motive is to render the electronic fields present to consciousness - to turn them into phenomena and therefore susceptible to human intention. (117)

The Matrix offers a similar link between seeing and control. Firstly, the language used to talk about the features of the Matrix often revolves around the act of seeing: Trinity tells Neo he has "to see it to believe it," the Agents had their 
"eye on [him] for some time," Morpheus tells him the Matrix is "the world that has been pulled over your eyes to blind you from the truth." Secondly, it is Neo's ability to "simultaneously see the virtual reality of the Matrix, the underlying code that writes and informs it, the bodies that are confined by it, the minds that are controlled by it, and the machines that generate it" (Barnett 369) that characterizes him as the One. Seeing is the sense that is singled out in the movie, and to a certain degree this is because it is a science fiction movie which relies heavily on special effects like bullet time to make visible the electronic space of the Matrix, to show us something we never perceived before. Moreover, the sense of seeing is linked closely with agency, since being conscious of a phenomenon enables us to react to it and, to a degree, shape it as we wish. "The human is inserted into the terminal space as a pure, totalizing, gaze," Bukatman summarizes. "The boundaries of the screen are eradicated, and the cyberscopic field becomes fully phenomenal, susceptible to human vision and action" (136).

With the phenomenological perception of the electronic fields comes a hitherto unseen form of body movement which is only possible in this particular space. What Bukatman says about William Gibson's Neuromancer (1984) in this context is valid for The Matrix as well:

The spatiality of Neuromancer exists to permit bodily mobility and, hence, subject definition. The human becomes the dramatic center, the active agent ... . [T] The phenomenology of perception is transformed into a transcendent valuation of human experience and its 'logical' consequent, human control. (206)

Mobility and perception, the two aspects of subjectivity named here, are according to Bukatman usually connected to a lived-body (207), but here they become characteristics of the "phenomenal body" of electronic space, the body-image generated by the mind, or the "residual self-image, the mental projection of your electronic self," as it is called in The Matrix. This becomes the reason why the simultaneous existence on two levels as experienced by someone who enters the Matrix is meaningless for subject definition. As Bukatman explains: "Thus, the duality between mind and body is superseded in a new formation that presents the mind as itself embodied. The body, here, exists only in phenomenological terms: it perceives and it moves" (208, emphasis in the original). The fact that the mind is detached from the physical body is presented as a gain of strength for the subject in the movie: not only does the phenomenal body in the Matrix offer a range of movements which would not be possible with one's actual body, but in this space Neo eventually acquires, in Morpheus's terms, the ability to "change what he wanted, to remake the Matrix as he saw fit," he has absolute control.

While such an obsolescence of the physical body is sometimes considered as the ultimate form of the death of the subject (as e.g. in Barnett 369), The Matrix instead presents it as the ultimate empowering of the subject. The new strength 
and power of agency gained by entering the virtual reality of the Matrix serve as elements for constructing a new sense of subjectivity in that they allow for the subject's control over its actions. Although this is only achieved through a merging of the human with technology, it is the human, i.e. Neo, who comes out on top in this fusion. ${ }^{2}$ Thus, despite the movie's celebration of the connection between human and technology and the body's devaluation, it still carries an affirmation of human agency and even supremacy. Therefore, it is also necessary that $\mathrm{Neo}$ is revealed as the One.

Neo is the center of the audience's focus during The Matrix's progression. This is not only because he is the protagonist, but mostly due to the fact that he is the one the viewer can best connect to since he is the only crew member to go through the painstaking process of revelation, alienation and redetermination of who he is in a new, strange world. He is the Alice or Dorothy we follow to accommodate to the unfamiliar wonderland we have been thrust into right alongside him.

Furthermore, he is also the only member of the crew to eventually completely master the Matrix, the only one with ultimate control over the spatiality of this virtual reality. With this development, the movie reassures us that even in a time when technology becomes more and more important and the interface between human and machine becomes more and more blurred and malleable, the human will be the one to come out on top. He will be the master of technology in the end, even though in the beginning it seemed to be the machines that had humanity completely subdued and mastered.

Only by establishing Neo as the powerful figure of the One can The Matrix offer an empowered version of the human mind, one that does not even need a body anymore to achieve agency. With this elevation of the mind, the movie solves the problem of identity that has been raised with the simultaneous obsolescence of the human body and the human self-identity based on geographic unity, mobility and agency that presupposes bodily control. All this, though, is only possible as long as Neo is the One who has the power to "remake the Matrix as he saw fit," for otherwise he would only be another victim of the machines' power so that the movie's message about the future of the human subject would be a pessimistic one instead. By allowing Neo to assume the role of the One, though, the movie follows a cyberpunk tradition of an empowering dissolution of the body (Bukatman 21) that simultaneously elevates the status of the non-physical mind.

2 For an analysis on similar instances in written science fiction, see Bukatman 208. 


\section{Works Cited}

Barnett, P. Chad. "Reviving Cyberpunk: (Re)Constructing the Subject and Mapping Cyberspace in the Wachowski Brothers' Film The Matrix." Extrapolation 41.4 (2000): 359-74. Print.

Bould, Mark. "Cyberpunk." A Companion to Science Fiction. Ed. David Seed. Malden, MA: Blackwell, 2005. 217-31. Print.

Bukatman, Scott. Terminal Identity: The Virtual Subject in Postmodern Science Fiction. Durham, NC: Duke UP, 1993. Print.

Giddens, Anthony. Modernity and Self-Identity: Self and Society in the Late Modern Age. Cambridge: Polity P, 1991. Print.

Hollinger, Veronica. "Science Fiction and Postmodernism." A Companion to Science Fiction. Ed. David Seed. Malden, MA: Blackwell, 2005. 232-47. Print.

Landon, Brooks. The Aesthetics of Ambivalence: Rethinking Science Fiction Film in the Age of Electronic (Re)Production. Westport, CO: Greenwood Press, 1992. Print.

Ravichandran, T. Postmodern Identity. Jaipur: RBSA Publishers, 2007. Print.

The Matrix. Dir. Andy Wachowski and Larry Wachowski. Perf. Keanu Reeves, Laurence Fishburne, and Carrie-Anne Moss. Warner Home Video, 1999. DVD. 
Epilogue 

Eric S. Rabkin

\section{The Creature from Brooklyn: My Life and Science Fiction Film}

Even today, fifty-six years later, I remember perching forward on the sticky, wornvelvet seats of the dark Beverly Theater on Church Avenue near my family's apartment in Brooklyn, New York, captivated during a shivery Saturday matinee, my eyes wide and mouth slack in amazement as The Creature From the Black Lagoon crept aboard a small diesel-powered river boat somewhere in the South American jungle and then, suddenly, snatched the bathing-suited beauty on deck, leaping with her into the murky deep. I can still see the Gill-Man, a prehistoric monster prodded into our world by self-righteous modern science, powering down into the water with one arm while clasping the woman's waist with another, dragging her clothed but utterly visible body ever further from air and light and toward me. Sitting in the chilly dark myself, it was stunning. I didn't know then that this was a " $\mathrm{B}$ " movie, cobbled together on a low-brow budget, a doublefeature filler the calculating studios produced to conjure a few more coins from the hands of children. The monster's rubber suit with its silly scales and webbed hands and feet was obviously a movie prop, but so what? That's what I wanted, movies! Adventure! Excitement! Bathing beauties in peril! I didn't know then - as the trailer must have announced the week before, as it still does on the Internet that I was watching "the most amazing underwater photography that the screen 
has ever known!" in this "strangest of all science fiction adventures!" I was eight and all I knew was that this was wonderful, and, somehow, deep down, that "they want our women." Strangely, "they" included me. If there was fear here, it was a fear I coveted because something deep and prehistoric in me wanted "their" women, too. Surely I wasn't the brainy, broad-chested scientist who strove to keep the "girl" (that's what beautiful women were called back then) to himself. Honestly, although it is hardly possible, I remember myself being alone in the theater. I know I don't remember how the movie ended. But I do remember the Gill-Man first becoming enamored of the bathing beauty, a fact recorded wordlessly by an underwater camera shooting up to show her swimming at the surface, her vibrant body half in and half out of the flowing river (of time?) and him swimming on his back six feet below her, looking up to her, matching her movements, following along fully immersed and utterly unseen by her. Like me in the theater. Without knowing it, I must have seen my own future dimly in that watery ballet, a future of unrecognized longing, struggling by stealth and desire against those strong, smart men who clearly owned the world, or at least the dry and lighted world, that I was expected someday to inhabit.

I remember coming out of the theater and, for a long, long moment, standing painfully blinded on the sidewalk in the overpowering sunlight.

I was very lucky. As I grew up, Hollywood seemed always to give me the science fiction movies I needed. In one sense, this is a fortuitous consequence of the development of cinema technology. Just as my tastes jaded, the magic factory always concocted new wonders. (Now that I think of it, I saw Jack Arnold's The Creature From the Black Lagoon (1954) in old-fashioned 3D, wearing cardboard eyeglasses that scratched the bridge of my nose. Did the novelty of that ersatz reality, and not the longing for the girl, make the movie so memorable? At this remove, I can only surmise that both ersatz realities worked together to allow me a scarysafe glimpse of my future.) But more than the technological development, this parallelism between my and the movies' growing up reflects both historical happenstance and the demographic fact that I was born at the leading edge of the post-World War II Baby Boom, a member of the most sought market ever. Nonetheless, I still think, this parallelism was also personal. Lucky, sure, but still personal.

A curious but important fact of cinema history is that virtually every major technological development has its first defining application either in science fiction or in fantasy, the larger category that includes science fiction. Sound, for example, arrives in the 1920's. The Jazz Singer, released in 1927, is often called the first talkie, because, indeed, it was the first theatrically-released movie with recorded dialogue. However, Don Juan in 1926 had recorded music, so The Jazz Singer wasn't the first sound movie. The first movie to be all sound - sound effects, music, and dialogue all captured at the studio and recreated in the theater, was Steamboat Willie, the 1928 Disney cartoon starring a chipper anthropomorphic 
mouse who would later be known as Mickey. And if a mouse piloting a river boat isn't exactly science fiction in the narrowest sense, it is certainly fantasy. It seems to me now that there is an important historical line, one revealing a crucial shift in American culture, between the happy man-mouse piloting Disney's riverboat and the Gill-Man sneaking aboard Jack Arnold's.

Georges Méliès gave us the first narrative film in color, special hand-painted private prints of his $A$ Trip to the Moon (1902), very loosely based on the Jules Verne novel; however, the use of color not as mere novelty but as a way to explore the theme of a commercial film found its defining moment in 1939 when The Wizard of $\mathrm{Oz}_{z}$ contrasted the mundane panchromatic sepiatone world of Kansas with the vivid Technicolor world of Oz. (This powerful, thematic use of panchromatic versus full color recurs, perhaps most notably in the red coat in Schindler's List in 1993 and in the contrast between drab and vivid worlds in Pleasantville in 1998.) Interestingly, while Oz captivates us visually, the explicit message of the movie is that "there's no place like home." Color - the heightened world of the Hollywood movie - is a fine place to visit, but its real value, the film implies, is in teaching us that the best place to live is the real world. Color stands for imagination, which is best valued for its use in training us to deal with the here and now. Given the Great Depression and the palpable approach of war in 1939, this practical turn made sense. And that the pluck of a little girl could galvanize a motley collection of failures to withstand the army of darkness, well, that gave hope. Once armed with hope, Dorothy (her name means "gift of God") could return to the American heartland and we viewers to the world outside the theater. The Wizard of $\mathrm{Oz}_{z}$ is certainly a fantasy, and, given the rusty plight of the Tin Man, the inevitable drug effects of the field of poppies, the mechanized beauty parlors of $\mathrm{Oz}$, the Wizard's mechanical self-projection, the role of hot air balloons, and so on, the film arguably fits also within the narrower genre called science fiction.

At the end of the $19^{\text {th }}$ century, Méliès also gave us perhaps the earliest theatrical use of time-lapse photography, the trick wherein a scene is recorded by a slowed down camera so that when the film is played back at normal speed, the motion appears very fast. We see this often in nature films with clouds racing across the sky or flowers budding in seconds. But perhaps the defining narrative use of time-lapse photography is Nosferatu, F. W. Murnau's classic 1922 version of Bram Stoker's novel Dracula (1897). Here the spectral horses flash across the landscape and the slow-moving demon occasionally darts from one location to another thanks to this technology.

The Shüfftan process for back projection that allowed the seamless integration of filmed miniatures into the filming of actors was first used in Fritz Lang's $\mathrm{Me}$ tropolis (1927), a work that for many reasons is also a high-water mark in science fiction film.

And so on from one technology to another. 
But to return to 3D: although in various ways it had been used as a curiosity as early as the 1890s, its first commercially successful use was in a 1952 adventure movie, based on historical fact, call Bwana Devil. That film has not lasted. But its success motivated investment in House of Wax, a 1952 film that began Vincent Price's decades-long career in horror and science fiction and that also gave most audiences their first experience of stereophonic sound.

The movies that showcased new technologies were, repeatedly fantasy and, more narrowly, science fiction. Look at the list of Oscar winners for Visual Effects (previously known as Special Effects). The list since World War II includes Mighty Joe Young (award received in 1949), Destination Moon (1950), When Worlds Collide (1951), The War of the Worlds (1953), The Time Machine (1960), Fantastic Voyage (1966), 2001: A Space Odyssey (1968), both King Kong and Logan's Run (1976), Star Wars (1977), Superman (1978), Alien (1979), Cocoon (1985), Jurassic Park (1993), The Matrix (1999), and, depending on how one defines the genre, nearly a dozen and a half others. All three nominees currently before the Academy of Motion Picture Arts and Sciences are unequivocally science fiction (Avatar, District 9, and Star Trek). In other words, the history of film is to an important extent a history of science fiction film. To say that I - along with millions upon millions of others grew up with the movies is to say that I grew up with science fiction film. In some ways film itself is science fiction.

Overt science fiction film begins with Méliès. Thomas Edison's Edison Films released a version of Frankenstein in 1910. But the melodramatic world of the Saturday matinee was particularly congenial to science fiction. As late as my childhood in the 1950s, theater managers still padded out their playbills with the episodes of Flash Gordon (first serialized in 1936), Buck Rogers (1939), Captain Marvel (1941), King of the Rocket Men (1949), and so on. But while the serials were fun, nostalgic in a way even though I knew that they couldn't really represent my own memories, the feature films were the more important.

In 1954, even at eight, I was thoroughly aware that we (that is "America," but America seemed like "we" to me) had just come through the Korean War. We (that is, the public, and particularly the young) had been told that, as in World War II, we had won; however, it didn't seem to me (or, for that matter, to my friends in Brooklyn) that we had. Although we couldn't actually remember World War II, its veterans walked among us, many of them our actual parents. Germany had surrendered. Japan had surrendered. Korea - North Korea - had not surrendered. Where was the decisive capitulation that signaled security for "our way of life"?

Sitting on the bench in the neighborhood playground, as children will, I tried on philosophy with my friends. How would we know when we were men? Not just pubic - that part was easy enough - but men? Was it ever right to lie, like when a friend's mother asked if he were really with you when you knew he was off doing something she didn't want but you and your friend thought was just fine, like reading borrowed comic books. Maturity, truth, loyalty: these were big issues. 
And many of our big issues included science and technology. We lived on a busy street. Auto accidents happened all the time. I heard sirens - "someone's having a bad day," my father would say with knowing sadness - every night in Brooklyn. Were cars really just wonderful or scary, too? Maybe even wrong, like the atom bomb. Sure, it ended the war and saved lives, even Japanese lives, one of us would say, but does anyone have the right to do that to other human beings? The war would have ended soon anyway, someone else would reply. We shouldn't have dropped the bomb. How can you know? You can't. So how can you make a decision, a life-or-death decision, and do it for someone else? You just have to.

We wrestled with those questions, trying on philosophy. It wasn't a perfect fit, but we felt that, somehow, we had to grow into it.

Godzilla helped.

In Godzilla (1954), the monster is released by the bomb of a Japanese scientist (read Pearl Harbor) and it stomps across Tokyo (read Hiroshima and Nagasaki) until an American journalist (read ordinary G.I.) forces the creature back out to sea (read suppression but not destruction) so the American can end the movie in the company of the scientist's beautiful, rescued young assistant (read military occupation fostering democracy). If I had thought about it at the time, I would have been grateful that a Japanese filmmaker had provided me with this comforting justification for American action, albeit not a thoroughly comforting view because that filmmaker and I and all the world knew that, despite the bombing of Pearl Harbor, using atomic bombs was a decision, a fraught decision, one that, like the Korean conflict, could be at best, suppressed. Godzilla was still out there, somewhere, under the waves.

Beginning in 1950s, it seems to me that science fiction film has gone through three roughly defined phases. The first phase dealt most importantly with fear. In Them! (1954), American atom bomb tests drive the mutation of ants into huge creatures capable of chewing through houses. Their utter commitment to their own collective purpose and their utter lack of individuality make Them perfect metaphors for the Communists Americans feared. When Their nest is discovered beneath Los Angeles, we have a perverse confirmation of Senator Joseph McCarthy's witch-hunting. The film industry, unbeknownst to many of us, the film seems to imply, has mutated and is our enemy. Fortunately, the actor who will come to play Sheriff Matt Dillon on the long-running television series Gunsmoke (James Arness), destroys Their eggs with flamethrowers and makes America safe again. But just for that one movie.

In Invasion of the Body Snatchers (1956), the pods are aliens from the sky but they become us - and then replace us - by reforming themselves into our simulacra in our basements while we sleep. Again, the notion that the enemy is single-minded both in purpose and absence of individuality is key. Living in Eisenhower's America, where "conformity" was an issue and cookie-cutter suburbia was burgeoning, Don Siegel's film resonated even to my then ten-year old mind. 
Not all fears were political. Although one often hears that American monster films of the '50s were xenophobic, that is too simple a statement. The Gill-Man was not released or created by a bomb but by unbridled curiosity, and he represented not an implacable destructive force but a thwarted desire for love. The fear that happiness would elude one, that the responsibilities of adulthood would overwhelm one, this, too, characterized those "B" movies. In The Fly (1958), the scientist who seeks to better the world by inventing a teleportation device winds up half-fly and trapped in a spider's web. Even a well intended search for new knowledge can destroy one. That is only "natural," as the spider web image suggests. But by the time I saw The Fly, I was twelve, and biologically destined to seek new knowledge. This was much scarier than The Creature From the Black Lagoon.

Between Steamboat Willie, the mouse who has no trouble piloting the riverboat in 1928 to the Gill-Man who can't stay more than a moment on the riverboat in 1954, America had changed. The expansive self-confidence of Willy, who so often happily whistles, is ground down by the Great Depression and a fear of war that led America to widespread isolationism. But even, in America's mind, having won the war, we could not return to that same cheerful anticipation. We knew that we had unleashed something terrible - like millions of others, I practiced "duck and cover" A-bomb drills in school - and we knew that our very virtues, our technological prowess and willingness to attack, reflected potentially dangerous traits deep within us, traits that might be aroused for the best of reasons love, for example - but might only show us to be monsters.

It is little wonder, then, that as the war receded in memory and America grew in strength, movies that dealt with such fears fell away.

Then, after a comparative dry spell, at the end of the 1960s, science fiction film returned and got arty. Instead of "B" movies with low budgets albeit sometimes high concepts, we got philosophical meditations that, beginning with Stanley Kubrick's 2001: A Space Odyssey (1968), were often gorgeous to watch. The last image of that film, of the Star Child in its celestial amnion hovering in space above the Earth, is haunting. Where will it lead? The movie doesn't say, but the last line of Arthur C. Clarke's novel of the same name is, "But he would think of something."

For a while, these "A" budget science fiction films, such as Silent Running (1972) and Blade Runner (1982), films that both look good and prompt us to think, dominated American science fiction and American science fiction dominated world science fiction. Soylent Green (1973), in which overpopulation has driven people - appropriately shielded by ignorance - to eat people, asks a simple literal but compelling philosophical question. In some sense, that serious phase has continued, visible in movies like Minority Report (2002).

A third phase, however, one that now runs alongside the second, may be said to have begun in the late '70s with Star Wars (1977). Here we took the good looks of the second phase and reached all the way back to the melodramatic serials of 
the 30's and 40's. While some science fiction films continued to raise questions, like Altered States (1980) and Brazil (1985), others grabbed ever more of the market share by making visually splendid fairy tales. Given the self-confidence and egotism of America, despite the humbling Viet Nam experience, in the '70s, '80s, and ' $90 \mathrm{~s}$ it is small wonder that films confirming what people hoped but memory tarnished found an audience. But by then I was too old. I was perfectly happy to watch "bullet time" played out in the gorgeous Matrix movies (starting in 1999), but that sort of simplicity seemed to me "childish things" which I didn't have to be asked to "put away." These films were good for a couple of hours, for me, but, for me, not much more.

And then I was honored to be asked by Kathleen Loock and Sonja Georgi, at Frank Kelleter's suggestion, to give the keynote talk at an undergraduate conference in Göttingen, Germany, in the summer of 2009. Kathleen and Sonja's students, at Göttingen and Siegen respectively, had studied "American Science Fiction Film" focusing on Invasion of the Body Snatchers, 2001: A Space Odyssey, Soylent Green, Blade Runner, The Matrix, and Minority Report. I had the opportunity not merely to address this conference but to spend three days with the organizers and the student presenters. They were marvelous: smart, generous, thoughtful, full of hope and high spirits. I admired their scholarly efforts, learned something from each presentation, and learned enormously from them collectively about life for them today, and where American science fiction fits not in America but in their world. But I was surprised that in all these close readings of individual films, of the motives behind them and the system of production that created them, no mention was made of the widespread notion that, to a significant degree, Hollywood is a community marked by Jews. Despite these wonderful students' extended and collective attention to this group of six films and despite individual students' attention to individual films, here are some facts, potentially relevant to film analysis, that went unsaid:

Don Siegel, director of Invasion of the Body Snatchers, was Jewish.

Stanley Kubrick, director of 2001: A Space Odyssey was Jewish.

Richard Fleischer, director of Soylent Green, and Edward G. Robinson, who played Fleischer's wise old man character, were Jewish.

And Stephen Spielberg, director of Minority Report (and Schindler's List), is Jewish.

But the wonderful young people I met in Göttingen did not seem to look back to see The Invasion of the Body Snatchers as an echo of Hitler Youth informing on their families and neighbors or the factories of Soylent Green as related to the crematoria of their grandparents' youth or the totalitarian illusions fostered by the machines in The Matrix as akin to Joseph Goebbels' propaganda factory or Minority Report as censorship in the name of a fascist state. These modern German young adults, who certainly are fully aware of those matters of their own national 
identity, in reading American culture, even American culture of the 1950s, did not address these fearful parallels. Why not?

Consider the typical American response to Them! at its release in 1954 and even thereafter. The recency of the McCarthy witch hunts and the threat of Soviet Communism with its explicitly imperialist ideology and atomic weapons made interpretation easy. But those immensely strong, suddenly destructive, six-foot tall, black ants, breeding under Los Angeles, arguably resonated so powerfully because they also tapped into America's constant, albeit often unconscious, awareness of racial tension. Ants, the archetypes of mindless industriousness, could have been seen just as easily as African American workers, commodified by white-owned industry, yet lurking, always near Anglo-America, often unnoticed, potentially violent. 1954 was, after all, the year of the Supreme Court's landmark racial integration case, Brown v. Board of Education, and in some sense the explosive opening of the modern Civil Rights movement. Yet despite that, other, more consciously pressing matters, matters that had been more recently terrifying and more widely discussed, took up most of the interpretative space and motivated the most searching discussions that followed from this film. As much as race was a constant question in Americans' mind then (and still today), it was not what the film seemed most pressingly about, and only becomes so when explicitly raised.

Among those German youths whom I listened to and learned from, the Nazi past is also, without doubt, widely felt, but it seems that, unless explicitly raised, other issues - today's issues - seem more pressing. Science fiction film, it seems, works so well for these engaged young adults right now precisely because science fiction film, in its makers, viewers, and implications, is no longer particularly American but has become just science fiction film, because, as those students proved, it is worldwide and trains us to look, feel, think, appreciate, and perhaps improve the world we share right now, and the one we all will have to share tomorrow. For me, because of those students, both what they did say and what they did not say, I have a renewed faith in my life in science fiction film. Vielen Dank. 


\section{List of Contributors}

The Editors

SONJA GEORGI is lecturer in American Studies at the Johannes GutenbergUniversity Mainz. She received a Master's degree in American Studies, Applied Linguistics and Economics from the University of Siegen and has recently completed her dissertation on Bodies and/as Technology: Counter-Discourses on Ethnicity and Globalization in the Works of Alejandro Morales, Larissa Lai and Nalo Hopkinson. Her fields of interest include Science Fiction, Ethnic Studies, and African American Literature.

KathleEn LoOCK is a member of the American Studies Program at the University of Göttingen, where she is writing her Ph.D. thesis on the ethnicization of Christopher Columbus in the late nineteenth- and early twentieth-century United States. She is currently co-editing the essay collection Remake | Remodel: New Perspectives on Film Remakes, Adaptations, and Fan Productions with Constantine Verevis from Monash University (Australia).

Special Contributor

ERIC S. RABKIN is Arthur F. Thurnau Professor of English at the University of Michigan in Ann Arbor. His many publications include Mars: A Tour of the Human Imagination and The Fantastic in Literature. His current research includes the Genre Evolution Project which, among other matters, studies American Science Fiction short stories within culture considered as a complex adaptive system.

The Contributors

SOLVEIG BURFEIND studies Italian and American Studies at the University of Göttingen and is currently writing her bachelor thesis in American literature focusing on motherhood and selfhood in Toni Morrison and Kate Chopin. She will continue with a master in European Studies.

DENNIS EDELMANN is a student of English and German language and literature at the University of Göttingen. In his research, he focuses mainly on literary, culture and media theory.

MORITZ EMmELMANN is a student of English Philology and Protestant Theology at the University of Göttingen. His research interests include American modernist 
literature, systematic theology of the twentieth century, religious education theory and theory of religious education.

NIKLAS FRANZEN was born in 1988 in Duisburg (Germany). He studies English Philology and Political Science at the University of Göttingen. His major interests of study are Media Studies and Marxist Theories.

FABIAN Grumbrecht has studied American Studies and German Philology at the University of Göttingen since 2007. His research interests include the representations of stereotypes in American popular culture portrayed in the media and literature of the twentieth century as well as polemical forms of language used in (everyday) communication situations.

DenNis Kogel is a BA student of Literary, Cultural and Media Studies at the University of Siegen and a freelance music journalist. He mainly works in the field of gender and popular (especially web) culture.

Manfred Alexander MüLler is a student of English Philology and History at the University of Göttingen. His current research interests focus on Post-colonial literature and modern movie adaptations of Shakespeare's works.

JÖRN PIONTEK is currently studying English Philology and General Linguistics at the University of Göttingen. Although he usually focuses on linguistics, he is also interested in contemporary literature, film and pop culture as well as in learning new languages.

IRIS SCHÄFER is a BA student of Literary, Cultural and Media Studies at the University of Siegen and is mostly interested in Gender- and Game Studies. Her current project is an investigation of Nintendo's discovery of the female gaming market.

Stefanie SCHWARZ has been a student of English Philology and Political Science at the University of Göttingen since 2008. Her research interests include American literature and culture of the twentieth century and especially of the Cold War era, as well as medieval literature and its modern adaptations, with a special focus on Chaucer's Canterbury Tales.

PHILIPP STÜCKRATH is a student of English Philology and History at the University of Göttingen. His research interests focus mainly on American literature and culture as well as German contemporary history since 1945 . He is currently writing his bachelor thesis on the victim-offender relationship with regard to the work 
of the Ministry for State Security (Stasi) in the German Democratic Republic (GDR).

Benjamin Ryan Ulonska (*1986) studied Literary, Cultural and Media Studies (English/German) at the University of Siegen. As an exchange student at Murdoch University in Perth, Western Australia, he focused on Drama and Screen Production. His research priorities are Digital Video Production, Media Management, Horror and Gender Studies

GINA ZIEBELL has been a student of American Studies and Portuguese at the University of Göttingen since 2007. Her research interest lies with questions of identity, early American Gothic literature, and Science Fiction films. 



\section{„Göttinger Schriften zur Englischen Philologie“: Zum Konzept der Reihe}

Die Reihe „Göttinger Schriften zur Englischen Philologie“ umfasst Schriften zur Forschung aus den Disziplinen englische, amerikanische und postkoloniale Literatur- und Kulturwissenschaft, englische Fachdidaktik, englische Sprache, Literatur und Kultur des Mittelalters, Linguistik des Englischen. Veröffentlicht werden können:

- im Rahmen des 1. Staatsexamens für das Lehramt an Gymnasien verfasste Zulassungsarbeiten (Staatsarbeiten), die mit ,sehr gut' benotet wurden bzw. die mit ,gut' benotet und entsprechend überarbeitet wurden, so dass sie zum Zeitpunkt der Veröffentlichung mit ,sehr gut' bewertet werden könnten;

- im Rahmen des Magisterexamens verfasste Zulassungsarbeiten (Magisterarbeiten), die mit ,sehr gut ${ }^{6}$ benotet wurden bzw. die mit ,gut benotet und entsprechend überarbeitet wurden, so dass sie zum Zeitpunkt der Veröffentlichung mit ,sehr gut ${ }^{6}$ bewertet werden könnten;

- im Rahmen des BA-Studiengangs (Zwei-Fächer-Bachelor-Studiengang) verfasste Abschlussarbeiten (Bachelor-Arbeiten), die mit ,sehr gut ${ }^{6}$ benotet wurden bzw. die mit ,gut ${ }^{`}$ benotet und entsprechend überarbeitet wurden, so dass sie zum Zeitpunkt der Veröffentlichung mit ,sehr gut' bewertet werden könnten;

- im Rahmen der einschlägigen MA-Studiengänge (Master of Arts / Master of Education) verfasste Abschlussarbeiten (Master-Arbeiten), die mit ,sehr gut' benotet wurden bzw. die mit ,gut ${ }^{6}$ benotet und entsprechend überarbeitet wurden, so dass sie zum Zeitpunkt der Veröffentlichung mit ,sehr gut bewertet werden könnten.

Zusätzlich können in der Reihe Sammelbände beispielsweise mit den Arbeitsergebnissen aus Kolloquien oder Workshops veröffentlicht werden. Die Werke werden auf Deutsch oder Englisch publiziert. 
Since its beginnings, science fiction has served as an intellectual playground where pressing issues such as scientific and technological progress, population growth, nuclear power, environmental protection, or genetic engineering have been projected onto different times and spaces in order to warn about inherent dangers, offer solutions, or to simply speculate about and experiment with the future. In the summer term of 2009, students from the University of Göttingen and the University of Siegen participated in two parallel courses entitled "Of Body Snatchers and Cyberpunks: American Science Fiction Film from the 1950s to the Present" and met for an undergraduate conference in Göttingen where they presented and discussed their research on American science fiction film together with Eric S. Rabkin, professor at the University of Michigan (USA) and an international expert in the field. The result of this project is the present volume of twelve student essays that were first presented at the conference, and then selected and revised for publication. Considering science fiction film as an essential element of American popular culture, the essays analyze and discuss the films Invasion of the Body Snatchers (Siegel, 1956), 2001: A Space Odyssey (Kubrick, 1968), Soylent Green (Fleischer, 1973), The Matrix (Wachowski, 1999), and Minority Report (Spielberg, 2002) against the background of social, political, cultural, and/or ecological developments in their contemporary U.S. societies. The introductory essay outlines the theoretical, methodological, and didactic considerations that informed the planning and teaching processes of the course format and the conference. The collection also features an autobiographical essay by Eric S. Rabkin in which he reflects on his personal experiences and lifelong fascination with science fiction films. 